\title{
PREOPERATIVE CARBOHYDRATE LOADING IN PATIENTS UNDERGOING CORONARY ARTERY BYPASS OR SPINAL SURGERY
}

By

Susan Tran

A thesis submitted in conformity with the requirements

for the degree of Master of Science

Graduate Department of Nutritional Sciences

University of Toronto

C Copyright by Susan Tran 2009 
Preoperative Carbohydrate Loading in Patients Undergoing Coronary Artery Bypass or Spinal Surgery

Master of Science, 2009

Susan Tran

Graduate Department of Nutritional Sciences

University of Toronto

\begin{abstract}
Patients undergoing elective surgery typically fast for 8-12 hours before surgery. However, oral preoperative carbohydrate ingestion may increase postoperative insulin sensitivity and reduce complications. To determine the effects of carbohydrate supplementation prior to CABG or spinal surgery, 38 patients were randomized to receive a carbohydrate supplement or to fast for 12 hours preoperatively. Baseline and postoperative measurements of insulin sensitivity were completed using the short insulin tolerance test and homeostasis model assessment (HOMA). Patient discomfort was measured immediately before surgery. Insulin sensitivity was not significantly different between groups. However, the supplemented group experienced a significantly smaller rise in glucose levels following surgery $(\mathrm{p}=0.03)$ and had higher postoperative HOMA- $\beta$ scores $(\mathrm{p}=0.02)$. Fasted patients were significantly more thirsty $(\mathrm{p}=0.01)$, hungry $(\mathrm{p}=0.04)$ and anxious $(\mathrm{p}=0.01)$ before surgery and experienced a significantly longer hospital stay ( $\mathrm{p}=0.008)$. Carbohydrate supplementation improved outcomes, warranting re-evaluation of fasting practices prior to major surgery.
\end{abstract}




\section{ACKNOWLEDGEMENTS}

I am extremely grateful for the support and guidance of many individuals whose enthusiasm and contributions helped bring this project to fruition. To begin with, I would like to thank my supervisor, Dr. Mary Keith, for being a constant source of support and encouragement throughout my graduate career. I am truly appreciative of her dedication to the project and the countless hours she spent with me, offering valuable advice and sharing her expertise. I would also like to express my deepest gratitude to Dr. David Mazer, whose passion and devotion to the study were inspirational and whose involvement in this endeavour was crucial to its success. Special thanks to Dr. Tom Wolever for his commitment to the project and for all his assistance with the baseline study visits. I wish to thank Dr. Henry Ahn, Dr. Lee Errett, Dr. Daniel Bonneau, and Dr. David Latter for their valuable contributions to this project. Also, I am grateful to the hospital staff in the cardiovascular and thoracic surgery department as well as the Martin Centre for their ongoing support of my research activities. I would like to thank Dr. Philip Connelly, Graham Maguire and Maureen Lee for their assistance with the benchwork and their expert advice which was always provided enthusiastically. I would also like to express my gratitude to Kevin Sorokin for all his help on the biochemical assays. Sincere thanks to Kevin Thorpe for all his statistical help. I am indebted to all the participants who were involved in this project as without their time commitment, dedication and keen interest in the study, this thesis would not have been possible. Lastly, I would like to thank my family and friends for their faith in me and the boundless support they have offered me. I would like to especially express thanks to HB for all his understanding, patience and support throughout this whole project. Again, thank you to everyone who was involved in this incredible journey. 


\section{TABLE OF CONTENTS}

LIST OF TABLES viii

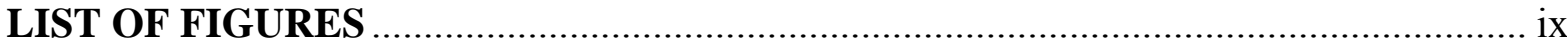

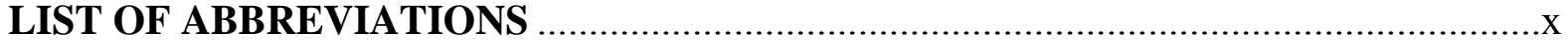

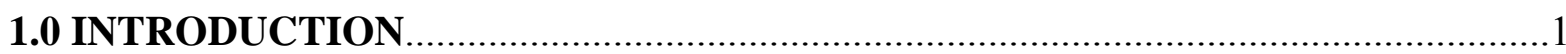

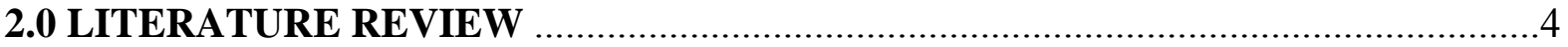

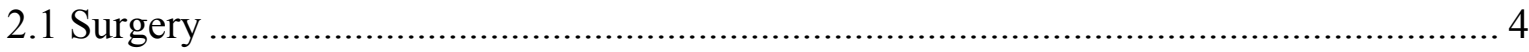

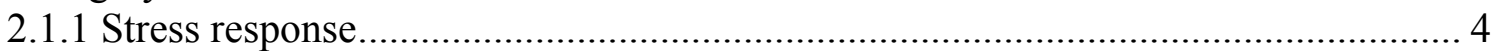

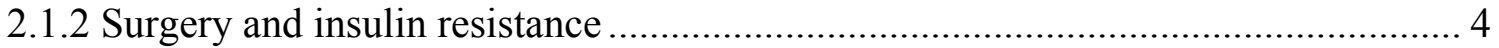

2.1.2.1 Stress-induced insulin resistance: mechanism of action ............................... 5

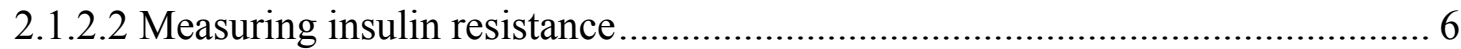

2.1.2.3 Negative impacts of insulin resistance...................................................... 9

2.1.2.4 Cardiac and spinal surgery and insulin resistance .................................... 10

2.1.2.5 Glycemic control in post-surgical patients ............................................. 11

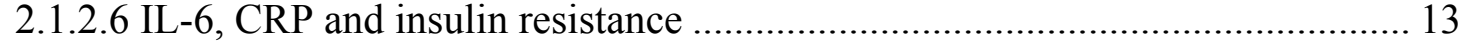

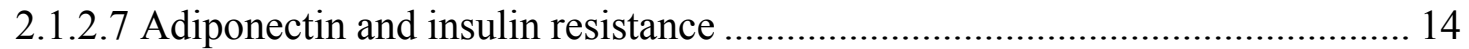

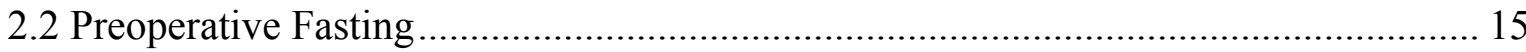

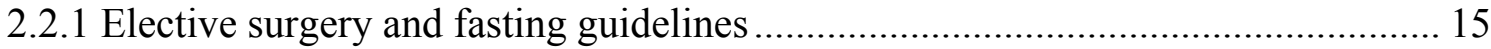

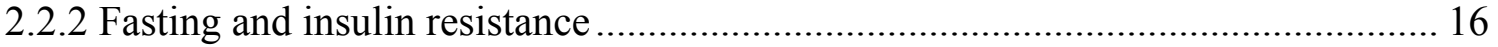

2.3 Fed vs. fasted state of elective surgical patients.................................................. 17

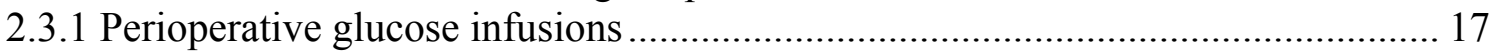

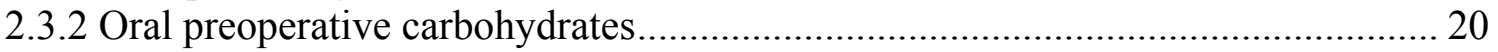

2.3.2.1 Oral preoperative carbohydrates and patient discomfort ............................. 22

2.3.2.2 Effects of oral preoperative carbohydrates on immune and muscle function.. 23

2.3.2.3 Oral preoperative carbohydrates and insulin resistance................................ 24

2.3.2.4 Preoperative carbohydrate loading and clinical outcomes........................... 28

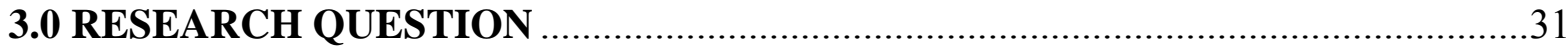

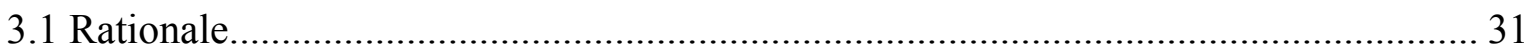

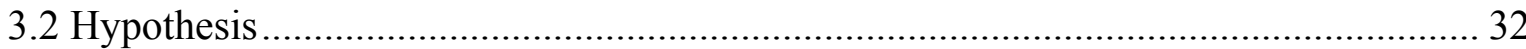

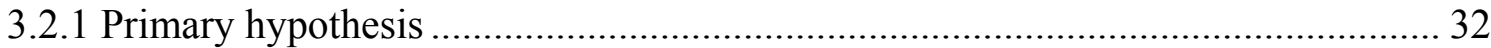

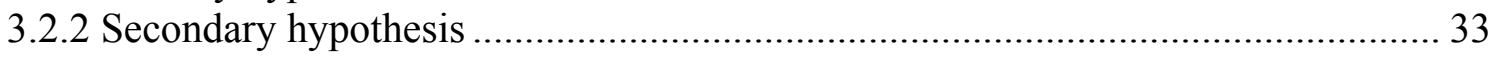

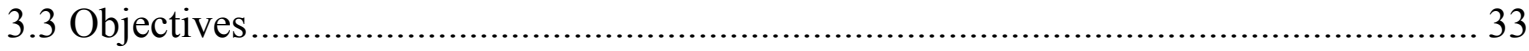

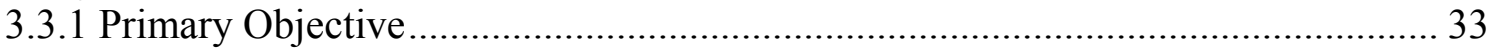

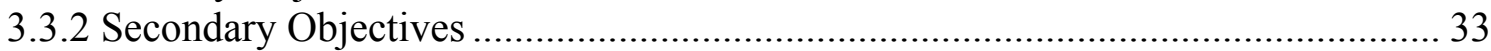




\subsection{MANUSCRIPT: PREOPERATIVE CARBOHYDRATE LOADING IN PATIENTS UNDERGOING CORONARY ARTERY BYPASS OR SPINAL SURGERY.................36}

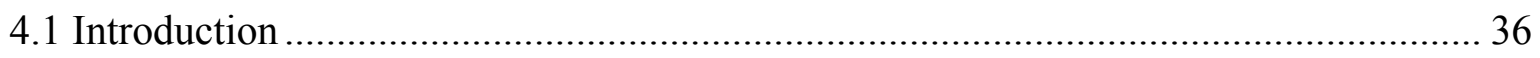

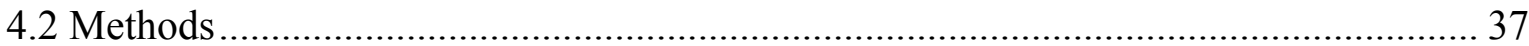

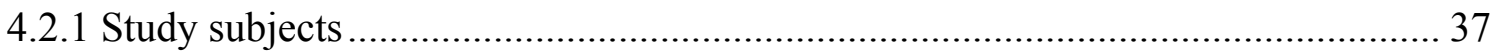

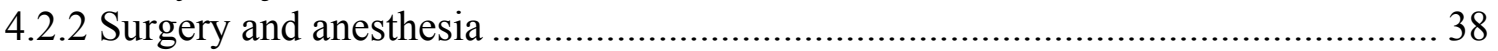

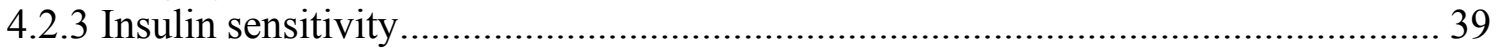

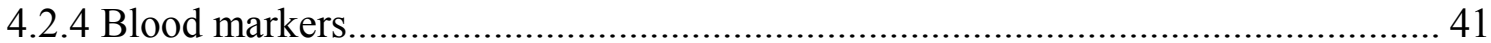

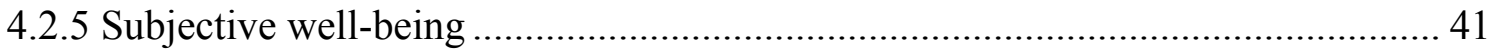

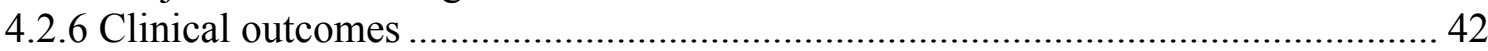

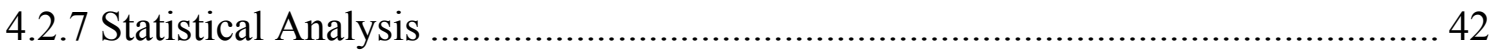

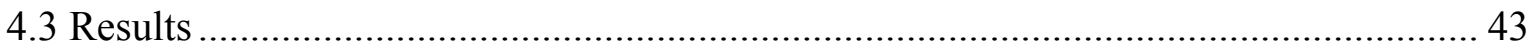

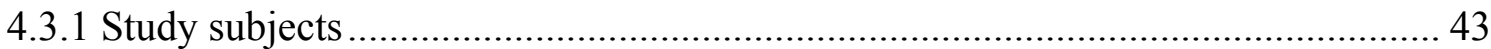

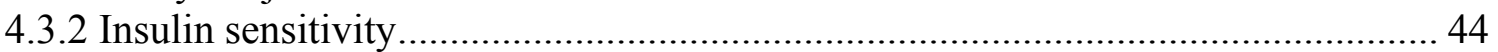

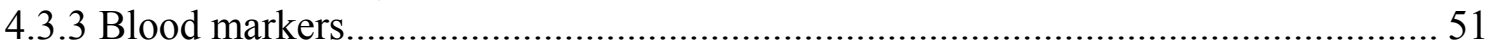

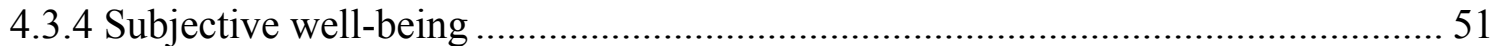

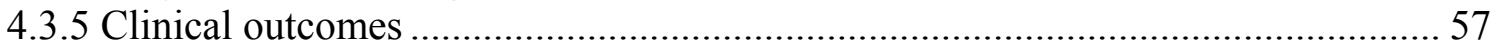

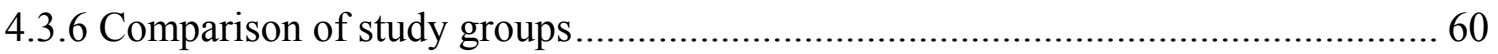

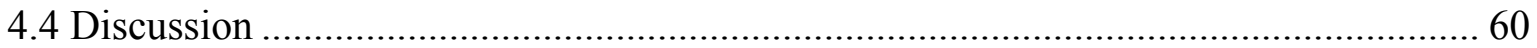

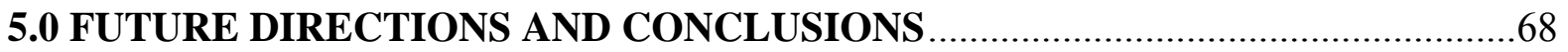

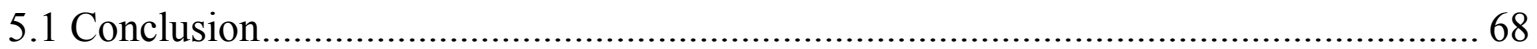

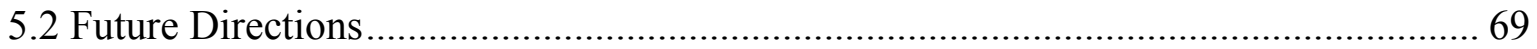

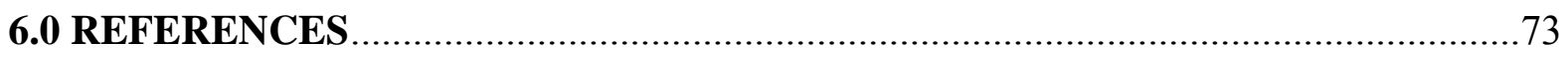

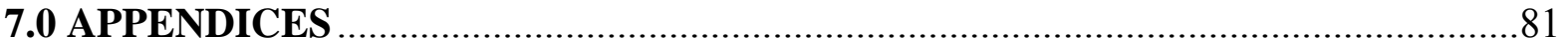

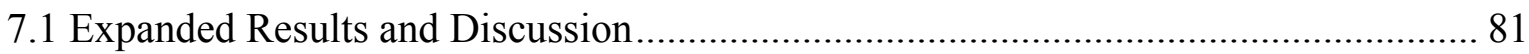

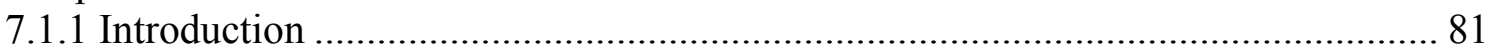

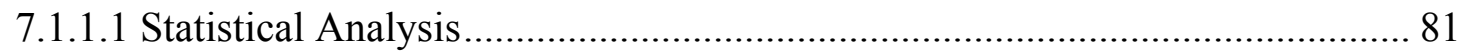

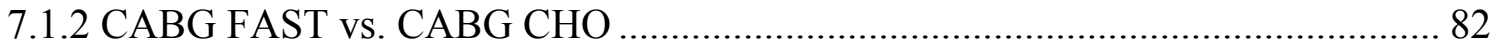

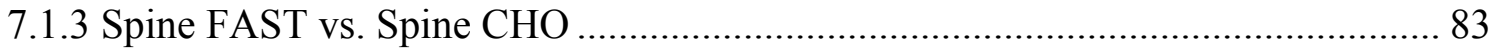

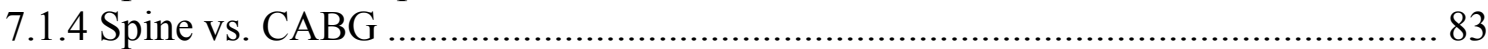

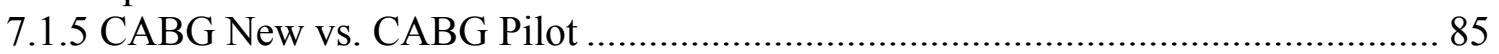

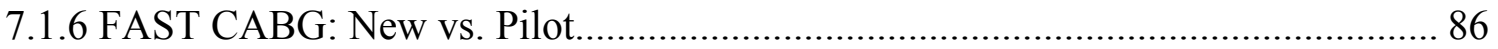

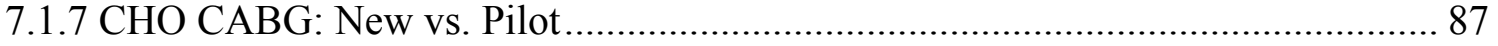




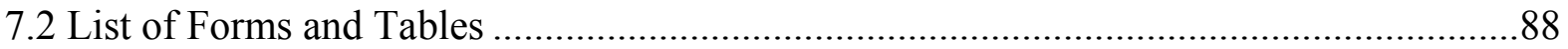

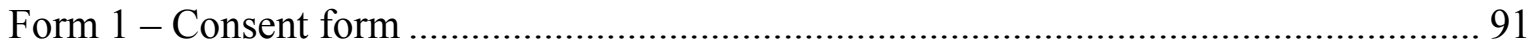

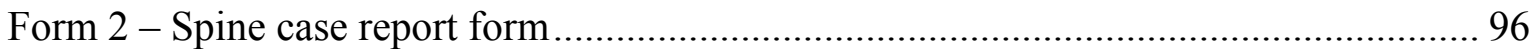

Form 3 - CABG case report form.......................................................................... 102

Table 1 - PreOp ${ }^{\circledR}$ drink composition ......................................................................... 108

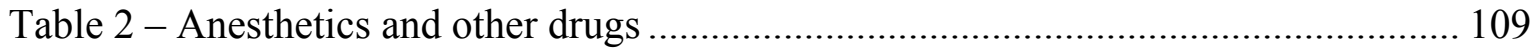

Form 4 - Visual analog scale questionnaire................................................................ 110

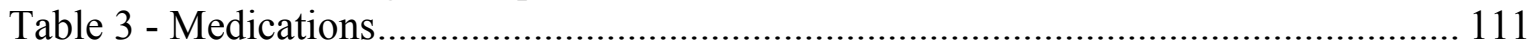

Table 4 - Baseline VAS scores.............................................................................. 112

Table 5 - Preoperative VAS scores, unadjusted for baseline scores ................................. 113

Table 6 - Change in scores (Preoperative - Baseline) ……………………………….... 114

Table 7 - Baseline subject characteristics (CABG FAST vs. CABG CHO) ...................... 115

Table 8 - Measures of insulin sensitivity (CABG FAST vs. CABG CHO) ...................... 116

Table 9 - Blood markers throughout study period (CABG FAST vs. CABG CHO)........ 117

Table 10 - Intra and postoperative clinical outcomes (CABG FAST vs. CABG CHO)... 118

Table 11 - Other intra and postoperative clinical outcomes (CABG FAST vs. CABG CHO) 119

Table 12 - Hyperglycemia outcomes (CABG FAST vs. CABG CHO) ............................ 120

Table 13 - Baseline subject characteristics (Spine FAST vs. Spine CHO) ........................ 121

Table 14 - Measures of insulin sensitivity (Spine FAST vs. Spine CHO) ........................ 122

Table 15 - Blood markers throughout study period (Spine FAST vs. Spine CHO)......... 123

Table 16 - Intra and postoperative clinical outcomes (Spine FAST vs. Spine CHO)....... 124

Table 17 - Other intra and postoperative clinical outcomes (Spine FAST vs. Spine CHO)... 125

Table 18 - Hyperglycemia outcomes (Spine FAST vs. Spine CHO) ................................. 126

Table 19 - Baseline subject characteristics (Spine vs. CABG) ………………………..... 127

Table 20 - Measures of insulin sensitivity (Spine vs. CABG) ......................................... 128

Table 21 - Blood markers throughout study period (Spine vs. CABG) ............................. 129

Table 22 - Intra and postoperative clinical outcomes (Spine vs. CABG) ......................... 130

Table 23 - Other intra and postoperative clinical outcomes (Spine vs. CABG) ................ 131

Table 24 - Hyperglycemia outcomes (Spine vs. CABG) ................................................. 132

Table 25 - Baseline subject characteristics (CABG New vs. CABG Pilot) ....................... 133

Table 26 - Measures of insulin sensitivity (CABG New vs. CABG Pilot)........................ 134

Table 27 - Blood markers throughout study period (CABG New vs. CABG Pilot)......... 135

Table 28 - Intra and postoperative clinical outcomes (CABG New vs. CABG Pilot)...... 136

Table 29 - Other intra and postoperative clinical outcomes (CABG New vs. CABG Pilot).. 137

Table 30 - Hyperglycemia outcomes (CABG New vs. CABG Pilot)................................ 138

Table 31 - Baseline subject characteristics (FAST CABG: New vs. Pilot) …………….... 139

Table 32 - Measures of insulin sensitivity (FAST CABG: New vs. Pilot) …………….... 140

Table 33 - Blood markers throughout study period (FAST CABG: New vs. Pilot) .......... 141

Table 34 - Intra and postoperative clinical outcomes (FAST CABG: New vs. Pilot) ....... 142

Table 35 - Other intra and postoperative clinical outcomes (FAST CABG: New vs. Pilot) .. 143

Table 36 - Hyperglycemia outcomes (FAST CABG: New vs. Pilot) ………………….... 144

Table 37 - Baseline subject characteristics (CHO CABG: New vs. Pilot) …………….... 145

Table 38 - Measures of insulin sensitivity (CHO CABG: New vs. Pilot) …………......... 146

Table 39 - Blood markers throughout study period (CHO CABG: New vs. Pilot) ........... 147

Table 40 - Intra and postoperative clinical outcomes (CHO CABG: New vs. Pilot) ....... 148

Table 41 - Other intra and postoperative clinical outcomes (CHO CABG: New vs. Pilot) ... 149 
Table 42 - Hyperglycemia outcomes (CHO CABG: New vs. Pilot) 


\section{LIST OF TABLES}

Table 4.1 Baseline subject characteristics ...................................................................46

Table 4.2 Cardiovascular disease characteristics.........................................................47

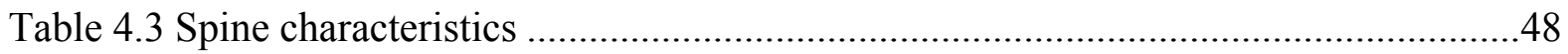

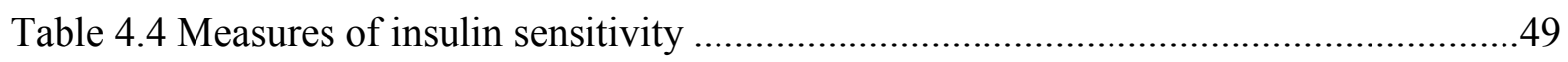

Table 4.5 Preoperative VAS scores, adjusted for baseline scores ....................................56

Table 4.6 Intra and postoperative clinical outcomes ......................................................58

Table 4.7 Other intra and postoperative clinical outcomes...............................................59

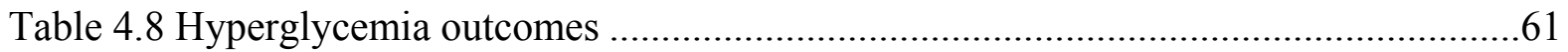

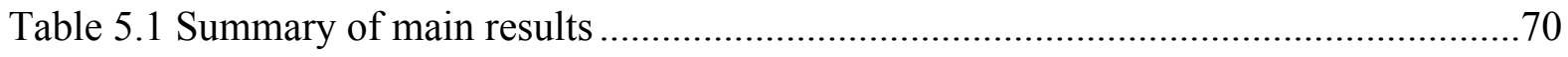




\section{LIST OF FIGURES}

Figure 2.1 Changes in insulin sensitivity due to fasting ................................................. 18

Figure 2.2 Preoperative carbohydrate loading and length of hospital stay..........................30

Figure 4.1 Subject recruitment and randomization....................................................45

Figure 4.2 FFA levels in FAST and CHO group during study period.................................52

Figure 4.3 IL-6 and logIL-6 levels in FAST and CHO group during study period................53

Figure 4.4 CRP and logCRP levels in FAST and CHO group during study period...............54

Figure 4.5 VAS scores for thirst, hunger and anxiety...............................................55 


\section{LIST OF ABBREVIATIONS}

BMI

CCS

CABG

CVICU

CPB

CRP

FFA

HLA

HOMA-IR

HOMA- $\beta$

IABP

ICU

IL-1

IL-6

$\mathrm{K}_{\text {ITT }}$

LOS

NS

MSICU

NYHA

OR

PACU

PE/DVT body mass index

Canadian Cardiovascular Society

coronary artery bypass graft

cardiovascular intensive care unit

cardiopulmonary bypass

C-reactive protein

free fatty acid

human leukocyte antigen

homeostasis model assessment for insulin resistance

homeostasis model assessment for beta-cell function

intra-aortic balloon pump

intensive care unit

interleukin-1

interleukin-6

rate constant for the disappearance of blood glucose

length of stay

non-significant

medical-surgical intensive care unit

New York Heart Association

operating room

post-acute care unit

pulmonary embolism/deep vein thrombosis 
POD

SITT

$\mathrm{SMH}$

TNF- $\alpha$

VAS postoperative day

short insulin tolerance test

St. Michael's Hospital

tumor necrosis factor alpha

visual analog scale 


\subsection{INTRODUCTION}

Surgery is associated with various metabolic derangements, one of which is related to the utilization of glucose in the body. Surgical stress results in the development of insulin resistance; muscle and adipose cells which are typically responsive to insulin become less sensitive to its effects. As a result, there is a rise in circulating blood glucose concentrations which can often reach hyperglycemic levels (1). This phenomenon, coined 'stress hyperglycemia' or 'diabetes of injury' affects the ability of the body to store and metabolize glucose. This can lead to post-surgical complications and less favourable outcomes, including increased risk of deep wound sternal infections (2), decreased renal function and mortality (3). Thus, modulating postoperative insulin resistance may positively impact the development of hyperglycemia and the incidence of adverse events.

Efforts to reduce this stress-induced insulin resistance include the use of epidural analgesia (4) and less-invasive surgical techniques such as laparoscopy (5). In addition, insulin resistance and hyperglycemia can be treated in the postoperative period through the use of intensive insulin therapy to restore blood glucose levels to normal values (3). Preoperative interventions, including the adoption of a low glycemic index diet (6), have also been investigated in an effort to improve postoperative insulin resistance.

In the preoperative setting, patients undergoing elective surgical procedures routinely fast for 8-12 hours prior to their surgery, in order to minimize the risk of aspiration of gastric contents upon induction of anesthesia. Upon closer examination of this protocol, studies have shown that fasting can intensify the insulin resistance which develops during and after surgery $(7,8)$. This finding led to investigations which examined patients in the fed state prior to surgery through the use of glucose infusions and found improvements in insulin 
sensitivity following this treatment $(9,10)$. Given that intravenous glucose infusions are costly, invasive and labour-intensive, an oral carbohydrate drink was developed to provide a more efficient method of delivering the carbohydrate load. It has been shown to be well tolerated and pose no additional risk of aspiration when ingested two hours before surgery (11).

The consumption of a carbohydrate beverage prior to surgery has been shown to reduce patient discomfort and anxiety in the preoperative period (12) and can lead to a shorter length of stay in the hospital (13). In studies examining patients undergoing abdominal and hip replacement surgery, insulin resistance was improved in the immediate postoperative period in those who received carbohydrate supplementation (14-16). A predictor of the extent of insulin resistance which develops postoperatively is the degree of surgical trauma (17). As such, this field has been limited in examining patients undergoing surgeries with relatively moderate metabolic stress, and thus, the effects of a carbohydrate supplement on those developing severe insulin resistance has not yet been investigated.

The aim of the present study was to assess the benefits of preoperative oral carbohydrate loading on a unique population of surgical patients. Coronary artery bypass graft and spinal decompression and fusion surgeries are ones which are large in magnitude highly invasive, long in duration with considerable blood loss - and as such, patients undergoing these surgeries are at increased risk of developing significant insulin resistance postoperatively. The ability of this drink to improve insulin sensitivity in patients undergoing major operations has not been explored and further details are needed on the clinical benefits. This study will provide new insight regarding the clinical utility of a 
carbohydrate supplement on those undergoing surgeries of high complexity and help to advance the preoperative care which patients receive 


\subsection{LITERATURE REVIEW}

\subsection{Surgery}

\subsubsection{Stress response}

Surgical trauma induces a hypermetabolic response in the body which is characterized by the release of stress hormones including glucagon, cortisol and catecholamines such as epinephrine and norepinephrine (18). As well, inflammatory cytokines are synthesized and released; one of importance is interleukin-6 (IL-6), which is mainly responsible for activating the acute phase response and stimulating the liver to produce acute phase proteins such as C-reactive protein (CRP) during times of stress (19). The catabolic effects of the above counter-regulatory hormones and cytokines cannot be balanced by the anabolic effects of insulin. Despite increased insulin release from the pancreatic $\beta$-cells after surgery, it is insufficient to offset the catabolism of the body.

\subsubsection{Surgery and insulin resistance}

Insulin resistance develops as a response to the surgical insult and is demonstrated by elevated endogenous glucose production in the liver and more importantly, decreased glucose uptake in peripheral tissues such as adipose and muscle tissue $(19,20)$. Carbohydrate metabolism is impaired and is shifted towards fat and protein catabolism, observed as high free fatty acid (FFA) levels and increased nitrogen losses, respectively (21). This insulin resistance results in a rise in blood glucose levels postoperatively; sustained high levels of blood glucose can lead to hyperglycemia, observed even in the non-diabetic population, and has been shown to be detrimental to recovery after trauma (22). Using the hyperinsulinemic euglycemic clamp technique (the gold standard) in patients who underwent elective open 
cholecystectomy, insulin resistance was found to persist on postoperative day (POD) 5 and was normalized by POD 20 (23).

\subsubsection{Stress-induced insulin resistance: mechanism of action}

The development of postoperative insulin resistance in surgical patients has been attributed to defects in intracellular glucose metabolism and the glucose transport system (24). Insulin resistance develops immediately after surgery. The development of insulin resistance may be due to a reduction in non-oxidative glucose disposal and/or altered glycogen synthase activity. Using the euglycemic clamp technique, it was found that glucose oxidation was unchanged in patients in the postoperative period; however, decreased rates of non-oxidative glucose disposal were present in post-surgical patients (24). Furthermore, glycogen synthase activity was significantly decreased postoperatively compared to before surgery $(\mathrm{p}<0.05)$, suggesting that the development of insulin resistance may be related to alterations in glycogen storage.

The development of insulin resistance postoperatively could also be due to defects in the translocation of GLUT-4, an intracellular glucose transporter protein regulated by insulin. Insulin release typically activates GLUT-4, causing translocation of this protein from skeletal muscle or adipose tissue to the plasma membrane to facilitate uptake of glucose (25). However, in the post-surgical setting, GLUT-4 functionality is altered. The infusion of insulin preoperatively in the above study (24) increased levels of GLUT-4 at the plasma membrane of skeletal muscle. Postoperatively, levels of GLUT-4 were not increased compared to basal values, even after insulin infusion was given to return glucose uptake to preoperative levels. It is unknown whether this lack of GLUT-4 at the plasma membrane is 
due to altered insulin signalling or impaired GLUT-4 trafficking. To date, research into the exact mechanism for acute insulin resistance remains sparse.

\subsubsection{Measuring insulin resistance}

Insulin resistance is present not only in post-surgical patients but is an underlying feature in a variety of conditions including obesity, cardiovascular disease, hypertension and type II diabetes (29). Thus, the quantification of insulin sensitivity in individuals is important and necessary in order to determine susceptibility, change and improvement of a particular condition. Several methods to evaluate insulin sensitivity are currently used in research and clinical settings.

The 'gold standard' for determining insulin sensitivity is the hyperinsulinemic euglycemic clamp technique. Developed by DeFronzo et al (30), this in vivo method involves the continuous intravenous infusion of exogenous insulin and glucose. Insulin is supplied at supraphysiological levels (hence the term, 'hyperinsulinemic') and it is assumed that at these concentrations, hepatic glucose production is suppressed (31). A glucose infusion is administered at a rate to maintain or 'clamp' blood glucose to normal fasting levels (e.g., $5 \mathrm{mmol} / \mathrm{L}$ ). Blood samples are taken during this time and the rate of glucose infusion may be adjusted to ensure maintenance of euglycemia. Once a steady state of glucose is achieved, insulin sensitivity can be determined using the glucose infusion rate (otherwise known as the $\mathrm{M}$ value) as this is proportional to whole body glucose disposal (31). The more glucose which is infused, the more insulin sensitive an individual is. Due to the invasiveness of this technique as well as the labour, time, skill and cost involved, the 
euglycemic clamp is predominantly used for research purposes and rarely performed in clinical practice.

The insulin tolerance test (ITT) is another in vivo method of measuring insulin sensitivity. This test involves the administration of a bolus of insulin $(0.1 \mathrm{U} / \mathrm{kg}$ of body weight) under fasting conditions (32). Subsequently, plasma glucose samples are collected in five minute intervals over the next 60 minutes. Theoretically, blood glucose concentrations decline after insulin administration and the rate of disappearance of glucose can be calculated using a standardized equation (31). A fast rate of decline is indicative of insulin sensitivity whereas slow rates demonstrate insulin resistance. The ITT is a measure of whole body insulin sensitivity, with no differentiation between hepatic and peripheral resistance. While the protocol for the ITT is simpler to administer than the euglycemic clamp, it does have its limitations. First, the insulin injection can lead to hypoglycemia which can be potentially dangerous to individuals (32). In addition, decreases in glucose levels due to exogenous insulin administration induce a counter-regulatory hormone response after 20 minutes in an attempt to restore blood glucose levels (32), affecting the results of any blood samples collected after this time.

As a result, the ITT was further modified and from this, the short insulin tolerance test was developed. In this version, a smaller dose of insulin $(0.05 \mathrm{U} / \mathrm{kg})$ is used to reduce the likeliness of hypoglycemic events and plasma glucose levels are measured every two minutes over 15 minutes so that the test is terminated before counter-regulatory hormones are released (33). This test has been found to be significantly correlated with the euglycemic clamp technique in healthy $(\mathrm{r}=0.86, \mathrm{p}<0.003)$ and obese subjects $(\mathrm{r}=0.81, \mathrm{p}<0.01)(32)$. More details about this test are found under methods in Chapter 4 (4.2.3). 
A more practical, quick and inexpensive method to determine insulin sensitivity is the use of fasting plasma or serum insulin as a surrogate marker. Higher insulin levels are indicative of greater insulin resistance (34). This marker is most useful in detecting insulin resistance in individuals with normal glucose tolerance. Previous studies have found that fasting insulin levels in individuals who were glucose intolerant or with type II diabetes did not correlate as well with physiological measures of insulin sensitivity $(34,35)$. A limitation of this method is the lack of consensus on a cut-off value defining insulin resistance (31). In addition, other factors such as insulin secretion, distribution and degradation play a role in determining levels of blood insulin, with insulin sensitivity explaining only a fraction (5 to $50 \%$ ) of its variability (31).

The use of the homeostasis model assessment (HOMA) offers some advantage over fasting insulin as it takes into account glucose levels as a factor in determining insulin sensitivity. HOMA is a mathematical model first described in 1985 and works on the assumption that there is interaction between plasma glucose and insulin levels (36); hepatic glucose release is balanced by the release of insulin to clear glucose from the blood, and levels of each are regulated by a feedback loop between the liver and the pancreatic $\beta$-cells. Hyperglycemia is the outcome of insulin resistance and $\beta$-cell dysfunction. HOMA-IR and HOMA- $\beta$ have been found to be significantly correlated with physiological insulin sensitivity measures, including the euglycemic clamp technique $(37,38)$. The mathematical equations are described below (37):

HOMA- $\% \beta=\underline{(20 \times \text { FPI })}$

$(\mathrm{FPG}-3.5)$
HOMA-IR $=\underline{(\text { FPI } \times \text { FPG })}$

22.5 
where FPI is fasting plasma insulin (mU/L) and FPG is fasting plasma glucose $(\mathrm{mmol} / \mathrm{L})$. Normal $\beta$-cell function is indicated at $100 \%$, with lower values indicating impaired or diminished $\beta$-cell function. Normal insulin sensitivity is valued at 1 , with higher values indicating increased insulin resistance.

\subsubsection{Negative impacts of insulin resistance}

The development of insulin resistance was once perceived as a survival benefit in redirecting energy resources in the body to essential needs such as supplying energy to the brain rather than musculo-skeletal functions. Now, in modern medicine, it is interpreted as a hindrance to the recovery process. Cells which are not insulin-dependent, such as red blood cells, epithelial and endothelial cells, and neuronal cells become overloaded with glucose, impairing their ability to function (26). The presence of cytokines promotes upregulation of glucose transporters such as GLUT1 and GLUT3 to the plasma membrane of these cells. Processes such as glycolysis, the Krebs cycle and oxidative phosphorylation are heightened in these cells, generating byproducts such as peroxynitrite and superoxide, thereby enhancing oxidative stress (26). Furthermore, high levels of glucose in the blood further exacerbate the inflammatory environment and promote non-enzymatic binding of glucose molecules to immunoglobulins and collagen which can lead to infectious complications and poor wound healing, respectively (2). Insulin resistance and hyperglycemia have therefore been linked to adverse outcomes and patient complications in the postoperative period (27). Multiple regression analysis further determined a model to predict length of hospital stay and found that postoperative insulin resistance was an independent factor which could predict the variability in length of stay (LOS), along with type of surgery and blood loss (17). For these 
reasons, minimizing insulin resistance in the postoperative period may be beneficial for the elective surgical patient.

\subsubsection{Cardiac and spinal surgery and insulin resistance}

The degree of postoperative insulin resistance which develops is proportional to the magnitude of the surgical trauma (17). For example, an $18 \%$ reduction in insulin sensitivity has been demonstrated in patients undergoing minimally-invasive laparoscopic cholecystectomy whereas observations of a $58 \%$ reduction were shown in those undergoing open cholecystectomy (5). Although preoperative insulin sensitivity varies in individuals in some cases, seven-fold - the drop in insulin sensitivity postoperatively (the delta $\Delta$ ) is relatively similar between individuals undergoing the same procedures (17). In another study which examined patients undergoing open cholecystectomy, results revealed that the relative reduction in insulin sensitivity was $56 \%$, a change quite similar to the above study (28). Another factor relating to the change in insulin sensitivity observed after surgery is the amount of perioperative blood loss (17). Interestingly, factors such as age, gender, body mass index (BMI) and preoperative insulin sensitivity are not related (17).

Elective coronary artery bypass graft $(\mathrm{CABG})$ and spinal decompression and fusion surgeries are similar in that they are both highly invasive procedures of long duration and are associated with substantial perioperative blood loss. Consequently, patients undergoing these surgeries are likely to develop significant insulin resistance postoperatively. We thus recruited elective $\mathrm{CABG}$ and spinal decompression and fusion surgical patients for this thesis project. 


\subsubsection{Glycemic control in post-surgical patients}

A large retrospective study examining almost 9000 patients who underwent open heart surgery demonstrated that diabetics were more likely to develop deep sternal wound infections than non-diabetics (1.7 vs. $0.4 \%)$ (2). After putting into practice a diabetic protocol to keep blood glucose levels to $<11.1 \mathrm{mmol} / \mathrm{L}$ in critical care units, the incidence of wound infections dropped in diabetics from 2.1 to $0.98 \%$. Using multivariate analysis, mean blood glucose over POD 1 and POD 2 was found to be a predictor of deep wound infection $(\mathrm{p}=0.002)$. Another retrospective study found that intraoperative glucose values during cardiac surgery were also a predictor of post-surgical complications (39).

The limitations of observational studies were overcome in one study published in the New England Journal of Medicine in 2001 (3). Van den Berghe et al. (2001) randomly assigned over 1500 patients who were admitted to the intensive care unit (ICU) and required ventilatory support to receive either: 1) intensive insulin therapy to maintain blood glucose levels between 4.4 and $6.1 \mathrm{mmol} / \mathrm{L}$ or 2) conventional treatment, receiving insulin only when blood glucose levels exceeded $11.9 \mathrm{mmol} / \mathrm{L}$ to maintain blood glucose between 10.0 and 11.1 $\mathrm{mmol} / \mathrm{L}$. Only $13 \%$ of patients were diabetic, so most of the high blood glucose levels observed would have been driven by the stress of the surgery. These researchers determined that maintaining tight blood glucose control postoperatively led to significant reductions in morbidity and mortality (3). These positive clinical outcomes experienced by the treatment group included a remarkable $46 \%$ decrease in episodes of sepsis, $41 \%$ decrease in renal failure requiring dialysis, $50 \%$ decrease in the number of red blood cell transfusions and importantly, a 34\% decrease in overall hospital mortality compared to the conventionally treated group. Intensive insulin therapy also resulted in a reduction in the inflammatory and 
acute phase response, indicated by reduced CRP levels (40). The importance of resolving stress-induced insulin resistance was clearly demonstrated in this paper.

Even though there was a higher incidence of hypoglycemia in the intensive insulin therapy group, none of these resulted in any serious adverse outcomes, outweighing the benefits from the risks. The encouraging results of this study as well as many other subsequent studies of similar nature have guided the American Diabetes Association and the American Association of Clinical Endocrinologists to include intensive insulin therapy in their treatment guidelines for critically ill patients $(41,42)$.

More recently in 2009, a large, randomized multi-centre trial of 6100 patients published in the New England Journal of Medicine determined that the optimal blood glucose target in the ICU may not be $<6.0 \mathrm{mmol} / \mathrm{L}$ but rather $<10 \mathrm{mmol} / \mathrm{L} \mathrm{(43).} \mathrm{These}$ researchers found that there were lower mortality rates when patients were randomized to the latter treatment group. Although this evolving field indicates that there is still much to learn about blood glucose control in the post-surgical patient, there is no doubt there can be significant benefits in reducing postoperative insulin resistance and optimizing blood glucose levels.

The debate on whether the benefit of intensive insulin therapy lies in its improvements in hyperglycemia or the anabolic effects of insulin is one that has not been resolved. The shift towards normoglycemia is significant in decreasing bacterial translocation, preventing cell toxicity, as well as reducing inflammation, coagulation and oxidative stress (26). However, the anabolic effects of insulin can help to change energy usage from protein and fat to glucose, resulting in a more positive nitrogen balance, less protein breakdown and less FFAs in the bloodstream (21). One study showed that insulin 
may inhibit cytokine-stimulated transcription of acute phase proteins, which may in turn blunt the acute phase response in the liver (44). The evidence indicates that it may be a combination of both which are contributing to the reduction in morbidity and mortality (45).

\subsubsection{IL-6, CRP and insulin resistance}

Hormones such as glucagon, cortisol and catecholamines have been studied extensively in the literature to determine their roles in the stress response and development of insulin resistance. Cytokines have been added to this list as more research indicates that they may play an important role in modulating surgical stress.

One study sought to investigate whether a relationship existed between surgical magnitude and release of stress hormones and cytokines (46). Elective laparoscopic cholecystectomy patients were compared pre- and postoperatively with patients who underwent open cholecystectomy. Measurements of tumor necrosis factor (TNF)- $\alpha$ and interleukin-1 (IL-1) showed no differences between groups, and were at times undetectable after surgery. The results for cortisol, norepinephrine and epinephrine were not robustly related to the magnitude of the surgeries. In contrast, IL-6 concentrations rose during the study period after skin incision, and was significantly lower in the laparoscopic group at 3, 4, 6,24 , and 48 hours compared to those undergoing the more invasive procedure $(\mathrm{p}<0.05)$. Lower CRP levels were also observed in the laparoscopic group at 24 and 48 hours after skin incision $(\mathrm{p}<0.05)$.

Another study set out to examine the relationship between cytokines and insulin resistance (47). Insulin sensitivity and cytokine levels including IL-1- $\beta$, interferon- $\gamma$, TNF- $\alpha$ and IL-6 were studied in patients undergoing inguinal hernia repair and open 
cholecystectomy. No significant changes were found in any of the cytokines after surgery except for IL-6. Further supporting the above study, IL-6 was found to be related to the magnitude of the surgery, in that there was a greater rise in IL-6 observed in those undergoing cholecystectomy (from $6 \mathrm{pg} / \mathrm{mL}$ to $36 \mathrm{pg} / \mathrm{mL}$ ) than those undergoing hernia repair (from $4 \mathrm{pg} / \mathrm{mL}$ to $12 \mathrm{pg} / \mathrm{mL}$ ) (47). The rise in IL-6 also correlated with the relative reduction in insulin sensitivity $(r=0.50, p=0.005)$, implying that IL-6 may play a role in modulating stress-induced insulin resistance and may be an important marker in detecting the degree of postoperative insulin resistance. Unfortunately, CRP was not measured in this study.

In summary, research has demonstrated that measurements of IL-6 and CRP are helpful in examining the degree of inflammation, surgical trauma and insulin resistance in surgical patients.

\subsubsection{Adiponectin and insulin resistance}

Recently, investigations into the role of adipose tissue have shown that along with being an energy storage site, it is also responsible for many endocrine functions. One of particular interest is the release of a protein hormone called adiponectin. As opposed to TNF- $\alpha$, leptin and resistin which are also released by adipose tissue and are increased in obesity, adiponectin levels have been shown to be inversely related to obesity (48). This negative association is also true in those with cardiovascular disease (49), diabetes (50) and underlying all of these, insulin resistance.

One cross-sectional study found that adiponectin concentrations in plasma were significantly and positively correlated with insulin sensitivity, even after adjusting for sex 
and measures of adiposity such as BMI, \% body fat and waist:hip ratio (51). A significant negative correlation was found between adiponectin and FFA concentrations (51). This supports studies using animal models, which have shown that high concentrations of adiponectin suppress hepatic gluconeogenesis (52) and promote lipid breakdown in skeletal muscle, decreasing triglyceride storage in muscle and reducing FFA concentrations. Both of these actions can make cells more insulin sensitive (53). Research into this unique adipokine has only recently surfaced but there is great interest in further investigating the relationship which exists between adiponectin and its modulation of insulin sensitivity.

\subsection{Preoperative Fasting}

\subsubsection{Elective surgery and fasting guidelines}

In many western hospital settings, including St. Michael's Hospital (SMH), it is common practice for patients to fast (no food or drink) 8-12 hours before elective surgical procedures to prevent pulmonary aspiration of gastric contents while under anesthesia. Fasting preoperatively causes the body to change from an anabolic to catabolic state and is accompanied by a depletion of glycogen stores. Moreover, processes such as gluconeogenesis, and fat and protein catabolism are heightened during the perioperative period (54). Surgery itself results in a physiological state of hypercatabolism which is further compounded by the metabolic stress of preoperative fasting.

Not surprisingly, in a study measuring patient discomfort using visual analog scales (VASs), fasting was shown to heighten hunger, thirst and anxiety immediately before surgery (12). The metabolic and psychological state of patients entering surgery can affect their clinical outcomes and therefore, researchers have recently questioned whether preoperative 
fasting was necessary and based more on tradition rather than scientific evidence. Studies conducted in the late 1980's and early 1990's found that such a long fast may be unnecessary (55), particularly for clear fluids which empty much faster from the stomach than solids (55), even when considering the anxiety effects of surgery (56).

Based on studies determining gastric emptying rates and the characteristics of liquids, fasting guidelines have been changed to allow clear fluids such as water, tea, coffee and juice without pulp to be consumed up to two hours before anesthesia without increasing the risk of pulmonary aspiration (57). An extensive Cochrane review examined the risk of a shortened fasting period preoperatively and found no additional regurgitation or aspiration events after induction of anesthesia (58). Despite current liberalized guidelines in many countries including the UK, Denmark, Norway, Sweden, the United States and Canada (59), the practice of fasting still remains as standard protocol in many institutions before elective surgical procedures.

\subsubsection{Fasting and insulin resistance}

Along with shifting the body from an anabolic to catabolic state in patients before surgery, fasting has also been found to promote insulin resistance in the body. A study conducted by Nygren et al. (1997) examined the change in insulin sensitivity in a group of healthy volunteers who underwent a 24 hour period of fasting and bed rest (7). The purpose of the trial was to determine how fasting and bed rest affected insulin sensitivity without any surgical insult. It was found that after the study period, there was a $22 \%$ decrease in insulin sensitivity (measured using the euglycemic clamp technique). There was no change in endogenous glucose production; however, there was a significant increase in fat oxidation 
$(\mathrm{p}<0.01)$ as well as a significant decrease in glucose oxidation and utilization $(\mathrm{p}<0.05)$, perhaps this being the result of decreased insulin sensitivity in tissues.

A further study tried to expand on the previous findings to delineate the effects of fasting versus bed rest (8). Healthy subjects underwent two protocols: 24 hours of fasting with free mobilization and on a separate day, 24 hours of bed rest with full oral nutrition. It was found that FFA levels were unchanged after bed rest compared to baseline. However, after 24 hours of fasting, levels were increased 116\% ( $<<0.05)$, indicating a shift from glucose to fatty acid metabolism. Furthermore, no change in insulin sensitivity was observed after bed rest whereas fasting led to a $43 \%$ reduction in insulin sensitivity $(\mathrm{p}<0.001)$. This decrease was greater compared with the previous study (22\%) This difference may be the result of the increased mobility of patients in the latter study (Figure 2.1). The insulin resistance which develops due to the surgery itself is then further exacerbated by fasting in the preoperative period, providing more reason to re-evaluate the tradition of fasting before surgery.

\subsection{Fed vs. fasted state of elective surgical patients}

\subsubsection{Perioperative glucose infusions}

To determine whether postoperative insulin sensitivity could be improved through preoperative feeding, studies were first conducted in patients who received parenteral glucose infusions. In one study, patients undergoing elective open cholecystectomy were randomized to receive glucose infusions at a rate of $5 \mathrm{mg} / \mathrm{kg} / \mathrm{min}$ the evening before surgery to about one hour before anesthesia or to fast after midnight the night preceding their surgery (10). Insulin sensitivity measured using the euglycemic clamp was not different between groups at 


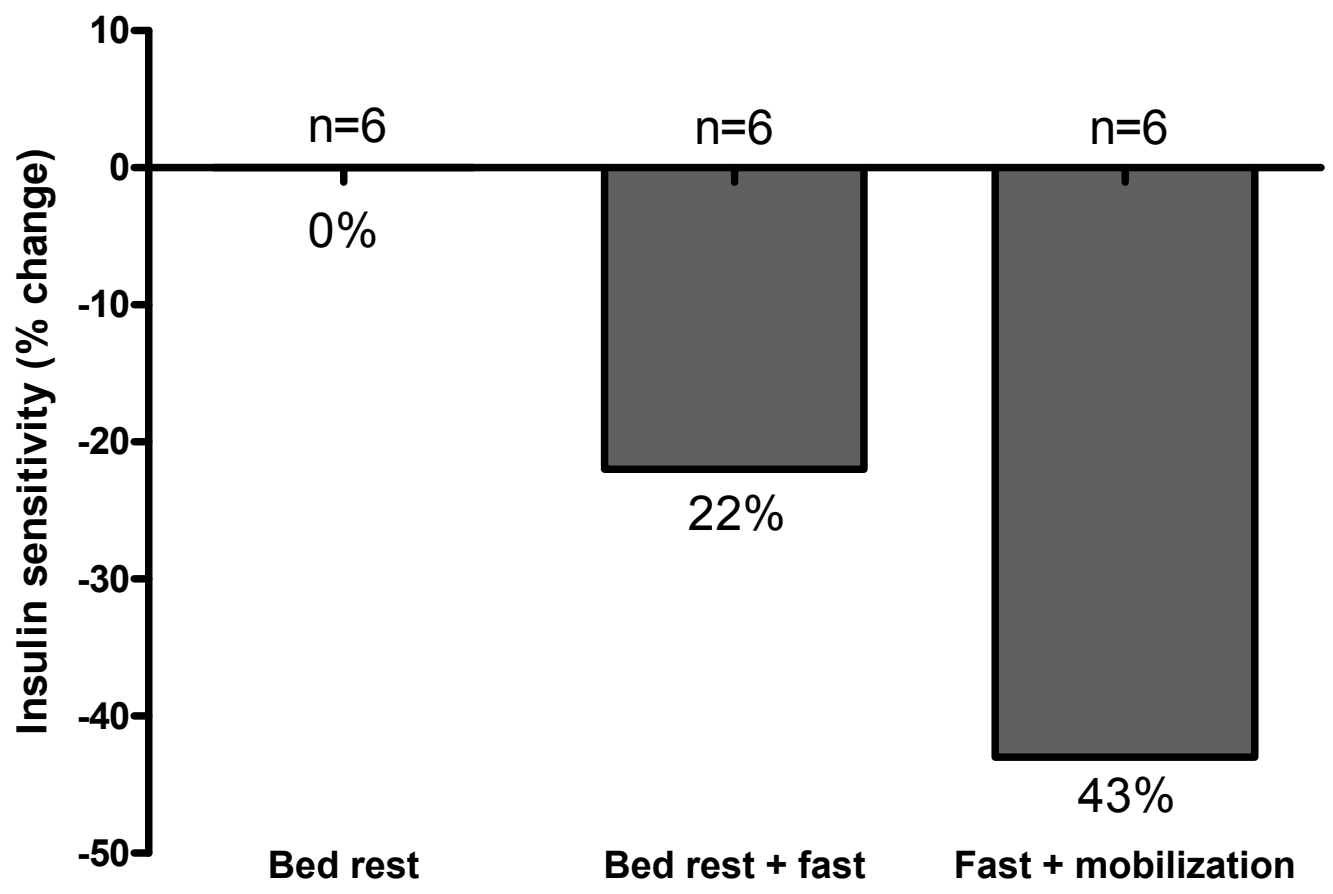

Figure 2.1 Changes in insulin sensitivity due to fasting

Decrease in insulin sensitivity after 24 hours of bed rest, 24 hours of bed rest and fasting, and 24 hours of fasting with free mobilization. Adapted from Figure 4, reference (17). 
baseline. However, on the first postoperative day, patients who received carbohydrates had a smaller reduction, or relative change, in insulin sensitivity compared to the fasted group (-32 $\pm 4 \%$ vs. $-55 \pm 3 \%, p<0.01)$, indicating that postoperative insulin sensitivity is modifiable through preoperative nutrition. This same group carried on to examine patients undergoing total hip replacement surgery (9). Patients who were assigned to the treatment group received glucose and insulin infusions before and during surgery and were studied immediately after surgery to determine if the stress of surgery was better handled in the fed state compared to the fasted state. This study showed that the group treated with infused glucose had better postoperative outcomes, indicated by maintained insulin sensitivity compared to decreased insulin sensitivity $(-40 \pm 5 \%, \mathrm{p}<0.05)$ and glucose disposal $(-29 \pm$ $6 \%, \mathrm{p}<0.05)$ in the fasted group. Furthermore, markers of surgical stress such as FFAs and glucagon were decreased in the infused group in comparison with the fasted group.

Besides improvements in insulin sensitivity, preoperative intravenous glucose infusions have also been shown to have protein-sparing effects (60). In a study conducted by Crowe et al. (1984), patients receiving glucose infusions of $5 \mathrm{mg} / \mathrm{kg} / \mathrm{min}$ the evening before surgery were compared to those who had received the same glucose infusion but commenced 12 hours after surgery. It was found that those who received preoperative carbohydrates experienced significantly less protein breakdown on POD 1, indicated by reduced urinary urea excretion $(\mathrm{p}<0.02)$. This was not surprising as in the fasted state, there is a greater need for protein to be utilized for endogenous glucose production and as a result, less protein and amino acids are available to repair tissue. This suggests that preoperative carbohydrate loading may result in enhanced tissue repair immediately after surgery. 
Altering the metabolic state of the patient using glucose, insulin and potassium before, during and after cardiac surgery has been shown to be clinically beneficial in reducing morbidity and $\operatorname{LOS}(61,62)$. For example, in a study conducted on CABG surgical patients with unstable angina (62), the group treated with infusion of glucose-insulinpotassium perioperatively was found to have better clinical outcomes than that of the group treated with a $5 \%$ dextrose solution: shorter duration on mechanical ventilation $(\mathrm{p}=0.003)$, less time in the ICU $(\mathrm{p}=0.002)$, lower frequency of atrial fibrillation $(\mathrm{p}=0.01)$ and shorter length of hospital stay $(\mathrm{p}=0.01)$.

Although the evidence indicates that glucose infusions may positively influence outcomes in elective surgical patients, the difficulties of implementing this in clinical practice are plentiful (63). Firstly, delivering carbohydrates through infusions is highly invasive for the patient as well as restrictive and would require access to large veins. It is also a labour-intensive task as hospital staff would need to continually monitor patients' glucose levels and adjust rates as necessary. Lastly, current standard care at our institution only requires elective surgical patients to arrive at the hospital a couple of hours before their procedure, which would make preoperative infusions clinically impractical.

\subsubsection{Oral preoperative carbohydrates}

Oral carbohydrate supplementation provides a good alternative to glucose infusions and overcomes many of its barriers. A beverage has been designed for elective surgical patients and is composed of $12.5 \%$ carbohydrates, $50 \mathrm{kcal} / 100 \mathrm{~mL}$ (PreOp®), Nutricia, Zoetermeer, the Netherlands); it is made up mostly of maltodextrins to keep the osmolality of the drink low at $285 \mathrm{mOsm} / \mathrm{kg}$ to promote rapid gastric emptying (11). Moreover, the drink 
is intended to be taken in two doses: 1) a loading dose of $800 \mathrm{~mL}$ (100 g of carbohydrates) the evening before surgery to prevent depletion of glycogen stores and 2) a morning dose of $400 \mathrm{~mL}$. Tracer studies have found that intake of $400 \mathrm{~mL}$ of an oral carbohydrate drink emptied from the stomach in 90 minutes when tested on a group of elective laparoscopic cholecystectomy patients preoperatively (11). This rate was similar to the control group who consumed water and to a group of healthy volunteers who consumed the carbohydrate beverage. The gastric emptying rate indicated that the stress and anxiety in the preoperative state had an insignificant effect on clearance of the drink from the stomach. Thus, if given approximately two hours before anesthesia, carbohydrate supplementation presents minimal risk of pulmonary aspiration of gastric contents.

In addition, oral carbohydrate ingestion has been shown to physiologically stimulate the release of insulin in the same way that is seen after consumption of a mixed meal such as breakfast, reaching peaks at about $60-70 \mu \mathrm{U} / \mathrm{mL}$ (64). In a study mimicking the preoperative setting, subjects were assigned to either consume a $400 \mathrm{~mL}$ carbohydrate supplement or to fast (65). It was found that carbohydrate ingestion resulted in increased insulin action three hours later, and also resulted in increased glucose oxidation and non-oxidative glucose disposal, compared to overnight fasted subjects. Fasting guidelines allow oral consumption of water, juice, coffee and tea up to two hours before surgery (57) but these all provide minimal calories to prevent catabolism. Indeed, patients will still be in a fasted state immediately before surgery. Thus, intake of an oral carbohydrate drink at least two hours prior to surgery will metabolically prepare patients with adequate insulin activity at the onset of surgery. 


\subsubsection{Oral preoperative carbohydrates and patient discomfort}

Besides the physiological benefits, the provision of a carbohydrate-rich drink can help alleviate some of the psychological stress associated with surgery. In one study, patients undergoing elective abdominal surgery were randomized into one of three groups: oral carbohydrate drink group, placebo group (flavoured water) or a fasted group (12). Subjective feelings of discomfort were measured during the preoperative period for 11 variables using VASs: depression, anxiety, hunger, inability to concentrate, malaise, nausea, pain, thirst, tiredness, unfitness and weakness. Results indicated that the fasted group experienced significantly increased thirst $(p<0.001)$, hunger $(p<0.05)$, tiredness $(p<0.0001)$, weakness $(\mathrm{p}<0.01)$ and inability to concentrate $(\mathrm{p}<0.05)$ during the preoperative period. This was opposed to the carbohydrate-treated group, who experienced significantly less hunger $(p<0.05)$, thirst $(p<0.001)$, anxiousness $(p<0.01)$, malaise $(p<0.01)$ and unfitness $(p<0.0001)$ throughout the preoperative period. A preoperative carbohydrate drink has then been shown to improve feelings of discomfort before surgery while providing minimal risk during surgery.

In a follow-up study, the research team decided to look at subjective well-being specifically nausea, vomiting and pain - in post-surgical patients (66). Patients were assigned to either consume a carbohydrate beverage, flavoured water or to fast prior to surgery. VAS scores for nausea at baseline and postoperatively ( 24 hours after surgery) were similar in those who received carbohydrate supplementation $(p=0.08)$. In contrast, the fasted and placebo group had significantly more nausea in the postoperative period compared to baseline ( $<<0.001$ and $p=0.02$, respectively). In addition, there was a significantly lower incidence rate of postoperative nausea and vomiting 12-24 hours after surgery in the 
carbohydrate-supplemented group compared to those who fasted $(\mathrm{p}=0.04)$. No difference was found between the treated and placebo group. The authors speculate that the improvement in postoperative well-being in those who were treated with carbohydrates may lie in fluid hydration preoperatively but the mechanism behind this remains to be elucidated.

\subsubsection{Effects of oral preoperative carbohydrates on immune and muscle function}

The ability of oral preoperative carbohydrate loading to stimulate the release of insulin and shift the body from a fasted, catabolic state to a fed, anabolic state has motivated researchers to examine the possible benefits this may have for the post-surgical patient.

One research group determined the effects of oral carbohydrate supplementation on immune function by analyzing human leukocyte antigen (HLA)-DR expression on monocytes (67). HLA-DR is necessary for an effective immune response; low expression of this antigen is associated with increased risk of infections postoperatively. Melis et al. (2006) found that there was decreased expression of this antigen postoperatively in a group of patients who had fasted before surgery $(\mathrm{p}<0.05)$, whereas two groups who consumed a carbohydrate beverage before surgery sustained expression of HLA-DR after surgery compared to baseline. Patients who fasted also had significantly less expression of HLA-DR after surgery compared to the two treated groups $(\mathrm{p}<0.05)$, suggesting that preoperative feeding may reduce the risk of infections in the postoperative period.

Another investigation sought to determine whether the increased energy gained by the carbohydrate supplement would decrease gluconeogenesis in the body and preserve lean muscle mass (68). Patients scheduled for elective abdominal surgery received either a 
placebo drink or a carbohydrate supplement the evening before and day of surgery. Skin calipers were used to measure triceps skinfold thickness (measurement of body fat) and midarm muscle circumference (measurement of lean body mass) at baseline and on day of discharge. Results indicated that the change in triceps skinfold at discharge was not significantly different between the two groups. However, the reduction in mid-arm muscle circumference was found to be significantly smaller in the treated group in comparison with the placebo group $(-0.5 \pm 0.2 \mathrm{~cm}$ vs. $-1.1 \pm 0.2 \mathrm{~cm}, \mathrm{p}<0.05)$. Another study found that those treated with preoperative carbohydrates had significantly lower postoperative nitrogen losses compared to placebo $(136 \pm 4 \mathrm{mg} / \mathrm{kg} /$ day vs. $161 \pm 10 \mathrm{mg} / \mathrm{kg} / \mathrm{day}, \mathrm{p}<0.05)(69)$. Research also demonstrated that patients who fasted prior to surgery had significantly reduced grip strength at discharge compared to baseline $(-11 \%, \mathrm{p}<0.05)$ in contrast to those in the treatment group who had no significant change (70). These studies suggest that similar to glucose infusions, oral carbohydrates may help to preserve lean muscle mass and decrease protein breakdown, which could in turn enhance the healing process.

\subsubsection{Oral preoperative carbohydrates and insulin resistance}

The positive effects of intravenous glucose feeding on improving postoperative insulin sensitivity have led researchers to question whether similar outcomes would be observed using oral carbohydrate loading. Besides eliminating the fasting regimen which has been shown to promote insulin resistance, providing carbohydrates a few hours before surgery may prime the body for the next glucose load more effectively, a phenomenon known as the Staub-Traugott effect (71). The carbohydrate supplement can stimulate insulin 
action and glycogenic and glycolytic enzymes, which can enhance insulin sensitivity in time for patients' surgeries.

Swedish researchers set out to examine this question in a series of investigations. Their first study tested a carbohydrate beverage in a group of patients undergoing elective colorectal surgery (14). Seven subjects were assigned to the fasted group where they did not consume any food after midnight before their surgery. Seven subjects were placed in the drink group where they consumed $800 \mathrm{~mL}$ of the drink on the evening before their surgical procedure. Two hours prior to their surgery, subjects in the drink group consumed another $400 \mathrm{~mL}$ of the drink. Insulin sensitivity was measured before surgery and on POD 1 using the euglycemic clamp technique. Results showed that the fasted group had a $24 \%$ greater decline in insulin sensitivity compared to patients who received the carbohydrate supplement. In addition, both groups experienced a decrease in glucose disposal in the postoperative period. The fasted group, however, experienced a significantly greater drop that was almost twice as much as that seen in the treated group $(-49 \pm 6 \%$ vs. $26 \pm 8 \%, p<0.05)$.

Furthermore, both groups had significant increases in fat oxidation postoperatively compared to baseline yet the fasted group had an $85 \%$ greater increase compared to the treated group $(\mathrm{p}<0.05)$. Endogenous glucose production was not different between groups.

The second study conducted by the same researchers placed 16 total hip replacement surgical patients into either a preoperative carbohydrate drink group or placebo group and administered the same amount of fluid as outlined above (15). Postoperative insulin sensitivity was measured after the completion of surgery rather on POD 1, to remove the effects of bed rest and fasting, which was a limitation in the above study. Immediately following surgery, insulin sensitivity significantly decreased in the placebo group $(-37 \pm 8 \%$; 
$\mathrm{p}<0.05)$ whereas no change $(16 \pm 7 \%$, not significant $)$ was found in the drink group. This was due to reduced rates of glucose oxidation and non-oxidative glucose disposal in the fasted group compared to maintained rates of glucose disposal postoperatively in the drink group. Endogenous glucose production was, again, not different between groups.

Soop et al. (2001) conducted an experiment on 15 subjects undergoing total hip replacement surgery in a randomized double-blinded trial (16). Eight subjects were assigned to consume $800 \mathrm{~mL}$ of a carbohydrate beverage the night before surgery and $400 \mathrm{~mL}$ of the drink two hours prior to their hip replacement surgery. Seven subjects were placed in the placebo group and administered sweetened water, identical in taste to the preoperative drink, in the same amounts as the treatment group. Although insulin sensitivity decreased in both groups after surgery, the magnitude of the reduction was significantly lower in the treatment group $(-18 \pm 6 \%$ vs. $-43 \pm 9 \%, \mathrm{p}<0.05)$. This was mainly due to maintained glucose oxidation rates perioperatively in the treatment group. Endogenous glucose release was not different in both groups compared to baseline. Non-oxidative glucose disposal was significantly lower after surgery in both groups compared to baseline; however, no differences between the two groups were observed postoperatively.

Rather than examining the effects of this carbohydrate supplement in the first 24 hours after surgery, the Swedish research team investigated the benefits of carbohydrate supplementation on POD 3 (69). Fourteen total hip replacement surgical patients were randomly assigned to receive either the evening and morning dose of a carbohydrate supplement or receive the same volume of a sweetened placebo drink. Insulin sensitivity was measured using the gold standard technique a week before surgery and on POD 3. In contrast to other studies, it was found that glucose disposal and glucose oxidation were 
similar in both treated and control groups after surgery. However, endogenous glucose release was increased in the placebo group after surgery compared to baseline (1.21 vs. 0.62 $\mathrm{mg} / \mathrm{kg} / \mathrm{min} ; \mathrm{p}<0.01)$ but this was not seen in the treated group ( 0.69 vs. $0.27 \mathrm{mg} / \mathrm{kg} / \mathrm{min}$, not significant). Endogenous glucose release was also significantly higher in the placebo group on POD 3 compared to the treated group $(\mathrm{p}<0.01)$. These findings are in contrast to the other studies which measured insulin sensitivity within the first 24 hours and found that postoperative insulin resistance occurred predominantly at the peripheral tissues rather than at the liver. This study suggests that peripheral insulin resistance may prevail for the first 24 hours postoperatively but this may shift to hepatic insulin resistance further in the time course. Preoperative carbohydrate loading can help to attenuate the insulin resistance seen on POD 3.

Not all studies have had similar findings. A study conducted by Breuer et al. (2006) investigated the effects of a preoperative carbohydrate drink on insulin resistance in CABG and valve replacement surgical patients (72). Glucose levels and insulin requirements to maintain blood glucose levels at $\leq 10.0 \mathrm{mmol} / \mathrm{L}$ postoperatively did not differ among the treatment, placebo or fasted group, suggesting that the carbohydrate drink did not provide any benefit in reducing insulin resistance. Another study examined elective CABG patients and assigned 101 patients to either fast after midnight before their surgery or ingest only the morning dose of a preoperative supplement ( $400 \mathrm{~mL}$ or $50 \mathrm{~g} \mathrm{CHO}$ ) (73). Researchers aimed to maintain perioperative blood glucose levels between 4 and $7 \mathrm{mmol} / \mathrm{L}$ and compared differences in both groups in the number of patients administered insulin and the amount of insulin required (in IU). The study also did not find any differences between groups in the outcome variables. As opposed to previous investigations by the Swedish research group 
who used the euglycemic clamp technique as a direct measure of insulin sensitivity, both of these studies used surrogate markers. This is a major limitation and thus, it is difficult to draw conclusions as to whether the drink had any effect on insulin sensitivity.

Researchers have also been interested in studying elderly patients undergoing CABG surgery as these patients may already have underlying insulin resistance due to their age that can be further exacerbated by fasting and the surgery itself (74). Eighteen patients over the age of 65 were recruited for this study. Patients ingested either $400 \mathrm{~mL}$ of a carbohydrate drink the evening before and the same volume three to five hours before surgery or underwent standard fasting procedures. No differences in insulin sensitivity were found in either group after surgery. HOMA was used to measure insulin sensitivity and $\beta$-cell function. Although this mathematical model shows good correlation with the euglycemic clamp technique (38), it is still not a direct measure of insulin sensitivity. As well, glucose infusions were administered in both groups during surgery to feed the ischemic heart and were not discontinued until POD 1. By this time, any benefits of the preoperative carbohydrate supplement may have been lost.

\subsubsection{Preoperative carbohydrate loading and clinical outcomes}

Three studies conducted by the Swedish research group surrounding preoperative carbohydrate loading did not find a significant difference in length of hospital stay in each of the individual studies. However, investigators recognized the limitation of the small sample sizes utilized, which presented problems in analyzing the data. Investigators performed a retrospective meta-analysis of the three studies combined, which included 52 patients; their findings indicated that patients who received preoperative carbohydrate loading had a 
significantly shorter LOS (equivalent to 1.2 days or $20 \%$ ) compared to those who fasted $(\mathrm{p}=0.02)(13)($ Figure 2.2).

In another supporting trial, patients undergoing elective colorectal resection were randomly assigned to one of three groups: two groups either consumed a preoperative carbohydrate drink or water orally and the third group fasted before surgery (70).

Postoperatively, patients who received the carbohydrate drink had a reduced length of hospital stay compared to the water group ( $\mathrm{p}=0.019$, significant) and the fasting group ( $p=0.06$, not significant). Unfortunately, besides these data, studies examining clinical outcomes of patients treated with carbohydrate supplementation in the preoperative period have been limited. 


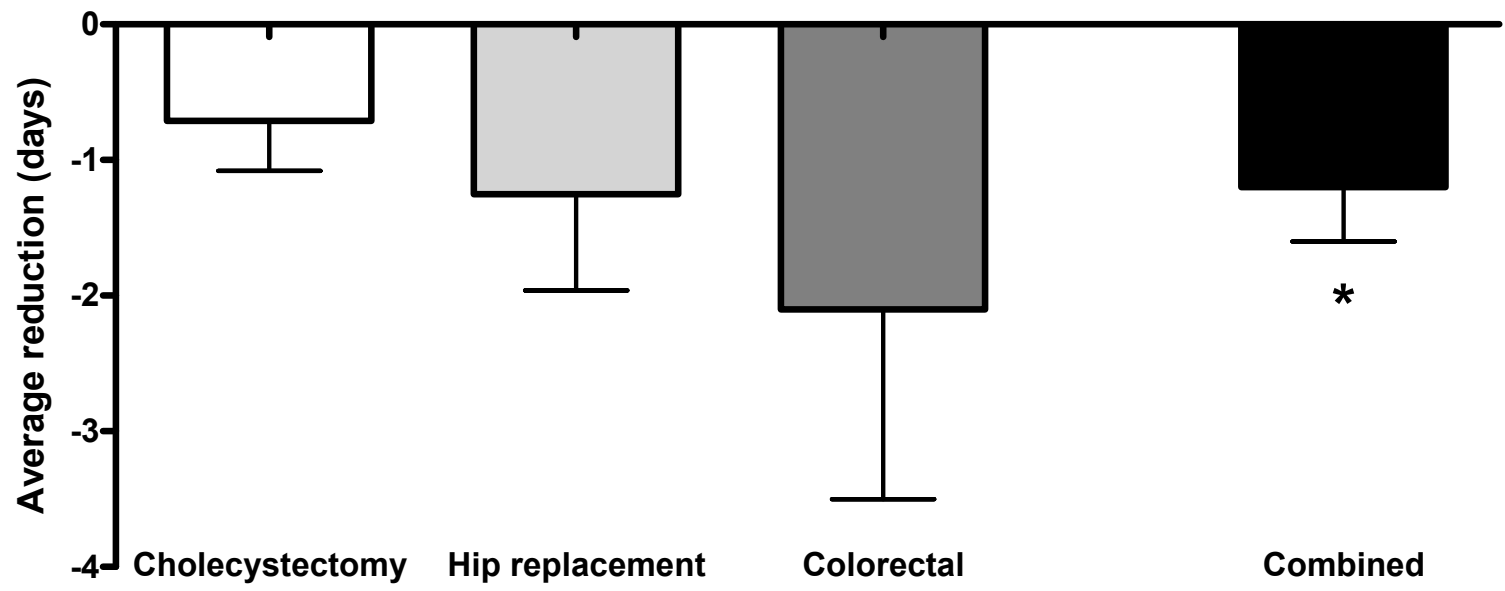

Figure 2.2 Preoperative carbohydrate loading and length of hospital stay

Values represent the difference in LOS between preoperative carbohydrate loaded and placebo groups, adjusted for age and BMI, from three studies. The combined effect represents the meta-analysis conducted on the three studies. ${ }^{*} p=0.02$. Adapted from Table 2, reference (13). 


\subsection{RESEARCH QUESTION}

\subsection{Rationale}

Oral preoperative carbohydrate supplementation provides a better alternative to glucose infusions and has been shown to effectively reduce insulin resistance in elective surgical patients after surgery. There also appears to be psychological and clinical benefits associated with preoperative carbohydrate loading.

Interestingly, studies which have used a standardized technique of measuring insulin sensitivity have shown improvement in postoperative insulin sensitivity in those who received oral carbohydrate supplementation preoperatively. However, these studies were limited due to the small sample sizes utilized and the surgeries examined were small in magnitude, and thus, these surgical patients were less likely to develop significant insulin resistance postoperatively. Studies which have examined highly invasive surgeries such as $\mathrm{CABG}$ surgery found no effect of the carbohydrate supplement on postoperative insulin sensitivity. However, these and other studies have been limited by their use of surrogate markers of insulin sensitivity as well as failing to examine any changes in clinical outcomes associated with carbohydrate supplementation.

Therefore, there is a need to investigate the effect of carbohydrate loading on insulin resistance and clinical outcomes in patients undergoing surgery of extended duration and complexity. Patients undergoing major cardiac and spinal surgery are ideal for studying the effects of preoperative carbohydrate loading. These types of operations are of long duration and relatively high surgical stress resulting in the development of significant insulin resistance, and thus these surgical patients can potentially benefit from carbohydrate supplementation. 
Therefore, we conducted a randomized, controlled trial of preoperative carbohydrate loading in patients undergoing $\mathrm{CABG}$ and spinal decompression and fusion surgery, using a carbohydrate-rich commercially available product.

A pilot study was conducted on CABG surgical patients at SMH (Keith M, Wolever T, Errett L, Mazer CD, unpublished observations, 2002). Thirteen subjects were randomly assigned to either consume a carbohydrate beverage in the two prescribed doses or to follow the hospital standard protocol of fasting. No improvements in postoperative insulin sensitivity were observed in the treatment group compared to the fasted group. However, positive outcomes such as preserved $\beta$-cell function $(\mathrm{p}=0.05)$, increased insulin release $(p=0.03)$ and maintained glucose levels were observed in the treatment group. As well, the treatment group required less time on mechanical ventilation $(\mathrm{p}=0.05)$, less blood $(\mathrm{p}=0.004)$, and spent less time in the ICU $(\mathrm{p}=0.008)$ and in the hospital $(\mathrm{p}=0.03)$ compared to the fasting group. Due to the small sample size, further investigation through enrolment of more patients was necessary to determine the impact of preoperative oral carbohydrate loading on insulin sensitivity in this unique population of patients undergoing invasive surgery.

\subsection{Hypothesis}

\subsubsection{Primary hypothesis}

1) The administration of $800 \mathrm{~mL}(100 \mathrm{~g} \mathrm{CHO})$ of a preoperative oral carbohydrate drink the night before and $400 \mathrm{~mL}(50 \mathrm{~g} \mathrm{CHO})$ two hours before elective CABG or spinal decompression and fusion surgery will reduce postoperative insulin resistance by $40 \%$ compared to patients who have undergone the standard of care of fasting the night before and day of surgery. 


\subsubsection{Secondary hypothesis}

2) Preoperative carbohydrate supplementation will reduce postoperative glucose levels and result in more preserved $\beta$-cell function compared to the fasted group.

3) The administration of a preoperative carbohydrate supplement will reduce levels of inflammatory markers such as CRP and IL-6 as well as FFA levels throughout the postoperative period.

4) The use of a preoperative carbohydrate supplement will improve surgical outcomes such as infectious complications and length of hospital stay compared to the fasted group.

5) Patients in the treatment group will experience less discomfort immediately prior to their surgery compared to the fasted group.

\subsection{Objectives}

\subsubsection{Primary Objective}

1) To determine and compare the change in insulin sensitivity in the carbohydrate supplemented group and fasted group using the short insulin tolerance test (SITT).

\subsubsection{Secondary Objectives}

2) To determine and compare the change in insulin sensitivity and $\beta$-cell function using the standardized HOMA mathematical equations. 
3) To determine and compare the change in glucose and insulin levels in the treatment and fasted group.

4) To determine and compare changes in markers of inflammation including CRP and IL-6 as well as FFA levels in the treatment and fasted group.

5) To compare surgical outcomes such as time on mechanical ventilation, incidence of infection, blood transfusions, LOS in the ICU and LOS in the hospital between the treatment and fasted group.

6) To compare subjective feelings of discomfort between the treatment and fasted group using VASs administered immediately prior to surgery.

7) To measure and correlate adiponectin values at baseline with indices of insulin sensitivity.

\subsection{Organization of Thesis}

The next sections of this thesis are presented in the following manner. Chapter 4 includes a manuscript written for publication and describes the methods, main results and discussion in an abbreviated form as appropriate for a manuscript. A short introduction is also included at the beginning of the chapter. The next chapter of the thesis includes the final conclusion and suggestions for future research directions. A section entitled "Expanded Results and Discussion" can be found in the Appendix and provides additional analyses of 
different sub-groups within our patient population (e.g., Spine patients vs. CABG patients). Relevant data from these analyses will be highlighted in the manuscript in Chapter 4. 


\subsection{MANUSCRIPT: PREOPERATIVE CARBOHYDRATE LOADING IN PATIENTS UNDERGOING CORONARY ARTERY BYPASS OR SPINAL SURGERY}

\subsection{Introduction}

Surgical stress creates a state of insulin resistance and hyperglycemia, which has been associated with post-surgical complications including increased morbidity and mortality (3). The degree of insulin resistance which develops is positively associated with length of hospital stay (17).

Elective surgery usually involves an 8-12 hour fast to reduce the risk of pulmonary aspiration of gastric contents at the induction of anesthesia. Preoperative fasting causes the body to change from an anabolic to catabolic state, accompanied by a depletion of glycogen stores, increased gluconeogenesis, and fat and protein catabolism during the perioperative period (63). Fasting has also been shown to contribute to the development of insulin resistance $(7,8)$ and has therefore been questioned in recent years whether 'nil per os' was based more on tradition rather than evidence-based research.

Investigations comparing fasting with glucose infusions preoperatively provided evidence that patients who were in a fed state preoperatively had better postoperative outcomes, including less protein breakdown (60) and improvements in postoperative insulin sensitivity (10). The development of a carbohydrate drink to be consumed prior to surgery appears to have the same metabolic benefits (14-16). However, these studies have not examined improvements in insulin sensitivity along with its effects on clinical outcomes. Furthermore, the degree of insulin resistance which develops is dependent on the magnitude of surgery (17). As such, patients undergoing major cardiac and spinal surgery are ideal for studying the effects of preoperative carbohydrate loading. These types of operations are of 
long duration and relatively high surgical stress with considerable perioperative blood loss resulting in the development of significant insulin resistance, and thus these surgical patients could potentially benefit from carbohydrate supplementation.

Therefore, the aims of our investigation were to determine whether preoperative carbohydrate loading would not only attenuate insulin resistance in the postoperative period but also improve clinical outcomes in a surgical population of coronary artery bypass graft $(\mathrm{CABG})$ and spinal decompression and fusion surgical patients.

\subsection{Methods}

\subsubsection{Study subjects}

Patients scheduled for elective $\mathrm{CABG}$ or spinal decompression and fusion surgery were eligible to participate in this randomized, controlled trial. Patients were ineligible if they had gastrointestinal motility or reflux issues, existing type I or type II diabetes, body mass index (BMI) $>40$, unable to speak English or were undergoing non-elective (urgent or emergent) surgery. Subjects who entered surgery greater than five hours after ingestion of the morning drink were also excluded. This study was approved by the St. Michael's Hospital (SMH) research ethics board and written informed consent was obtained from all study participants (Appendix, Form 1 - Consent form). The study protocol was registered at http://clinicaltrials.gov (Identifier: NCT00618592).

Participants met with investigators on a date prior to their surgery to collect baseline demographic, anthropometric and medical data (Appendix, Form 2 and 3 - Spine and CABG case report form). Randomization was conducted in permuted blocks of six to either receive preoperative carbohydrate supplementation (CHO group) or to fast prior to surgery (FAST 
group). Patients randomized to the $\mathrm{CHO}$ group consumed $800 \mathrm{~mL}$ of an iso-molar preoperative drink $\left(12.5 \mathrm{~g} / 100 \mathrm{~mL}\right.$ CHO, PreOp ${ }^{\circledR}$, Nutricia, Zoetermeer, The Netherlands) the evening before surgery between $2100-2300 \mathrm{~h}$ and another $400 \mathrm{~mL}$ of the supplement two hours before their scheduled elective procedure (Appendix, Table 1 - PreOp ${ }^{\circledR}$ drink composition). This second dose was consumed over a ten minute period. Patients randomized to the FAST group were instructed to consume no food or drink after 8:00 pm the evening before their operation.

\subsubsection{Surgery and anesthesia}

The surgeon, nursing staff and anesthesiologist were blinded to the nature of the preoperative treatment. General anesthesia was at the discretion of the anesthesiologist and consisted of a combination of intravenous and inhaled anesthetics including midazolam, fentanyl, morphine, rocuronium, isoflurane, thiopental, remifentanil and/or sufentanil citrate (Appendix, Table 2 - Anesthetics and other drugs). Propofol was not administered as the lipid emulsion in which it is delivered may have induced insulin resistance in our patients and confounded our results.

All cardiac participants underwent conventional CABG surgery using cardiopulmonary bypass $(\mathrm{CPB})$ and standard operating procedures. The $\mathrm{CPB}$ circuit consisted of a hollow-fibre membrane oxygenator, heparin coated tubing, arterial line filter and a roller pump for perfusion. The circuit was primed with a combination of $1200 \mathrm{~mL}$ plasmalite (Baxter), $500 \mathrm{~mL}$ pentaspan, $5000 \mathrm{U}$ heparin and 25 milliequivalents of bicarbonate. Heparin (300-400 U/kg body weight) was administered prior to initiating CPB to achieve an activated clotting time of at least 450 seconds. Cardiac arrest was initiated with 
cold blood cardioplegia (high potassium). Mild hypothermic perfusion $\left(33-34^{\circ} \mathrm{C}\right)$ was maintained during the period of myocardial ischemia. Myocardial protection consisted of intermittent antegrade cold blood cardioplegia followed by a warm "hot shot" at the end of the procedure. Protamine was administered to reverse the anticoagulation. Non-glucose containing solutions were administered in the operating room (OR) and cardiovascular intensive care unit (CVICU) for intravenous fluid therapy as well as for the measurement of cardiac index.

Posterior spinal surgery of the thoracic, lumbar and/or sacral spine was conducted in the prone position on a Jackson table with or without three-dimensional navigation. A preoperative antibiotic (e.g., cefazolin) was administered prior to general anesthesia. Patients were mechanically ventilated and topical and intravenous warming was used to maintain normothermia. An arterial line was inserted and mean blood pressure and heart rate were maintained by the anesthesiologist within $30 \%$ of baseline values. Fusion was performed with autogenous, morselized bone grafts from localized bone from decompression, the pelvis, iliac crest, or through pars osteotomy. Instrumentation with interbody cage, pedicle screws and precontoured lordosis rods of appropriate lengths were utilized. Most patients were extubated prior to being transferred to the medical-surgical intensive care unit (MSICU) or the post-acute care unit (PACU) following surgery.

\subsubsection{Insulin sensitivity}

Insulin sensitivity was measured at baseline after a 12 hour fast and in the immediate postoperative period using the short insulin tolerance test (SITT). Blood samples from an arterialized, cannulated vein were collected by a study physician prior to the administration 
of a bolus of human insulin $(0.05 \mathrm{U} / \mathrm{kg}$, Humulin $\mathrm{R} \AA$, Eli Lilly). Blood samples were then drawn at 3, 5, 7, 9, 11, 13 and 15 minutes after insulin injection. In the postoperative period, the SITT was performed immediately upon stabilization in the ICU or recovery room by a physician or nurse, usually within an hour after surgery.

The slope of the decline in blood glucose from 3 to 15 minutes was determined using linear regression by plotting plasma glucose concentrations against time on a semilogarithmic scale. Insulin sensitivity was calculated by taking the slope and multiplying it by -100 and expressed as the rate constant for the disappearance of blood glucose $\left(\mathrm{K}_{\mathrm{ITT}}\right)$. $\mathrm{K}_{\mathrm{ITT}}$ represents the percent decline in plasma glucose concentration per minute. Results $>2 \% /$ minute are considered normal and $\mathrm{K}_{\mathrm{ITT}}$ values $<1.5 \% /$ minute are abnormal or insulin resistant (31). The SITT has been found to be reproducible, with a within-subject variability of $13 \%$ and $26 \%$ between-subject variability, (33) and to have good correlation with the hyperinsulinemic euglycemic clamp $(32,75)$.

Fasting insulin and glucose levels were determined at baseline and in the immediate postoperative period to assess insulin resistance and $\beta$-cell function using the homeostasis model assessment (HOMA) (37). HOMA-IR and HOMA- $\beta$ are widely used mathematical models and have been found to be significantly correlated to physiological insulin sensitivity measures, including the euglycemic clamp technique $(37,38)$.

Serum insulin and glucose were measured by the hospital core laboratory using a standard radioimmunoassay and the glucose oxidase method (Beckman-Coulter LX-20, Fullerton, CA, USA), respectively. 


\subsubsection{Blood markers}

Blood samples for analysis of free fatty acid (FFA) levels and inflammatory markers including interleukin-6 (IL-6) and C-reactive protein (CRP) were collected at baseline, immediately after surgery as well as 24,48 and 72 hours following surgery. Plasma aliquots were stored in a $-70^{\circ} \mathrm{C}$ freezer for batch analysis. FFA levels were determined using an enzymatic colorimetric assay (Wako Chemicals, Richmond, VA, USA). IL-6 was measured using a commercial ELISA kit (R\&D Systems, Minneapolis, MN, USA) and high sensitivity CRP was measured by Dr. Phillip Connelly's lab at SMH using endpoint nephelometry (BN ProSpec System, Siemens, Deerfield, IL, USA). Plasma adiponectin was measured at baseline only using a commercial ELISA kit (Millipore, Billerica, MA, USA).

\subsubsection{Subjective well-being}

Participants completed 100-mm visual analog scales (VASs) to measure subjective feelings of discomfort on two occasions: 1) at baseline and 2) before entering the OR. The 11 variables studied were measured in a previous study (12) and included anxiety, depression, hunger, malaise, inability to concentrate, nausea, pain, thirst, tiredness, unfitness and weakness. Each scale consisted of ungraded, horizontal lines anchored at two ends. The left anchor of the scale represented "not at all" (score: 0) and the right anchor represented "extremely" (score: 100); patients completed each scale by marking an X somewhere along the horizontal line (Appendix, Form 4 - Visual analog scale questionnaire). 


\subsubsection{Clinical outcomes}

Intra and postoperative events were documented as well as various hyperglycemic outcomes. Hyperglycemia was defined as $>8 \mathrm{mmol} / \mathrm{L}$. Intra-operative hypotension was defined as the administration of dobutrex, epinephrine, dopamine or levophed for $>30$ minutes in the OR. A postoperative inotrope event was defined as the administration of the following inotropes for at least six hours after surgery: dobutrex $>5 \mu \mathrm{g} / \mathrm{kg} / \mathrm{min}$, epinephrine $>0.5 \mu \mathrm{g} / \mathrm{kg} / \mathrm{min}$, dopamine $>5 \mu \mathrm{g} / \mathrm{kg} / \mathrm{min}$ or levophed $>0.05 \mu \mathrm{g} / \mathrm{kg} / \mathrm{min}$. A complication was defined as any one of the following: intra-op bleeding, intra-op hypotension, intra-op hyperglycemia, post-op hyperglycemia, wound infection, other infection, pneumonia, urinary tract infection, myocardial infarction, post-op inotropes received, post-op intra-op aortic balloon pump (IABP) required, atrial fibrillation, pleural effusion, pulmonary embolism/deep vein thrombosis (PE/DVT) or transfusion required. These events were documented on OR flow sheets or nurses' notes. The total number of patients who experienced a complication and the total number of complications which occurred were determined.

\subsubsection{Statistical Analysis}

Continuous data were analyzed using the Mann-Whitney $U$ test to determine differences between groups or the Wilcoxon signed rank test to determine within-group differences and are presented as median $\left(25^{\text {th }}, 75^{\text {th }}\right.$ percentile). Categorical data were analyzed using the chi-square test, or the Fisher's exact test when the number in any cell was less than five, and described as counts (percentage). Changes between two time points were also calculated $\left(\mathrm{x}_{1}-\mathrm{x}_{0}\right)$ in both groups for variables including glucose, insulin and insulin sensitivity. To correct for baseline differences in VAS scores, regression analysis was 
applied. Mixed model statistics were applied to outcomes with repeated measures to determine the effect of time, treatment and interaction and the Mann-Whitney $\mathrm{U}$ test was utilized to determine differences at 72 hours postoperatively. IL-6 and CRP were logtransformed prior to analysis. For FFAs, baseline values were added as a covariate in the model as values were significantly different between groups at this time point and change from baseline to 72 hours post-op was determined and compared. An independent samples ttest was used to compare the total number of complications. Due to our heterogeneous study population, statistical testing was used to compare various sub-groups such as spine vs. CABG patients. Spearman's rank correlation coefficient was applied to determine associations between variables.

\subsection{Results}

\subsubsection{Study subjects}

A total of 26 non-diabetic, elective $\mathrm{CABG}$ and 12 spinal decompression and fusion surgical patients were recruited for this study. 90 patients (53 CABG, 37 spine) were approached between April 2008 and February 2009. Patients were unable to participate for the following reasons: unable to travel to SMH for the baseline visit $(\mathrm{n}=19)$; unable to speak English ( $\mathrm{n}=9$ ); scheduling conflicts $(\mathrm{n}=4)$; ineligible for the study (e.g., patient had undocumented type II diabetes) $(\mathrm{n}=7)$; decided not to go ahead with surgery $(\mathrm{n}=2)$; surgery was imminent $(\mathrm{n}=2)$; was put on a surgical wait list and had not received a booked date at the time recruitment ended $(\mathrm{n}=5)$; or other $(\mathrm{n}=3)$. Fourteen patients declined to participate and 25 patients (13 CABG, 12 spine) were enrolled. In addition, $13 \mathrm{CABG}$ patients recruited in a previous pilot study conducted at our institution were included in the analysis (unpublished 
data). Data on IL-6, adiponectin and VAS scores were not collected on these patients. Each participant was randomized to either the CHO group or the FAST group (Figure 4.1).

Baseline subject, cardiovasular disease and spine characteristics are summarized in Table 4.1, 4.2 and 4.3, respectively. Patients were well-matched in both groups with respect to age, BMI, medical history as well as clinical classifications. However, CABG patients in the FAST group had a higher number of previous myocardial infarctions compared to the CHO group $(\mathrm{p}=0.02)$. Patients' medication profile can be found in the Appendix (Table 3 Medications).

\subsubsection{Insulin sensitivity}

Glucose levels were not different between groups at baseline (Table 4.4). Following surgery, both groups had a significant rise in blood glucose $(\mathrm{p}<0.001)$; however, the $\mathrm{CHO}$ group had lower blood glucose levels but this did not achieve statistical significance $(p=0.08)$. The change in blood glucose from baseline to the postoperative period showed a significantly smaller rise in those who received the CHO supplement compared to the FAST group (mmol/L: $0.8(-0.1,1.9)$ vs. $1.9(0.7,2.5), \mathrm{p}=0.03)$. Baseline and postoperative insulin levels were similar between groups (Table 4.4). The CHO group experienced a rise in insulin postoperatively whereas those in the FAST group demonstrated a decline (pmol/L: $4.5(-25.3,53.0)$ vs. $-10.0(-19.0,10.0))$, although this difference did not achieve significance.

One patient in the FAST group was unable to complete the baseline SITT due to a vago-vagal response. Interestingly, 24 patients were found to be insulin resistant at baseline $\left(\mathrm{K}_{\mathrm{ITT}}<1.5 \% / \mathrm{min}\right)$ and these patients were not evenly distributed between groups as only nine 


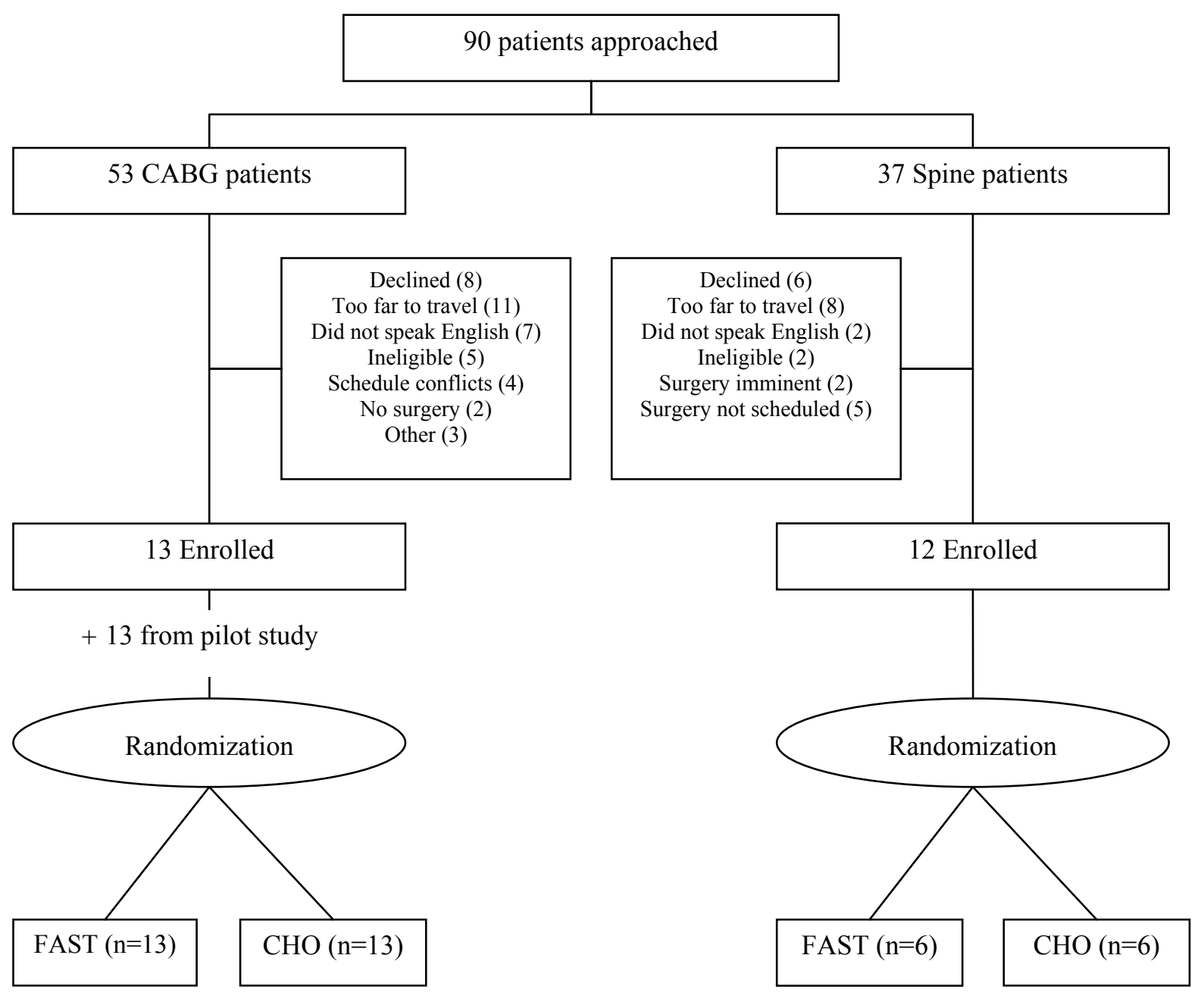

Figure 4.1 Subject recruitment and randomization 
Table 4.1 Baseline subject characteristics

\begin{tabular}{|c|c|c|c|}
\hline & $\begin{array}{c}\text { Fast } \\
(n=19)\end{array}$ & $\begin{array}{c}\mathrm{CHO} \\
(\mathrm{n}=19)\end{array}$ & p-value \\
\hline Age (years) ${ }^{*}$ & $59.0(52.0,64.0)$ & $59.0(50.0,67.0)$ & $\mathrm{NS}(0.92)$ \\
\hline $\begin{array}{l}\text { Body mass index } \\
\left(\mathrm{kg} / \mathrm{m}^{2}\right)^{*}\end{array}$ & $25.6(23.5,29.3)$ & $26.9(24.4,30.1)$ & NS (0.54) \\
\hline Gender - Male ${ }^{\dagger}$ & $9(47)$ & $15(79)$ & NS (0.09) \\
\hline Smoker ${ }^{\dagger}$ & $10(53)$ & $7(37)$ & NS (0.33) \\
\hline Hypertension $^{\dagger}$ & $11(58)$ & $14(74)$ & NS (0.31) \\
\hline $\begin{array}{l}\text { Family history of heart } \\
\text { disease }^{\dagger}\end{array}$ & $11(58)$ & $7(39)^{1}$ & NS (0.25) \\
\hline Hypercholesterolemia $^{\dagger}$ & $15(79)$ & $14(74)$ & NS (1.00) \\
\hline $\begin{array}{l}\text { Peripheral vascular } \\
\text { disease }^{\dagger}\end{array}$ & $1(5)$ & $3(16)$ & NS $(0.60)$ \\
\hline Transient ischemic $^{\dagger}$ & 0 & 0 & NS \\
\hline Stroke $^{\dagger}$ & 0 & $1(5)$ & NS (1.00) \\
\hline Respiratory disease $^{\dagger}$ & $3(16)$ & $2(11)$ & NS (1.00) \\
\hline Renal disease $^{\dagger}$ & 0 & 0 & NS \\
\hline
\end{tabular}


Table 4.2 Cardiovascular disease characteristics

\begin{tabular}{|c|c|c|c|}
\hline & $\begin{array}{c}\text { Fast } \\
(n=13)\end{array}$ & $\begin{array}{c}\mathrm{CHO} \\
(n=13)\end{array}$ & p-value \\
\hline CCS Angina Class & & & NS (0.69) \\
\hline Class I-II & $7(54)$ & $9(69)$ & \\
\hline Class III-IV & $6(46)$ & $4(31)$ & \\
\hline NYHA Class & & & NS (1.00) \\
\hline Class I-II & $8(80)$ & $9(82)$ & \\
\hline Class III-IV & & & \\
\hline Left ventricular & & & NS (0.59) \\
\hline Grade I-II & $10(77)$ & $12(92)$ & \\
\hline Grade III-IV & $3(23)$ & $1(8)$ & \\
\hline $\begin{array}{l}\text { Previous myocardial } \\
\text { infarction }\end{array}$ & $6(46)$ & 0 & 0.02 \\
\hline \multicolumn{4}{|c|}{$\begin{array}{l}\text { n (\%); Fisher's Exact Test } \\
\text { CCS, Canadian Cardiovascular Society } \\
\text { NS, non-significant } \\
\text { NYHA, New York Heart Association } \\
1 n=10 ; \text { missing data } \\
{ }^{2} n=11 ; \text { missing data }\end{array}$} \\
\hline
\end{tabular}


Table 4.3 Spine characteristics

\begin{tabular}{lccc}
\hline & $\begin{array}{c}\text { Fast } \\
(\mathbf{n}=6)\end{array}$ & $\begin{array}{c}\text { CHO } \\
(\mathbf{n}=6)\end{array}$ & p-value \\
\hline Central stenosis & $5(83)$ & $6(100)$ & NS (1.00) \\
Foraminal stenosis & $4(67)$ & $5(83)$ & NS (1.00) \\
Deformity & $1(17)$ & $1(17)$ & NS (1.00) \\
Disc herniation & 0 & $1(17)$ & NS (1.00) \\
\hline $\begin{array}{l}\text { n (\%); Fisher's Exact Test } \\
\text { NS, non-significant }\end{array}$ & & & \\
\hline
\end{tabular}


Table 4.4 Measures of insulin sensitivity

\begin{tabular}{|c|c|c|c|}
\hline & Fast & $\mathrm{CHO}$ & p-value \\
\hline $\begin{array}{c}\text { KITT (\%/min) } \\
\text { Baseline }\end{array}$ & $1.53(0.96,1.84)^{1}$ & $1.09(0.91,1.39)$ & NS (0.06) \\
\hline Post-op & $0.38(0.22,0.43)^{1 a}$ & $0.34(0.23,0.56)^{2 a}$ & NS (0.66) \\
\hline Change & $-1.12(-1.82,-0.66)^{1}$ & $-0.71(-0.95,-0.50)^{2}$ & NS (0.07) \\
\hline $\begin{array}{l}\text { Relative IS (\%) } \\
\text { (Post/Pre x 100) }\end{array}$ & $25.8(12.7,37.3)^{1}$ & $29.4(18.7,48.0)^{2}$ & NS (0.30) \\
\hline $\begin{array}{l}\text { HOMA-IR (units) } \\
\text { Baseline }\end{array}$ & $1.7(1.2,2.0)$ & $2.2(1.5,2.9)$ & NS $(0.10)$ \\
\hline Post-op & $1.8(1.2,3.1)$ & $2.5(1.1,5.9)^{3}$ & NS (0.37) \\
\hline Change & $-0.1(-0.4,1.2)$ & $0.3(-0.9,3.6)^{3}$ & NS $(0.44)$ \\
\hline $\begin{array}{c}\text { HOMA- } \beta(\%) \\
\text { Baseline }\end{array}$ & $97.2(65.5,135.1)$ & $111.8(80.2,151.9)$ & NS $(0.64)$ \\
\hline Post-op & $35.2(25.3,70.3)^{b}$ & $72.7(38.1,109.2)^{3}$ & 0.02 \\
\hline Change & $-59.9(-98.8,-31.0)$ & $-28.5(-67.6,4.9)^{3}$ & NS (0.09) \\
\hline $\begin{array}{l}\text { Glucose (mmol/L) } \\
\text { Baseline }\end{array}$ & $5.0(4.7,5.2)$ & $5.2(4.9,5.5)$ & NS (0.14) \\
\hline Post-op & $6.6(6.0,8.1)^{a}$ & $6.1(5.4,6.9)^{a}$ & NS (0.08) \\
\hline Change & $1.9(0.7,2.5)$ & $0.8(-0.1,1.9)$ & 0.03 \\
\hline $\begin{array}{l}\text { Insulin (pmol/L) } \\
\text { Baseline }\end{array}$ & $47.0(39.0,61.0)$ & $71.0(44.0,85.0)$ & NS (0.25) \\
\hline Post-op & $44.0(28.0,66.0)$ & $61.5(30.0,133.0)^{3}$ & NS (0.19) \\
\hline Change & $-10.0(-19.0,10.0)$ & $4.5(-25.3,53.0)^{3}$ & NS (0.27) \\
\hline $\begin{array}{l}\text { median }\left(25^{\text {th }}, 75^{\text {th }} \text { perc }\right. \\
\text { KITT, rate of disappea } \\
\text { HOMA- } \beta \text {, Homeostasis } \\
\text { HOMA-IR, Homeostas } \\
\text { NS, non-significant } \\
\text { Wilcoxon Signed Rank } \\
\text { a significantly di } \\
\text { b significantly d } \\
{ }^{1} n=18 \text {; SITT not compl } \\
{ }^{2} n=17 \text {; SITT not compl } \\
{ }^{3} n=18 \text {; insulin outlier e> }\end{array}$ & $\begin{array}{l}\text { Mann-Whitney } U \text { Test } \\
\text { blood glucose } \\
\text { assessment for } \beta \text {-cell fu } \\
\text { assessment for insulin } \\
\text { om baseline, } p<0.001 \\
\text { rom baseline, } p=0.003 \\
\text { from analysis }\end{array}$ & $\begin{array}{l}\mathrm{n} \\
\text { tance }\end{array}$ & \\
\hline
\end{tabular}


patients were insulin resistant in the FAST group (Table 4.4). This difference was approaching significance $(\mathrm{p}=0.06)$. Immediately following surgery, both groups experienced a significant decrease in insulin sensitivity compared to baseline measures $(p<0.001)$ but no significant differences were found between groups (Table 4.4). Less insulin resistance developed in the $\mathrm{CHO}$ group compared to the FAST group following surgery $\left(\mathrm{K}_{\mathrm{ITT}}:-0.71\right.$ $(-0.95,-0.50)$ vs.-1.12 $(-1.82,-0.66))$ and this difference was approaching significance $(\mathrm{p}=0.07)$.

HOMA-IR scores were not different between groups at baseline, postoperatively or when change was calculated (Table 4.4). HOMA- $\beta$ revealed no differences at baseline between the two groups (Table 4.4). Following surgery, $\beta$-cell function was significantly decreased in the FAST group compared to baseline $(\mathrm{p}=0.003)$ whereas no difference was found in the $\mathrm{CHO}$ group ( $\mathrm{p}=0.06)$. Postoperative $\beta$-cell function was also found to be significantly better in the $\mathrm{CHO}$ group compared to the FAST group (percent: 72.7 $(38.1,109.2)$ vs. $35.2(25.3,70.3), \mathrm{p}=0.02)$.

An examination of the relationship between markers of insulin sensitivity indicated a significant negative correlation between baseline $\mathrm{K}_{\mathrm{ITT}}$ and HOMA-IR $\left(\mathrm{r}_{\mathrm{s}}=-0.46\right.$, $\left.\mathrm{p}=0.004\right)$ and a trend for post-op $\mathrm{K}_{\text {ITT }}$ and HOMA-IR to be inversely correlated $\left(\mathrm{r}_{\mathrm{s}}=-0.32, \mathrm{p}=0.07\right)$. No relationship was found between baseline $\mathrm{K}_{\text {ITT }}$ and age $\left(\mathrm{r}_{\mathrm{s}}=-0.11\right.$, $\left.\mathrm{p}=0.50\right)$ or BMI $\left(\mathrm{r}_{\mathrm{s}}=-0.21\right.$, $\mathrm{p}=0.21)$. Bivariate analysis revealed no relationship between pre- and post- $\mathrm{K}_{\mathrm{ITT}}\left(\mathrm{r}_{\mathrm{s}}=-0.12\right.$, $\mathrm{p}=0.50)$. 


\subsubsection{Blood markers}

FFA levels were significantly higher in the FAST group at baseline compared to the CHO group (mEq/L: $0.56(0.34,0.68)$ vs. $0.32(0.19,0.56), \mathrm{p}=0.03)$ (Figure 4.2).

Postoperatively, FFA levels were preserved in both groups and no difference was observed between groups after calculating the change from baseline to 72 hours post-op. In addition, no time or treatment effect was found. LogIL-6 and $\log$ CRP levels were similar between groups at baseline (Figures 4.3 and 4.4, respectively). Following surgery, $\log I L-6$ and $\log \mathrm{CRP}$ levels rose but no differences were found between groups at 72 hours post-op. Mixed model analysis indicated a significant effect of time $(\mathrm{p}<0.001)$ but not treatment on the two inflammatory markers.

Adiponectin levels were similar between the FAST and $\mathrm{CHO}$ group at baseline $(\mu \mathrm{g} / \mathrm{mL}: 9.01(5.75,17.16)$ vs. $9.95(6.33,13.49), \mathrm{p}=0.85)$. Bivariate analysis revealed no relationship between adiponectin and baseline $\mathrm{K}_{\mathrm{ITT}}\left(\mathrm{r}_{\mathrm{s}}=-0.06, \mathrm{p}=0.76\right)$ or HOMA-IR $\left(\mathrm{r}_{\mathrm{s}}=-\right.$ $0.08, \mathrm{p}=0.72)$.

\subsubsection{Subjective well-being}

After adjusting for baseline scores, patients in the FAST group were found to be significantly more thirsty (score: $50.0(24.0,69.8)$ vs. $10.0(7.0,34.0), p=0.01)$, hungry (score: $48.5(28.5,63.5)$ vs. $25.0(6.5,42.5), \mathrm{p}=0.04)$ and anxious (score: $61.5(38.2,71.5)$ vs. 34.0 $(17.5,48.0), \mathrm{p}=0.01)$ immediately prior to surgery compared to the $\mathrm{CHO}$ group (Figure 4.5). No differences were found between groups for any other measures of subjective well-being (Table 4.5). Tables of baseline VAS scores, unadjusted preoperative scores and change in 


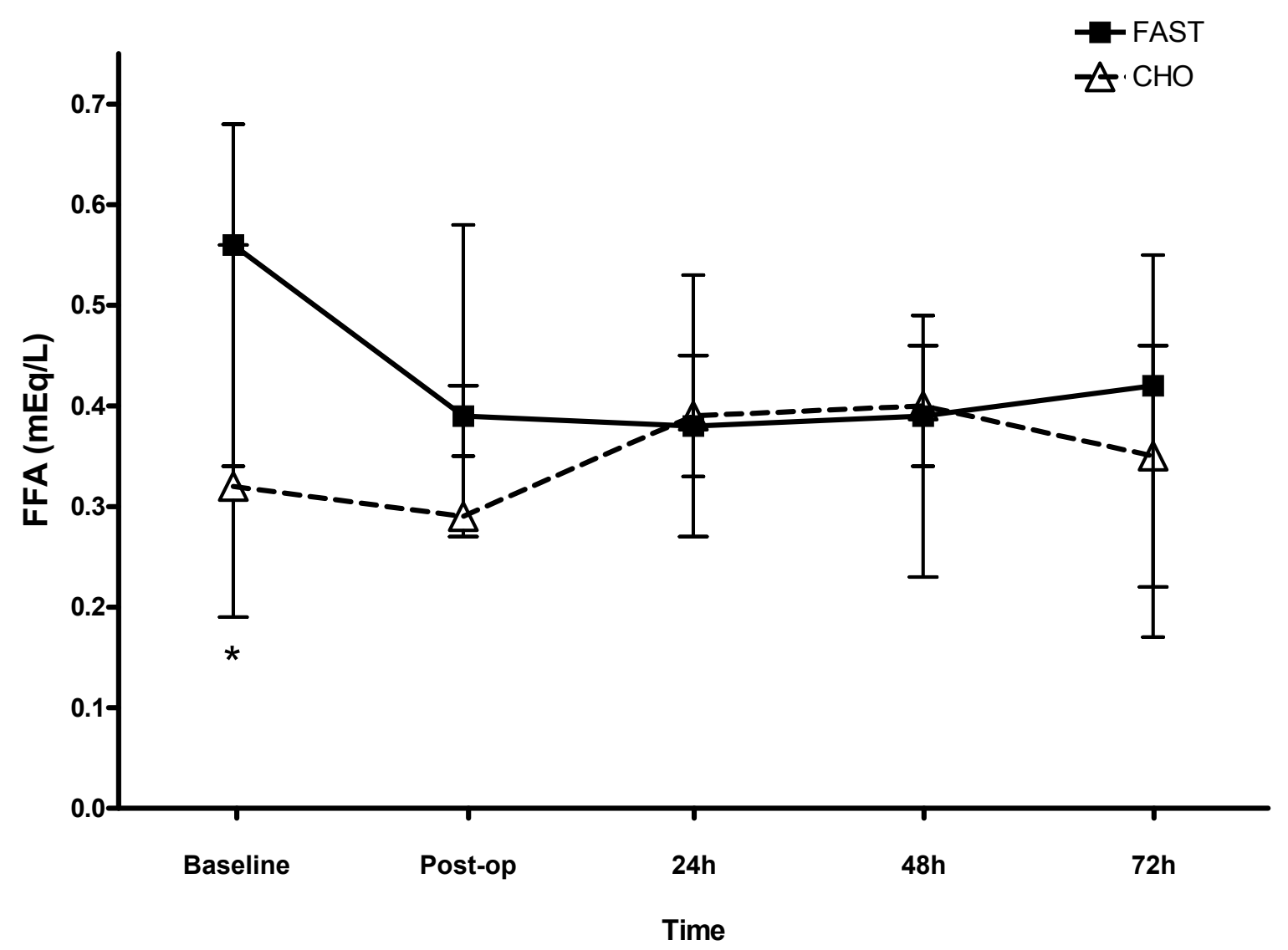

Figure 4.2 FFA levels in FAST and CHO group during study period

Figure shows median $\left(25^{\text {th }}, 75^{\text {th }}\right.$ percentile $)$ for each time point. $* p=0.03$ 

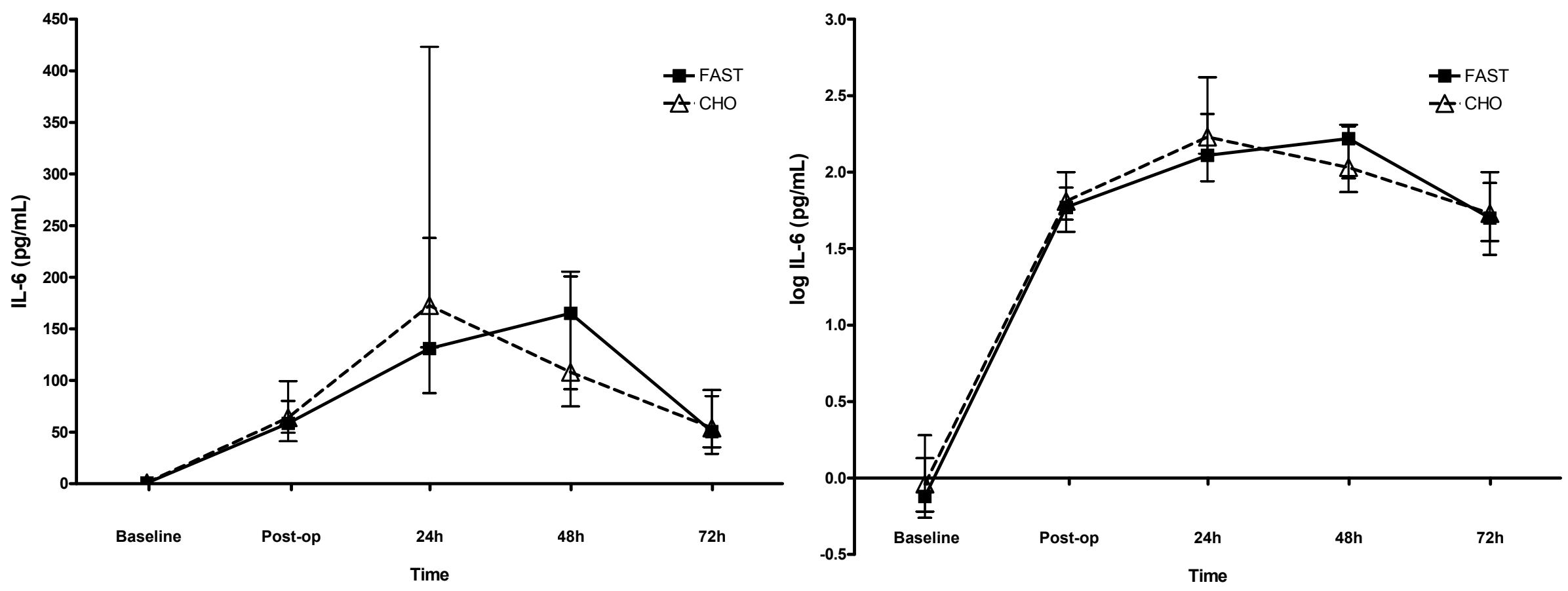

Figure 4.3 IL-6 and logIL-6 levels in FAST and CHO group during study period

Figures show median $\left(25^{\text {th }}, 75^{\text {th }}\right.$ percentile $)$ for each time point. 


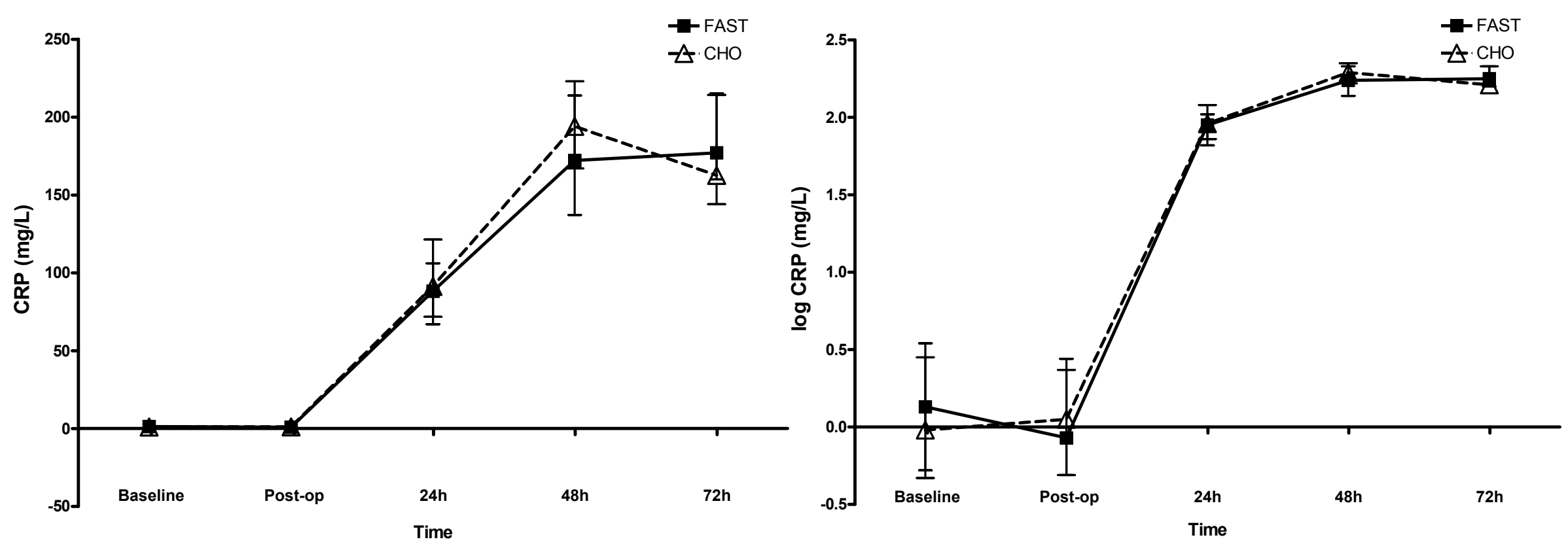

Figure 4.4 CRP and logCRP levels in FAST and CHO group during study period Figures show median $\left(25^{\text {th }}, 75^{\text {th }}\right.$ percentile $)$ for each time point. 


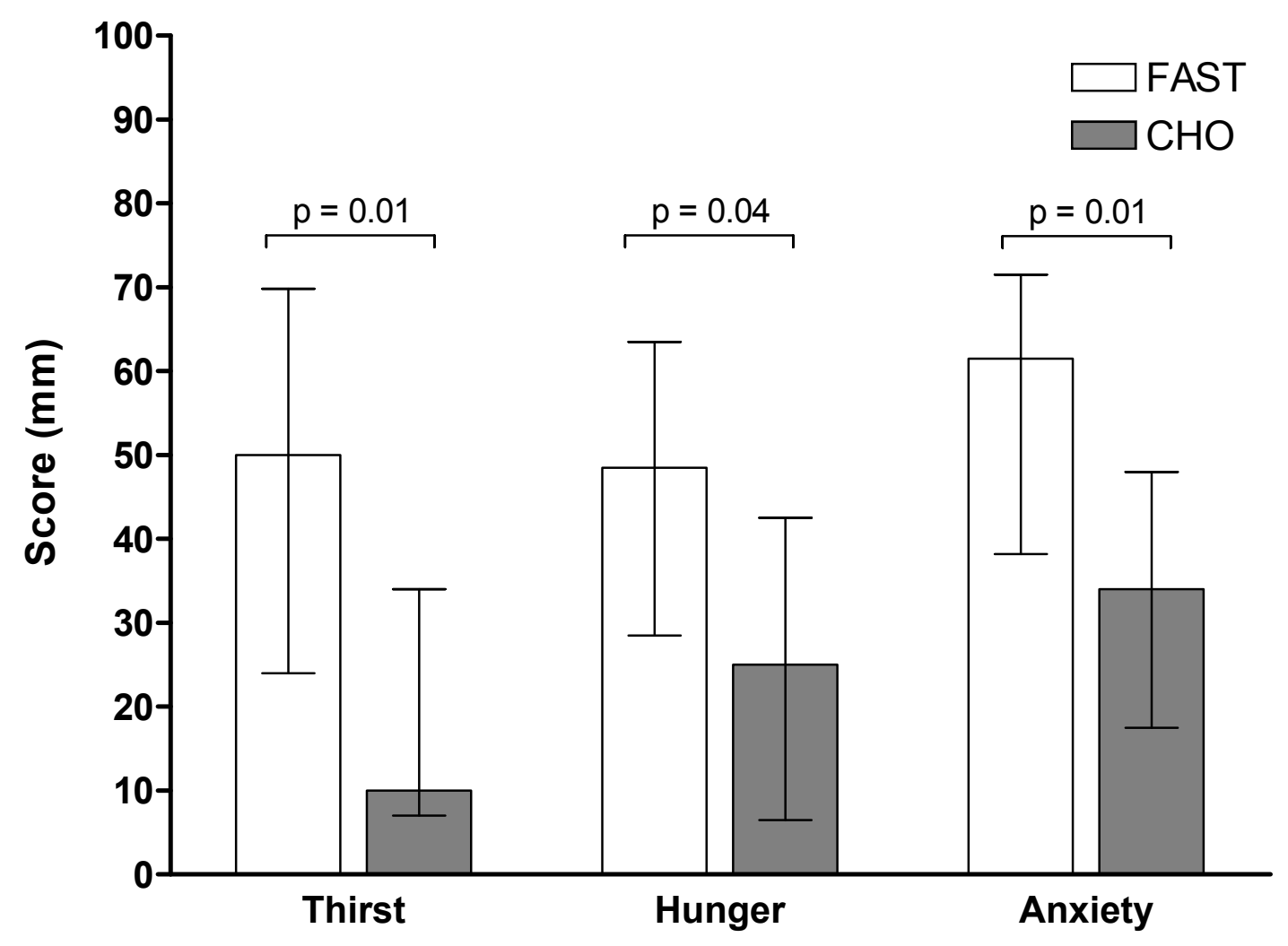

Figure 4.5 VAS scores for thirst, hunger and anxiety Figure shows median $\left(25^{\text {th }}, 75^{\text {th }}\right.$ percentile $)$ for each variable. 
Table 4.5 Preoperative VAS scores, adjusted for baseline scores

\begin{tabular}{lccc}
\hline & $\begin{array}{c}\text { Fast } \\
(\mathbf{n = 1 2})^{\#}\end{array}$ & $\begin{array}{c}\text { CHO } \\
(\mathbf{n}=13)^{\#}\end{array}$ & p-value \\
\hline Depression & $26.0(6.8,42.0)$ & $11.0(4.0,43.0)$ & NS $(0.87)$ \\
Malaise & $24.5(6.3,49.8)$ & $26.0(8.0,47.5)$ & NS $(0.60)$ \\
$\begin{array}{l}\text { Inability to } \\
\text { concentrate }\end{array}$ & $36.5(6.5,61.0)$ & $25.0(7.5,44.0)$ & NS $(0.23)$ \\
Nausea & $5.5(2.3,12.0)$ & $12.0(4.0,36.5)$ & NS $(0.28)$ \\
Pain & $50.0(7.0,74.0)$ & $17.0(3.0,47.5)$ & NS $(0.32)$ \\
Tiredness & $46.5(4.5,71.5)$ & $38.0(19.5,54.0)$ & NS $(0.64)$ \\
Unfitness & $52.5(22.5,77.3)$ & $57.0(38.0,65.5)$ & NS $(0.71)$ \\
Weakness & $30.5(10.8,54.5)$ & $34.0(9.5,55.0)$ & NS $(0.79)$ \\
\hline $\begin{array}{l}\text { median (25 } \\
\text { NS, non-significant }\end{array}$ & & \\
total n=25; pilot study patients did not complete questionnaire & & \\
& & & \\
\end{tabular}


scores from baseline to the preoperative period are found in the Appendix (Tables 4, 5, and 6, respectively).

\subsubsection{Clinical outcomes}

Intra and postoperative results are presented in Table 4.6 and 4.7. Perioperative outcomes including OR time, infectious complications, time on mechanical ventilation and transfusions were similar between groups. Patients in the $\mathrm{CHO}$ group required significantly fewer units of red blood cells in comparison with those who fasted $(p=0.05)$. When LOS in PACU, MSICU, and CVICU were combined, the CHO group was found to have a significantly shorter LOS in these units $(\mathrm{p}=0.02)$, which may have translated to a signficantly shorter LOS in the hospital compared to fasted patients $(\mathrm{p}=0.008)$. A significant inverse relationship was found between the LOS in a unit before entering the ward and post-op HOMA- $\beta$ scores $\left(r_{s}=-0.40, p=0.02\right)$. In regards to the total number of complications, patients in the FAST group tended to experience more complications compared to the CHO group (61 vs. 44; average number of complications: 3.2 vs. $2.3, \mathrm{p}=0.11$ ). The total number of complications was significantly related to post-op glucose levels $\left(r_{s}=0.41, p=0.01\right)$ and also related to the rise in glucose after surgery, although this did not achieve significance $\left(\mathrm{r}_{\mathrm{s}}=0.27\right.$, $\mathrm{p}=0.10$ ). A relationship between hospital stay and post-op glucose levels was not found $\left(r_{s}=0.25, p=0.14\right)$. However, the association between hospital stay and change in glucose approached significance $\left(\mathrm{r}_{\mathrm{s}}=0.30, \mathrm{p}=0.07\right)$. Bivariate analysis also revealed a significant correlation between hospital stay and preoperative anxiety $\left(r_{s}=0.66, p<0.001\right)$. 
Table 4.6 Intra and postoperative clinical outcomes

\begin{tabular}{|c|c|c|c|}
\hline & Fast & $\mathrm{CHO}$ & p-value \\
\hline Vessels bypassed ${ }^{\star \#}$ & $3.0(2.5,4.0)$ & $3.0(2.0,3.5)$ & NS (0.55) \\
\hline Cross clamp time $(\min )^{\star \#}$ & $44.0(30.8,48.5)^{1}$ & $39.0(31.0,47.5)$ & NS (0.89) \\
\hline Pump time $(\min )^{\star \#}$ & $61.0(51.8,72.5)^{1}$ & $59.0(50.5,81.5)$ & NS (0.85) \\
\hline Levels decompression ${ }^{\star \# \#}$ & $2.0(1.5,3.0)$ & $2.0(2.0,3.0)$ & NS (0.82) \\
\hline Levels fusion*\#\# & $2.0(2.0,3.0)$ & $2.0(2.0,3.0)$ & NS (0.94) \\
\hline OR time $(\min )^{*}$ & $240.0(210.0,265.0)$ & $230.0(205.0,305.0)$ & NS (0.84) \\
\hline Intra-op bleeding ${ }^{\dagger}$ & $3(16)$ & 0 & NS $(0.23)$ \\
\hline Intra-op hypotension $^{\dagger}$ & $8(42)$ & $4(21)$ & NS (0.30) \\
\hline Wound infection $^{\dagger}$ & 0 & $1(5)$ & NS (1.00) \\
\hline Other infection $^{\dagger}$ & $1(5)$ & 0 & NS (1.00) \\
\hline Pneumonia $^{\dagger}$ & 0 & $1(5)$ & NS (1.00) \\
\hline Urinary tract infection ${ }^{\dagger}$ & $1(5)$ & 0 & NS (1.00) \\
\hline Myocardial infarction $^{\dagger}$ & $1(5)$ & 0 & NS (1.00) \\
\hline Post-op inotropes ${ }^{\dagger}$ & $3(17)^{2}$ & $3(16)$ & NS (1.00) \\
\hline Post-op IABP ${ }^{\dagger}$ & $1(6)^{2}$ & 0 & NS (1.00) \\
\hline Atrial fibrillation $^{\dagger \#}$ & $4(31)$ & $3(23)$ & NS (1.00) \\
\hline Pleural effusion $^{\dagger \#}$ & $4(31)$ & $2(15)$ & NS (0.65) \\
\hline PE/DVT ${ }^{\dagger \#}$ & $1(17)$ & 0 & NS (1.00) \\
\hline Complication (Yes) $^{\dagger}$ & $18(95)$ & $18(95)$ & NS (1.00) \\
\hline Total complications $^{\dagger \dagger}$ & 61 & 44 & NS $(0.11)$ \\
\hline \multicolumn{4}{|l|}{$\begin{array}{l}{ }^{*} \text { median }\left(25^{\text {th }}, 75^{\text {th }} \text { percentile); Mar }\right. \\
{ }^{\dagger} n(\%) ; x^{2} \text { or Fisher's Exact Test } \\
{ }^{\dagger}+n \text {; Independent Samples T-Test } \\
\text { NS, non-significant } \\
{ }^{1} n=12 ; \text { missing data } \\
{ }^{2} n=18 ; \text { missing data } \\
{ }^{\#} \text { total } n=26: \text { FAST } n=13, \text { CHO } n=1 \\
{ }^{\#} \text { total } n=12: \text { FAST } n=6, C H O ~ n=6 ;\end{array}$} \\
\hline
\end{tabular}


Table 4.7 Other intra and postoperative clinical outcomes

\begin{tabular}{|c|c|c|c|}
\hline & Fast & $\mathrm{CHO}$ & p-value \\
\hline Transfusion required $^{\dagger}$ & $12(63)$ & $8(42)$ & NS (0.33) \\
\hline Platelets (Units)* & $0(0,0)$ & $0(0,0)$ & NS $(0.56)$ \\
\hline Whole blood (Units)* & $0(0,0)$ & $0(0,0)$ & NS (0.91) \\
\hline Plasma (Units)* & $0(0,2)$ & $0(0,0)$ & NS $(0.28)$ \\
\hline Red Blood Cells (Units)* & $1(0,4)$ & $0(0,0)$ & 0.05 \\
\hline $\begin{array}{l}\text { Chest tube losses }-6 \\
\text { hour }(\mathrm{mL})^{\star \#}\end{array}$ & $345.0(220.0,652.5)^{1}$ & $340.0(150.0,437.5)$ & NS $(0.35)$ \\
\hline $\begin{array}{l}\text { Chest tube losses - total } \\
(\mathrm{mL})^{\star \#}\end{array}$ & $890.0(640.0,1090.0)^{2}$ & $830.0(405.0,1085.0)$ & NS (0.39) \\
\hline $\begin{array}{l}\text { Time on ventilation } \\
\text { (hours) }\end{array}$ & $7.5(4.7,15.6)$ & $6.6(4.5,12.8)$ & NS $(0.62)$ \\
\hline LOS PACU (hours) ${ }^{\star \# \#}$ & $3.9(1.7,7.4)$ & $3.4(2.3,4.0)$ & NS (0.59) \\
\hline LOS MSICU (hours) ${ }^{\star \# \#}$ & $0.0(0.0,24.4)$ & $0.0(0.0,4.5)$ & NS $(0.70)$ \\
\hline LOS CVICU (hours) ${ }^{\star \#}$ & $23.1(21.8,25.6)^{1}$ & $21.3(20.4,22.9)$ & NS (0.06) \\
\hline LOS before ward (hours)* & $23.1(20.1,30.3)^{3}$ & $20.7(4.6,22.2)$ & 0.02 \\
\hline $\begin{array}{l}\text { Length of hospital stay } \\
\text { (days)* }^{*}\end{array}$ & $5.0(5.0,8.0)^{3}$ & $4.0(4.0,5.0)$ & 0.008 \\
\hline \multicolumn{4}{|c|}{ 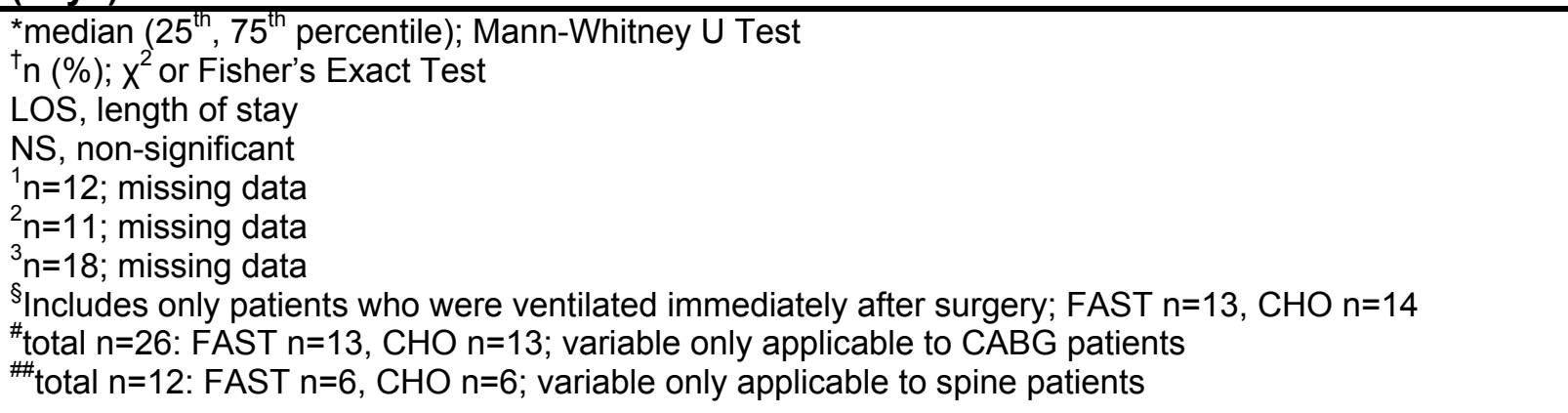 } \\
\hline
\end{tabular}


No differences were noted between groups in hyperglycemia outcomes which included the number of patients who required insulin, the number of hyperglycemic events in the OR and postoperatively as well as the peak glucose level on the day of surgery (Table 4.8).

\subsubsection{Comparison of study groups}

In terms of the comparison of sub-groups within our study population, results were consistent with the findings of the main analysis (Appendix - Tables 7 to 42). Although not all results of the sub-analysis were significant, the directionality of our findings was comparable to that of the main analysis. Results indicated that pre- and postoperative insulin sensitivity markers (including the $\mathrm{K}_{\mathrm{ITT}}$, HOMA-IR, HOMA- $\beta$, glucose and insulin) were similar between spine and CABG patients as well as CABG patients recently recruited vs.

pilot study participants (Appendix - Tables 20 and 26, respectively). Clinical outcomes including length of hospital stay were also similar in spine vs. CABG patients in addition to CABG: new vs. pilot study patients (Appendix - Tables 23 and 29, respectively).

\subsection{Discussion}

This study compared the effects of oral preoperative carbohydrate loading and fasting on postoperative insulin sensitivity. Patients who received carbohydrate supplementation were found to have a smaller decrease in insulin sensitivity postoperatively in comparison with patients who fasted. Although this difference did not achieve significance, these results are encouraging and support the use of preoperative carbohydrate loading in patients undergoing major surgery. We also observed remarkable results in our secondary outcomes. 


\begin{tabular}{|c|c|c|c|}
\hline & Fast & $\mathrm{CHO}$ & p-value \\
\hline Intra-op hyperglycemia $^{\dagger}$ & $9(47)$ & $10(53)$ & $\mathrm{NS}(0.75)$ \\
\hline $\begin{array}{l}\text { Insulin within } 24 \text { hours } \\
\text { (Units)* }^{*}\end{array}$ & $0(0,0)^{1}$ & $0(0,0)$ & NS $(0.78)$ \\
\hline Insulin received (yes) ${ }^{\dagger}$ & $5(26)$ & $2(11)$ & NS $(0.41)$ \\
\hline $\begin{array}{l}\text { Average insulin } \\
\text { administered (Units)* }\end{array}$ & $5.0(3.3,6.5)^{2}$ & $14.5(10.0,--)^{3}$ & NS $(0.38)$ \\
\hline $\begin{array}{l}\text { Intra-op hyperglycemic } \\
\text { events* }\end{array}$ & $0.0(0.0,3.0)$ & $1.0(0.0,2.0)$ & NS $(0.71)$ \\
\hline $\begin{array}{l}\text { Postoperative } \\
\text { hyperglycemic events* }\end{array}$ & $2.0(0.0,5.0)$ & $1.0(0.0,2.0)$ & NS $(0.19)$ \\
\hline $\begin{array}{l}\text { OR and postoperative } \\
\text { hyperglycemic events* }\end{array}$ & $5.0(1.0,7.0)$ & $2.0(0.0,4.0)$ & NS $(0.13)$ \\
\hline $\begin{array}{l}\text { Peak glucose level on } \\
\text { day of surgery } \\
\text { (mmol/L)* }\end{array}$ & $8.8(7.5,10.9)$ & $8.4(8.0,9.9)$ & NS (0.47) \\
\hline \multicolumn{4}{|c|}{$\begin{array}{l}\text { NOTES: } \\
\text { 'Hyperglycemia' defined as }>8.0 \mathrm{mmol} / \mathrm{L} \\
\text { 'Insulin received' refers to \# of patients who received insulin during hospital stay } \\
\text { 'Average insulin administered' refers to the average amount of insulin administered to patients who } \\
\text { received insulin }\end{array}$} \\
\hline \multicolumn{4}{|c|}{$\begin{array}{l}{ }^{*} \text { median }\left(25^{\text {th }}, 75^{\text {th }} \text { percentile); Mann-Whitney U Test }\right. \\
{ }^{n} n(\%) ; x^{2} \text { or Fisher's Exact Test } \\
\text { NS, non-significant } \\
{ }^{1} n=18 ; \text { missing data }\end{array}$} \\
\hline
\end{tabular}


Patients in the $\mathrm{CHO}$ group experienced a blunted rise in postoperative blood glucose levels and higher $\beta$-cell function. Preoperatively, the treated group was less thirsty, hungry and anxious compared the fasted group. Even more noteworthy is the improvement in clinical outcomes which included a shorter length of stay in the ICU and recovery room and a one day reduction in length of hospital stay.

Insulin sensitivity was significantly decreased in both groups immediately following surgery. The relative reduction in insulin sensitivity was found to be $74 \%$ in the FAST group and $71 \%$ in the $\mathrm{CHO}$ group. This was a greater reduction than that reported after open cholecystectomy (58\%) (5) and hernia repair (32\%) (28). This was not surprising as the degree of postoperative IR which develops is proportional to the magnitude of the surgical trauma and is related to the degree of perioperative blood loss (17); both CABG and decompression and fusion surgery are highly invasive procedures of long duration, resulting in significant blood loss.

Preoperative carbohydrate loading with an oral beverage did not result in a significant improvement in postoperative insulin sensitivity in this surgical population. These results are in disparity with previous studies examining elective gastrointestinal and hip replacement surgical patients $(14,16)$. Recent studies investigating preoperative oral carbohydrate loading in CABG patients have shown no improvement in insulin sensitivity postoperatively $(73,74)$. However, these studies were limited as they infered insulin sensitivity only from the insulin requirements needed to maintain blood glucose at $\leq 10$ (72) or between 4 to $7 \mathrm{mmol} / \mathrm{L}$ (73). This approach is not a generally accepted measure of insulin sensitivity and has not been related to the gold standard hyperinsulinemic euglycemic clamp technique. We chose to use the SITT as well as HOMA scores as these two standardized 
methods have been studied individually and correlate well with the euglycemic clamp (32, 37).

There was a trend for patients in the $\mathrm{CHO}$ group to experience a smaller decline in insulin sensitivity. Since the SITT and HOMA scores measure whole body insulin sensitivity, we were unable to determine whether the increase in insulin sensitivity was at the hepatic level or in peripheral tissues. Other studies have found that preoperative carbohydrate supplementation helped to improve peripheral insulin sensitivity in the immediate postoperative period with a shift to improved hepatic insulin sensitivity by postoperative day $3(16,69)$.

A larger sample size may have been needed to identify differences in the $\mathrm{K}_{\text {ITT. }}$. As well, more than half of our patients were insulin resistant at baseline. Although previous work has suggested that those with insulin resistance do not respond differently to the supplement (76), this may have been a factor preventing improvement in postoperative insulin sensitivity observed in our patients. In addition, when patients were stratified and analyzed based on surgery type, we did find that there were different responses in CABG and spine patients. No differences were observed between CABG patients in the FAST or CHO group in insulin sensitivity markers (Appendix - Table 8). However, spine patients who received carbohydrate supplementation were found to have a significantly smaller decrease in postoperative insulin sensitivity in comparison with spine patients in the FAST group $(p=0.02)$ (Appendix - Table 14). The administration of glucose-containing cardioplegia to CABG patients in the OR may have impacted our ability to dectect differences in insulin resistance following surgery in these patients compared to spine patients. 
There were some important benefits of carbohydrate supplementation found in this study. Both groups experienced a rise in circulating blood glucose concentrations postoperatively; this rise, however, was significantly higher in those who fasted prior to surgery. In addition, when changes in insulin levels were calculated, the FAST group experienced a drop in insulin levels whereas the CHO group demonstrated a rise immediately after surgery. This suggests impaired $\beta$-cell function in the FAST group as insulin secretion was inadequate to compensate for higher circulating blood glucose levels. Postoperative HOMA- $\beta$ score confirms this observation in the FAST group as $\beta$-cell function was less than half compared to that of the $\mathrm{CHO}$ group. Improved $\beta$-cell function may be an important factor in postoperative recovery as a significant correlation was found between post-op HOMA- $\beta$ scores and LOS in a recovery unit. Nevertheless, HOMA scores are based on fasting glucose and insulin levels (37) and thus, difficult to infer conclusions since the postoperative situation reflects hyperphysiological levels of each of these blood markers rather than basal.

VAS scores revealed that patients in the CHO group were significantly less thirsty, hungry and anxious immediately prior to surgery compared to those who fasted. These improved variables of discomfort are consistent with findings of another study (12). It has been speculated that through the action of insulin, serotonin levels may be increased in the brain to regulate mood (64). This can contribute to lower levels of anxiety prior to surgery, which could improve psychological well-being in the preoperative period as well as enhancing recovery postoperatively (77). Previous work found that participants who were more stressed had poor wound repair compared to matched healthy controls (78). In 
addition, those who were more anxious prior to surgery experienced a longer postoperative recovery period (79).

A substantial rise in IL-6 and CRP was observed in both groups, consistent with the inflammatory reaction seen after surgical stress $(46,80)$. Levels were not normalized by 72 hours postoperatively and no effect of treatment was found on IL-6 or CRP. Inflammation has been shown to be reduced after treatment with intensive insulin therapy to normalize postoperative blood glucose levels (40). However, preoperative carbohydrate supplementation may not exert a strong enough effect physiologically to blunt the postoperative inflammatory response.

No time or treatment effect was found for postoperative levels of FFA. Previous studies investigating preoperative carbohydrate loading showed that levels of FFA were similar between treated and control groups following surgery, as seen in our findings $(16,81$, 82). The reasons behind this are unclear. High FFA levels are typically an indication of fat rather than glucose oxidation and have been found to induce insulin resistance in those with obesity and type II diabetes (83). As suggested by Thorell et al. (81), levels of FFA may contribute to insulin resistance in chronic disease states but may not be related to the insulin resistance observed after surgical stress. This may explain our results as insulin sensitivity decreased in both groups following surgery, but FFA levels were not increased.

Correlation with the $\mathrm{K}_{\mathrm{ITT}}$ and HOMA revealed no significant relationship between these insulin sensitivity markers and adiponectin, contrary to other findings $(84,85)$. As only a subset of our patients were analyzed for this marker $(n=25)$, perhaps the small sample size was not large enough to detect an association or there was not enough heterogeneity in the data to determine a relationship. 
The $\mathrm{CHO}$ group experienced a significantly shorter stay in a unit before entering the ward and a shorter stay in the hospital, remarkable findings of clinical importance. A previous finding from a small meta-analysis showed that patients who received preoperative carbohydrate loading had a significantly shorter LOS in the hospital (equivalent to 1.2 days or $20 \%$ ) compared to those who fasted (13). In our study, patients who had a higher post-op rise in glucose (the FAST group) tended to be those who experienced a longer hospital stay. High blood glucose levels, or hyperglycemia, have been shown to be related to postoperative complications $(86,87)$. A significant relationship between post-op glucose levels and total number of complications was also found, with the FAST group experiencing more complications than the $\mathrm{CHO}$ group. We speculate that the smaller rise in blood glucose levels may have contributed to less total complications in the $\mathrm{CHO}$ group compared to the FAST group (44 vs. 61), leading to an overall shorter hospital stay.

We also found a significant relationship between preoperative anxiety scores and hospital stay. This may provide another reason for the shortened hospital stay since patients who received carbohydrate supplementation were less anxious prior to surgery. Previous studies suggest that preoperative anxiety is related to the degree of pain experienced postoperatively (88). Greater postoperative pain can result in decreased ambulation or mobility, increased analgesic requirements which may result in side effects such as nausea and vomiting, and ultimately a longer hospital stay (89).

This study is not without its limitations. Previous studies examining preoperative carbohydrate supplementation employed the gold standard hyerinsulinemic euglycemic clamp technique to measure insulin sensitivity. The SITT, though physiological and correlated with the clamp technique, may not have been sensitive enough to detect 
differences in insulin sensitivity. In addition, four of our patients received insulin in the OR to treat high glucose levels. This provision of insulin may have confounded the results of the postoperative insulin sensitivity tests. The diverse composition of our study population which included $\mathrm{CABG}$ patients, spine patients and pilot study patients may have been a limitation to this study. However, the additional analyses conducted on our data determined that results observed in the main analysis were not influenced by any particular group. Markers of insulin sensitivity and clinical outcomes were relatively similar between spine and CABG patients as well as between pilot study and recently recruited CABG patients. Thus, despite the heterogeneity of our study population, outcomes were quite consistent no matter what surgery patients had undergone or the time they were recruited.

In conclusion, significant postoperative insulin resistance developed in our patients undergoing major elective cardiac and spinal surgery. The consumption of a carbohydrate drink prior to surgery did not increase the risk of pulmonary aspiration or any adverse events. Although there were no significant changes observed in postoperative insulin sensitivity, those who received preoperative carbohydrate supplementation had a blunted rise in blood glucose postoperatively, an increased insulin response and preserved $\beta$-cell function. Moreover, improvements in patient discomfort including thirst, hunger and anxiety were observed in the preoperative period and a shorter length of hospital stay in the postoperative period. The benefits of a reduced length of stay include enhanced patient satisfaction as well as tremendous cost-savings in clinical institutions. Thus, further investigation into the physiological and clinical effects of preoperative carbohydrate loading is warranted. 


\subsection{CONCLUSION AND FUTURE DIRECTIONS}

\subsection{Conclusion}

The carbohydrate drink was well tolerated in the preoperative period and posed no additional risk of aspiration in any of our patients. Current clinical practice for surgical preparation is a 8-12 hour fast prior to the induction of anesthesia. This is in spite of liberalized anesthesia guidelines which allow clear fluids to be ingested up to two hours before elective surgical procedures $(57,59)$. In contrast to other clear fluids such as water, tea, and coffee, the advantages of administering a preoperative carbohydrate drink can be the replenishishment of glycogen stores and a shift from a catabolic to anabolic, fed state prior to surgery, which can positively influence postoperative outcomes.

We hypothesized that patients receiving preoperative carbohydrate supplementation would experience a $40 \%$ reduction in postoperative insulin resistance compared to patients who fasted prior to surgery. We conclude that a $4 \%$ reduction was found and while this reduction was not what we expected, this difference was approaching significance and is a promising finding of this study.

As a secondary hypothesis, we predicted that the $\mathrm{CHO}$ group would have reduced levels of FFA and inflammatory markers. Our study found that levels of FFA were not different between groups post-surgically and an effect of time was not seen. Both groups experienced an expected postoperative rise in inflammatory markers such as IL-6 and CRP, but no differences were found between groups.

We had a number of secondary outcomes which were significant and important indicators of the benefits of preoperative carbohydrate supplementation. We hypothesized that preoperative carbohydrate loading would reduce postoperative glucose levels and result 
in preserved $\beta$-cell function in comparison with patients who fasted. This was confirmed in our study as patients in the $\mathrm{CHO}$ group experienced a smaller rise in glucose levels as well as sustained $\beta$-cell function. We also predicted that our treatment group would experience less patient discomfort in the preoperative period. Indeed, our results indicated that patients who received preoperative carbohydrates were less thirsty, hungry and anxious prior to surgery. Lastly, we anticipated that the CHO group would have improved clinical outcomes compared to the FAST group. An exciting result of our study showed that supplemented patients stayed in the hospital one day less than patients who fasted. In addition, length of stay in a unit before entering the ward was also reduced. The cost of a one day stay in the ward and ICU at St. Michael's Hospital is about $\$ 400$ and $\$ 1500$, respectively (C. Sungur, personal communication). Thus, our findings could have tremendous implications in terms of costreduction strategies in hospitals (Table 5.1).

The positive influence of a preoperative fed state on patients' well-being and postoperative glucose-insulin response indicates the detrimental effects of fasting on patient outcomes. The accumulating research contradicting the preoperative practice of fasting suggests a need to adopt new guidelines which reflect the current literature. We hope the findings of this study will generate discussion among clinicians to improve the quality of preoperative care at clinical institutions.

\subsection{Future Directions}

The main objective of this study was to determine whether postoperative insulin sensitivity was modifiable through preoperative carbohydrate supplementation in patients undergoing large magnitude surgical procedures. Although we did not find any differences 
Table 5.1 Summary of main results

FAST $\quad \mathrm{CHO}$

Post-op insulin

sensitivity

$\Delta$ Glucose

Post-op HOMA- $\beta$
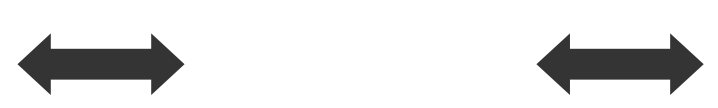

II

11

Pre-op thirst

Pre-op hunger

Pre-op anxiety
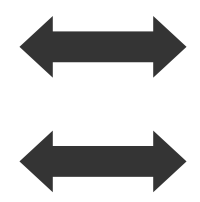

II

II

II

LOS in unit before Ward

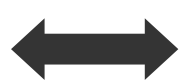

11

LOS in hospital

11 
between our treated and control group, patients in the $\mathrm{CHO}$ group experienced a smaller decrease in insulin sensitivity following surgery and this difference was approaching significance. Future studies should consider utilizing a larger sample size with equal distribution of $\mathrm{CABG}$ and spine patients. Moreover, employing the gold standard hyperinsulinemic euglycemic clamp technique may help clarify differences in insulin sensitivity. We also found that preoperative carbohydrate loading reduced length of hospital stay, even though no differences were seen between the treatment and fasted group in postoperative insulin sensitivity. Further investigation into the mechanism behind this is warranted. In addition, a large multi-centre trial examining preoperative oral carbohydrate supplementation using clinical outcomes such as length of stay as the primary markers should be considered.

Patients recruited for this study were not at high risk for pulmonary aspiration as we excluded patients who were diabetic, severely obese (BMI $>40)$ or those with gastrointestinal disorders. It would be interesting to study the effects of this drink in these high risk populations to determine appropriate fasting guidelines for these patients. One previous study administered the preoperative carbohydrate beverage to a group of type 2 diabetics and found that gastric emptying of the drink was the same - if not faster - than that of healthy controls, with a return to baseline blood glucose levels three hours after ingestion (90). It may be that gastric emptying of liquids remains relatively normal in these populations with alterations found only in the emptying of solids (91).

Lastly, we provided carbohydrate supplementation to patients the evening before and the day of surgery. Perhaps future studies could control the amount of carbohydrates consumed the day before surgery to ensure equal intake between groups (in addition to the 
carbohydrate supplement). Moreover, carbohydrate loading days before surgery may prove to be beneficial for patients in order to maximize muscle glyogen stores in preparation for surgery, similar to that which is done by athletes prior to competitions to increase endurance (92). 


\subsection{REFERENCES}

1. Ljungqvist O, Nygren J, Soop M, Thorell A. Metabolic perioperative management: novel concepts. Curr Opin Crit Care 2005;11(4):295-9.

2. Zerr KJ, Furnary AP, Grunkemeier GL, Bookin S, Kanhere V, Starr A. Glucose control lowers the risk of wound infection in diabetics after open heart operations. Ann Thorac Surg 1997;63(2):356-61.

3. Van den Berghe G, Wouters P, Weekers F, Verwaest C, Bruyninckx F, Schetz M, Vlasselaers D, Ferdinande P, Lauwers P, Bouillon R. Intensive insulin therapy in critically ill patients. N Engl J Med 2001;345(19):1359-67.

4. Uchida I, Asoh T, Shirasaka C, Tsuji H. Effect of epidural analgesia on postoperative insulin resistance as evaluated by insulin clamp technique. Br J Surg 1988;75(6):557-62.

5. Thorell A, Nygren J, Essén P, Gutniak M, Loftenius A, Andersson B, Ljungqvist O. The metabolic response to cholecystectomy: insulin resistance after open compared with laparoscopic operation. Eur J Surg 1996;162(3):187-91.

6. Tully V, Wolever TM, Darling P, Errett L, Keith ME. Pre-operative modification of dietary glycemic index improves pre but not post-operative indices of insulin resistance in patients undergoing coronary artery bypass graft surgery. J Am Coll Nutr 2008;27(1):168-76.

7. Nygren J, Thorell A, Efendic S, Nair KS, Ljungqvist O. Site of insulin resistance after surgery: the contribution of hypocaloric nutrition and bed rest. Clin Sci 1997;93(2):137-46.

8. Nygren J, Thorell A, Brismar K, Karpe F, Ljungqvist O. Short-term hypocaloric nutrition but not bed rest decrease insulin sensitivity and IGF-1 bioavailability in healthy subjects: the importance of glucagon. Nutrition 1997;13(11-12):945-51.

9. Nygren J, Thorell A, Soop M, Efendic S, Brismar K, Karpe F, Nair KS, Ljungqvist O. Perioperative insulin and glucose infusion maintains normal insulin sensitivity after surgery. Am J Physiol Endocrinol Metab 1998;275(1):E140-8.

10. Ljungqvist O, Thorell A, Gutniak M, Häggmark T, Efendic S. Glucose infusion instead of preoperative fasting reduces postoperative insulin resistance. J Am Coll Surg 1994;178(4):329-36.

11. Nygren J, Thorell A, Jacobsson H, Larsson S, Schnell PO, Hylén L, Ljungqvist O. Preoperative gastric emptying: effects of anxiety and oral carbohydrate administration. Ann Sur 1995;222(6):728-34.

12. Hausel J, Nygren J, Lagerkranser M, Hellström PM, Hammarqvist F, Almström C, Lindh A, Thorell A, Ljungqvist $\mathrm{O}$. A carbohydrate-rich drink reduces preoperative discomfort in elective surgery patients. Anesth Analg 2001;93(5):1344-50. 
13. Ljungqvist O, Nygren J, Thorell A, Brodin U, Efendic S. Preoperative nutrition - elective surgery in the fed or the overnight fasted state. Clin Nutr 2001;20(Suppl 1):167-71.

14. Nygren J, Soop M, Thorell A, Efendic S, Nair KS, Ljungqvist O. Preoperative oral carbohydrate administration reduces postoperative insulin resistance. Clin Nutr 1998;17(2):65-71.

15. Nygren J, Soop M, Thorell A, Sree Nair K, Ljungqvist O. Preoperative oral carbohydrates and postoperative insulin resistance. Clin Nutr 1999;18(2):117-20.

16. Soop M, Nygren J, Myrenfors P, Thorell A, Ljungqvist O. Preoperative oral carbohydrate treatment attenuates immediate postoperative insulin resistance. Am J Physiol Endocrinol Metab 2001;280(1):E576-83.

17. Thorell A, Nygren J, Ljungqvist O. Insulin resistance: a marker of surgical stress. Curr Opin Clin Nutr Metab Care 1999;2(1):69-78.

18. Bessey PQ, Lowe KA. Early hormonal changes affect the catabolic response to trauma. Ann Surg 1993;218(4):476-89.

19. Desborough JP. The stress response to trauma and surgery. Br J Anaesth 2000;85(1):10917.

20. Weissman C. The metabolic response to stress: an overview and update. Anesthesiology 1990;73(2):308-27.

21. Martinez-Riquelme AE, Allison SP. Insulin revisited. Clin Nutr 2003;22(1):7-15.

22. Doenst T, Wijeysundera D, Karkouti K, Zechner C, Maganti M, Rao V, Borger MA. Hyperglycemia during cardiopulmonary bypass is an independent risk factor for mortality in patients undergoing cardiac surgery. J Thorac Cardiovasc Surg 2005;130(4):1144.

23. Thorell A, Efendic S, Gutniak M, Häggmark T, Ljungqvist O. Insulin resistance after abdominal surgery. Br J Surg 1994;81(1):59-63.

24. Thorell A, Nygren J, Hirshman MF, Hayashi T, Nair KS, Horton ES, Goodyear LJ, Ljungqvist O. Surgery-induced insulin resistance in human patients: relation to glucose transport and utilization. Am J Physiol Endocrinol Metab 1999;276(4):E754-61.

25. Simpson F, Whitehead JP, James DE. GLUT4 - at the cross roads between membrane trafficking and signal transduction. Traffic 2001;2(1):2-11.

26. Van den Berghe G. How does blood glucose control with insulin save lives in intensive care? J Clin Invest 2004;114(9):1187-95. 
27. Montori VM, Bistrian BR, McMahon MM. Hyperglycemia in acutely ill patients. JAMA 2002;288(17):2167-9.

28. Thorell A, Efendic S, Gutniak M, Häggmark T, Ljungqvist O. Development of postoperative insulin resistance is associated with the magnitude of operation. Eur J Surg 1993;159(11-12):593-9.

29. DeFronzo RA, Ferrannini E. Insulin resistance. A multifaceted syndrome responsible for NIDDM, obesity, hypertension, dyslipidemia, and atherosclerotic cardiovascular disease. Diabetes Care 1991;14(3):173-94.

30. DeFronzo RA, Tobin JD, Andres R. Glucose clamp technique: a method for quantifying insulin secretion and resistance. Am J Physiol 1979;237(3):E214-23.

31. Monzillo LU, Hamdy O. Evaluation of insulin sensitivity in clinical practice and in research settings. Nutr Rev 2003;61(12):397-412.

32. Akinmokun A, Selby PL, Ramaiya K, Alberti KG. The short insulin tolerance test for determination of insulin sensitivity: a comparison with the euglycaemic clamp. Diabet Med 1992;9(5):432-7.

33. Hirst S, Phillips DI, Vines SK, Clark PM, Hales CN. Reproducibility of the short insulin tolerance test. Diabet Med 1993;10(9):839-42.

34. Laakso M. How good a marker is insulin level for insulin resistance? Am J Epidemiol 1993;137(9):959-65.

35. Anderson RL, Hamman RF, Savage PJ, Saad MF, Laws A, Kades WW, Sands RE, Cefalu W. Exploration of simple insulin sensitivity measures derived from frequently sampled intravenous glucose tolerance (FSIGT) tests. The Insulin Resistance Atherosclerosis Study. Am J Epidemiol 1995;142(7):724-32.

36. Matthews DR, Hosker JP, Rudenski AS, Naylor BA, Treacher DF, Turner RC. Homeostasis model assessment: insulin resistance and $\beta$-cell function from fasting plasma glucose and insulin concentrations in man. Diabetologia 1985;28(7):412-9.

37. Wallace TM, Levy JC, Matthews DR. Use and abuse of HOMA modeling. Diabetes Care 2004;27(6):1487-95.

38. Bonora E, Targher G, Alberiche M, Bonadonna RC, Saggiani F, Zenere MB, Monauni T, Muggeo M. Homeostasis model assessment closely mirrors the glucose clamp technique in the assessment of insulin sensitivity: studies in subjects with various degrees of glucose tolerance and insulin sensitivity. Diabetes Care 2000;23(1):57-63.

39. Gandhi GY, Nutall GA, Abel MD, Mullany CJ, Schaff HV, Williams BA, Schrader LM, Rizza RA, McMahon MM. Intraoperative hyperglycemia and perioperative outcomes in cardiac surgery patients. May Clin Proc 2005;80(7):862-6. 
40. Hansen TK, Thiel S, Wouters PJ, Christiansen JS, Van den Berghe G. Intensive insulin therapy exerts antiinflammatory effects in critically ill patients and counteracts the adverse effect of low mannose-binding lectin levels. J Clin Endocrinol Metab 2003;88(3):1082-8.

41. American Diabetes Association. Standards of medical care in diabetes - 2008. Diabetes Care 2008;31(Suppl 1):S12-54.

42. AACE Diabetes Mellitus Clinical Practice Guidelines Task Force. American Association of Clinical Endocrinologists medical guidelines for clinical practice for the management of diabetes mellitus. Endocr Pract 2007;13(Suppl 1):1-68.

43. NICE-SUGAR Study Investigators. Intensive versus conventional glucose control in critically ill patients. N Engl J Med 2009;360(13):1283-97.

44. Campos SP, Baumann H. Insulin is a prominent modulator of the cytokine-stimulated expression of acute-phase plasma protein genes. Mol Cell Biol 1992;12(4):1789-97.

45. Soop M, Nygren J, Thorell A, Ljungqvist O. Stress-induced insulin resistance: recent developments. Curr Opin Clin Nutr Metab Care 2007;10(2):181-6.

46. Kristiansson M, Saraste L, Soop M, Sundgvist KG, Thörne A. Diminished interleukin-6 and C-reactive protein responses to laparoscopic versus open cholecystectomy. Acta Anaesthesiol Scand 1999;43(2):146-52.

47. Thorell A, Loftenius A, Andersson B, Ljungqvist O. Postoperative insulin resistance and circulating concentrations of stress hormones and cytokines. Clin Nutr 1996;15(2):75-9.

48. Kadowaki T, Yamauchi T, Kubota N, Hara K, Ueki K, Tobe K. Adiponectin and adiponectin receptors in insulin resistance, diabetes, and the metabolic syndrome. J Clin Invest 2006;116(7):1784-92.

49. Pischon T, Girman CJ, Hotamisligil GS, Rifai N, Hu FB, Rimm EB. Plasma adiponectin levels and risk of myocardial infarction in men. JAMA 2004;291(14):1730-7.

50. Lindsay RS, Funahashi T, Hanson RL, Matsuzawa Y, Tanaka S, Tataranni PA, Knowler WC, Krakoff J. Adiponectin and development of type 2 diabetes in the Pima Indian population. Lancet 2002;360(9326):57-8.

51. Tschritter O, Fritsche A, Thamer C, Haap M, Shirkavand F, Rahe S, Staiger H, Maerker E, Häring H, Stumvoll M. Plasma adiponectin concentrations predict insulin sensitivity of both glucose and lipid metabolism. Diabetes 2003;52(2):239-43.

52. Combs TP, Berg AH, Obici S, Scherer PE, Rossetti L. Endogenous glucose production is inhibited by the adipose-derived protein Acrp30. J Clin Invest 2001;108(12):1875-81. 
53. Yamauchi T, Kamon J, Waki H, Terauchi Y, Kubota N, Hara K, Mori Y, Ide T, Murakami K, Tsuboyama-Kasaoka N, Ezaki O, Akanuma Y, Gavrilova O, Vinson C, Reitman ML, Kagechika H, Shudo K, Yoda M, Nakano Y, Tobe K, Nagai R, Kimura S, Tomita M, Froguel P, Kadowaki T. The fat-derived hormone adiponectin reverses insulin resistance associated with lipoatrophy and obesity. Nat Med 2001;7(8):941-6.

54. Diks J, van Hoorn DEC, Nijveldt RJ, Boelens PG, Hofman Z, Bouritius H, van Norren K, van Leeuwen PAM. Preoperative fasting: an outdated concept? JPEN J Parenter Enteral Nutr 2005;29(4):298-304.

55. Maltby JR, Sutherland AD, Sale JP, Shaffer EA. Preoperative oral fluids: is a five-hour fast justified prior to elective surgery? Anesth Analg 1986;65(11):1112-6.

56. Haavik PE, Søreide E, Hofstad B, Steen PA. Does preoperative anxiety influence gastric fluid volume and acidity? Anesth Analg 1992;75(1):91-4.

57. American Society of Anesthesiologists Task Force on Preoperative Fasting. Practice guidelines for preoperative fasting and the use of pharmacologic agents to reduce the risk of pulmonary aspiration: application to healthy patients undergoing elective procedures. Anesthesiology 1999;90(3):896-905.

58. Brady M, Kinn S, Stuart P. Preoperative fasting for adults to prevent perioperative complications. Cochrane Database Syst Rev 2003;4:CD004423.

59. Eriksson LI, Sandin R. Fasting guidelines in different countries. Acta Anaesthesiol Scand 1996;40:971-4.

60. Crowe PJ, Dennison A, Royle GT. The effect of preoperative glucose loading on postoperative nitrogen metabolism. Br J Surg 1984;71(8):635-7.

61. Quinones-Galvan A, Ferrannini E. Metabolic effects of glucose-insulin-potassium infusions: myocardium and whole body. Curr Opin Clin Nutr Metab Care 2001;4(2):157-63.

62. Lazar HL, Philippides G, Fitzgerald C, Lancaster D, Shemin RJ, Apstein C. Glucoseinsulin-potassium solutions enhance recovery after urgent coronary artery bypass grafting. $\mathrm{J}$ Thorac Cardiovasc Surg 1997;113(2):354-60.

63. Nygren J, Thorell A, Ljungqvist O. Preoperative oral carbohydrate nutrition: an update. Curr Opin Clin Nutr Metab Care 2001;4(4):255-9.

64. Ljungqvist O, Nygren J, Thorell A. Modulation of post-operative insulin resistance by pre-operative carbohydrate loading. Proc Nutr Soc 2002;61(3):329-36.

65. Svanfeldt M, Thorell A, Hausel J, Soop M, Nygren J, Ljungqvist O. Effect of "preoperative" oral carbohydrate treatment on insulin action - a randomised cross-over unblinded study in healthy subjects. Clin Nutr 2005;24(5):815-21. 
66. Hausel J, Nygren J, Thorell A, Lagerkranser M, Ljungqvist O. Randomized clinical trial of the effects of oral preoperative carbohydrates on postoperative nausea and vomiting after laparoscopic cholecystectomy. Br J Surg 2005;92(4):415-21.

67. Melis GC, van Leeuwen PAM, von Blomberg-van der Flier, B.M.E., Goedhart-Hiddinga AC, Uitdehaag BMJ, Strack van Schijndel RJM, Wuisman PIJM, van Bokhorst-de van der Schueren, MAE. A carbohydrate-rich beverage prior to surgery prevents surgery-induced immunodepression: a randomized, controlled, clinical trial. JPEN J Parenter Enteral Nutr 2006;30(1):21-6.

68. Yuill KA, Richardson RA, Davidson HIM, Garden OJ, Parks RW. The administration of an oral carbohydrate-containing fluid prior to major elective upper-gastrointestinal surgery preserves skeletal muscle mass postoperatively - a randomised clinical trial. Clin Nutr 2005;24(1):32-7.

69. Soop M, Nygren J, Thorell A, Weidenhielm L, Lundberg M, Hammarqvist F, Ljungqvist O. Preoperative oral carbohydrate treatment attentuates endogenous glucose release 3 days after surgery. Clin Nutr 2004;23(4):733-41.

70. Noblett SE, Watson DS, Huong H, Davison B, Hainsworth PJ, Horgan AF. Pre-operative oral carbohydrate loading in colorectal surgery: a randomized controlled trial. Colorectal Dis 2006;8(7):563-9.

71. Abraira C, Lawrence AM. The Staub-Traugott phenomenon. III. Effects of starvation. Am J Clin Nutr 1978;31(2):213-21.

72. Breuer JP, von Dossow V, von Heymann C, Griesbach M, von Schickfus M, Mackh E, Hacker C, Elgeti U, Konertz W, Wernecke KD, Spies CD. Preoperative oral carbohydrate administration to ASA III-IV patients undergoing elective cardiac surgery. Anesth Analg 2006;103(5):1099-108.

73. Järvela K, Maaranen P, Sisto T. Pre-operative oral carbohydrate treatment before coronary artery bypass surgery. Acta Anaesthesiol Scand 2008;52(6):793-7.

74. Rapp-Kesek D, Stridsberg M, Andersson LG, Berne C, Karlsson T. Insulin resistance after cardiopulmonary bypass in the elderly patient. Scand Cardiovasc J 2007;41(2):102-8.

75. Gelding SV, Robinson S, Lowe S, Niththyananthan R, Johnston DG. Validation of the low dose short insulin tolerance test for evaluation of insulin sensitivity. Clin Endocrinol 1994;40(5):611-5.

76. Can MF, Yagci G, Dag B, Ozturk E, Gorgulu S, Simsek A, Tufan T. Preoperative administration of oral carbohydrate-rich solutions: comparison of glucometabolic responses and tolerability between patients with and without insulin resistance. Nutrition 2009;25(1):72-7. 
77. Kiecolt-Glaser JK, Page GG, Marucha PT, MacCallum RC, Glaser R. Psychological influences on surgical recovery. Perspectives from psychoneuroimmunology. Am Psychol 1998;53(11):1209-18.

78. Kiecolt-Glaser JK, Marucha PT, Malarkey WB, Mercado AM, Glaser R. Slowing of wound healing by psychological stress. Lancet 1995;346(8984):1194-6.

79. Schmitt FE, Wooldridge PJ. Psychological preparation of surgical patients. Nurs Res $1973 ; 22(2): 108-16$.

80. Kohl BA, Deutschman CS. The inflammatory response to surgery and trauma. Curr Opin Crit Care 2006;12(4):325-32.

81. Thorell A, Alston-Smith J, Ljungqvist O. The effect of preoperative carbohydrate on hormonal changes, hepatic glycogen, and glucoregulatory enzymes during abdominal surgery. Nutrition 1996;12(10):690-5.

82. Henriksen MG, Hessov I, Dela F, Vind Hansen H, Haraldsted V, Rodt SA. Effects of preoperative oral carbohydrates and peptides on postoperative endocrine response, mobilization, nutrition and muscle function in abdominal surgery. Acta Anaesthesiol Scand 2003;47(2):191-9.

83. Delarue J, Magnan C. Free fatty acids and insulin resistance. Curr Opin Clin Nutr Metab Care 2007;10(2):142-8.

84. Spranger J, Kroke A, Möhlig M, Bergmann MM, Ristow M, Boeing H, Pfeiffer AF. Adiponectin and protection against type 2 diabetes mellitus. Lancet 2003;361(9353):226-8.

85. Matsubara M, Katayose S, Maruoka S. Decreased plasma adiponectin concentrations in nondiabetic women with elevated homeostasis model assessment ratios. Eur J Endocrinol 2003;148(3):343-50.

86. McAlister FA, Man J, Bistritz L, Amad H, Tandon P. Diabetes and coronary artery bypass surgery: an examination of perioperative glycemic control and outcomes. Diabetes Care 2003;26(5):1518-24.

87. Ramos M, Khalpey Z, Lipsitz S, Steinberg J, Panizales MT, Zinner M, Rogers SO. Relationship of perioperative hyperglycemia and postoperative infections in patients who undergo general and vascular surgery. Ann Surg 2008;248(4):585-91.

88. Kain ZN, Sevarino F, Alexander GM, Pincus S, Mayes LC. Preoperative anxiety and postoperative pain in women undergoing hysterectomy. A repeated-measures design. J Psychosom Res 2000;49(6):417-22. 
89. Morrison RS, Magaziner J, McLaughlin MA, Orosz G, Silberzweig SB, Koval KJ, Sui AL. The impact of post-operative pain on outcomes following hip fracture. Pain 2003;103(3):303-11.

90. Gustafsson UO, Nygren J, Thorell A, Soop M, Hellström PM, Ljungqvist O, HagströmToft E. Pre-operative carbohydrate loading may be used in type 2 diabetes patients. Acta Anaesthesiol Scand 2008;52(7):946-51.

91. Ljungqvist O, Søreide E. Preoperative fasting. Br J Surg 2003;90(4):400-6.

92. Bosch AN, Dennis SC, Noakes TD. Influence of carbohydrate loading on fuel substrate turnover and oxidation during prolonged exercise. J Appl Physiol 1993;74(4):1921-7.

93. Lehot JJ, Piriz H, Villard J, Cohen R, Guidollet J. Glucose homeostasis. Comparison between hypothermic and normothermic cardiopulmonary bypass. Chest 1992;102(1):10611. 


\subsection{APPENDICES}

\subsection{Expanded Results and Discussion}

\subsubsection{Introduction}

The main analysis of this study involved comparisons between the CHO group and the FAST group. However, given that different groups made up our total patient population (e.g., CABG patients from pilot study, CABG patients recently recruited, and spine patients), patients were stratified into different groupings and further statistical analyses were conducted on these groupings in order to determine whether the heterogeneity of our patient population influenced our main findings. These stratified groups will be presented in the following manner and include: 1) CABG FAST vs. CABG CHO patients; 2) Spine FAST vs. Spine CHO patients; 3) Spine vs. CABG patients; 4) CABG patients: New vs. Pilot; 5) FAST CABG: New vs. Pilot and 6) CHO CABG: New vs. Pilot. Statistical differences will be highlighted.

\subsubsection{Statistical Analysis}

Statistical analyses of data was similar to that conducted for the main analysis. If levels of FFA were different at baseline between groups, this was added as a covariate in mixed model analysis to determine the effect of time, treatment and interaction. The Mann-

Whitney $U$ test was utilized to determine differences in the change in levels from baseline to 72 hours post-op. If FFA levels at baseline were not statistically different, baseline values were not added as a covariate in the model and differences at 72 hours post-op were determined. 


\subsubsection{CABG FAST vs. CABG CHO}

Baseline subject characteristics are presented in the Appendix - Table 7. No differences were noted in measures of insulin sensitivity between these two groups (Appendix - Table 8).

Analysis of inflammatory markers including logIL-6 and logCRP revealed an effect of time throughout the experimental period $(\mathrm{p}<0.001)$ but no treatment effect (Appendix Table 9). No differences in FFA levels were found at baseline or at 72 hours post-op (Appendix - Table 9). A significant effect of treatment was found $(p=0.004)$ with patients in the FAST group having higher levels of FFA throughout the study period. No effect of time was observed.

Intra and postoperative clinical outcomes were similar between groups (Appendix Table 10). However, CABG patients in the FAST group had a greater number of total complications $(\mathrm{p}=0.04)$ (Appendix - Table 10) and required significantly more blood transfusions than the CHO group $(\mathrm{p}=0.05)$ (Appendix - Table 11). Moreover, patients who fasted received significantly more units of red blood cells $(p=0.002)$. The FAST group also experienced a greater number of total hyperglycemic events in the OR and postoperatively in contrast to the CHO group ( $\mathrm{p}=0.04)$ (Appendix - Table 12). All of these factors suggest that patients in the FAST group were less able to cope with the surgical stress as well as the CHO group, and this may have led to an overall signficantly shorter length of hospital stay in the $\mathrm{CHO}$ group in comparison with the FAST group $(\mathrm{p}=0.03)$ (Appendix - Table 11). 


\subsubsection{Spine FAST vs. Spine CHO}

Baseline subject characteristics are described in the Appendix - Table 13. With respect to the SITT, spine patients placed in the $\mathrm{CHO}$ group were significantly more insulin resistant at baseline compared to the FAST group ( $\mathrm{p}=0.002)$ (Appendix - Table 14). Postoperatively, no differences were found between groups in insulin sensitivity. The CHO group, however, experienced a significantly smaller decrease in insulin sensitivity compared to the FAST group ( $\mathrm{p}=0.02$ ). This suggests that spine patients who received carbohydrate supplementation may have benefited from its ability to modify postoperative insulin resistance. Furthermore, patients in the $\mathrm{CHO}$ group experienced a signficantly smaller rise in blood glucose postoperatively compared to the FAST group ( $\mathrm{p}=0.02)$ (Appendix - Table 14).

Analysis of $\log C R P$ indicated a significant effect of time $(\mathrm{p}<0.001)$ and an effect of treatment was approaching significance $(\mathrm{p}=0.06)$ (Appendix - Table 15). Time and treatment had a significant effect on $\log I L-6(p<0.001$ and $p=0.04$, respectively) but no interaction effect was found (Appendix - Table 15). FFA levels were similar at baseline and 72 hours post-op and no time or treatment effect was observed (Appendix - Table 15).

No differences were noted between groups in intra and postoperative events (Appendix - Table 16 and 17) as well as hyperglycemia outcomes (Appendix - Table 18).

\subsubsection{Spine vs. CABG}

Baseline subject characteristics are presented in the Appendix - Table 19. No differences were found between spine and CABG patients in measures of insulin sensitivity (Appendix - Table 20). 
Mixed model analysis indicated a significant effect of time on $\log C R P(p<0.001)$ but no differences were revealed in regards to type of surgery (Appendix - Table 21). Patients who underwent spinal surgery had significantly higher logCRP levels at 72 hours post-op compared to CABG patients $(\mathrm{p}=0.01)$. LogIL-6 was significantly affected by time $(\mathrm{p}<0.001)$, surgery type $(\mathrm{p}=0.02)$ and an interaction was found between time and surgery $(p=0.04)$ (Appendix - Table 21). Also, higher levels of logIL-6 were observed at 72 hours post-op in spine patients $(\mathrm{p}=0.05)$. FFA levels were similar between groups at baseline but significantly higher in spine patients at 72 hours post-op $(p=0.007)$ (Appendix - Table 21). There was a significant effect of surgery on levels of FFA $(p=0.03)$ but no time effect was observed. Lastly, adiponectin levels were found to be significantly higher in spine patients at baseline compared to $\mathrm{CABG}$ patients $(\mathrm{p}=0.008)$.

Spine patients had a significantly longer OR time compared to CABG patients $(\mathrm{p}<0.001)$ (Appendix - Table 22). Spine patients were also found to have a significantly lower number of total complications $(\mathrm{p}=0.006)$ (Appendix - Table 22). This was expected as there were more CABG patients recruited than spine patients (26 vs. 12 patients), and therefore, $\mathrm{CABG}$ patients would more likely experience a higher number of complications. If spine patients were mechanically ventilated when transferred out of the OR (only two patients), it took a significantly longer duration of time to be extubated compared to CABG patients $(\mathrm{p}=0.05)$ (Appendix - Table 23). All CABG patients were transferred to the CVICU immediately following surgery and the earliest patients could be transferred to the ward is the morning of POD 1. This is in contrast to spine patients who were typically transferred to PACU where the LOS was from three to six hours. Due to these differences, the LOS in a 
unit before being transferred to the ward was significantly shorter for spine patients compared to $\mathrm{CABG}$ patients $(\mathrm{p}=0.009)$.

CABG patients had a significantly higher incidence of intra-op hyperglycemia compared to spine patients $(\mathrm{p}=0.01)$ (Appendix - Table 24). Moreover, $\mathrm{CABG}$ patients experienced significantly more intra-op hyperglycemic events and postoperative hyperglycemic events when examined individually as well as when combined $(\mathrm{p}=0.005$, $\mathrm{p}=0.001$ and $\mathrm{p}<0.001$, respectively). Lastly, the peak glucose level achieved on the day of surgery was significantly higher in $\mathrm{CABG}$ patients compared to spine patients $(\mathrm{p}<0.001)$.

Overall, spine patients experienced a longer OR time, which may have contributed to a greater inflammatory response compared to $\mathrm{CABG}$ patients. $\mathrm{CABG}$ patients experienced more hyperglycemic events in the OR and postoperatively. This was unexpected given that there were no differences between groups in insulin sensitivity markers. This may have been due to different counter-regulatory hormone responses in surgical groups. It has been suggested that hypothermic $\mathrm{CPB}$ suppresses insulin secretion, making $\mathrm{CABG}$ patients more prone to hyperglycemic events (93). As well, glucose contained in the cardioplegia solution and administered to CABG patients may have altered blood glucose levels in these patients, making them more likely to experience hyperglycemia in comparison with spine patients.

\subsubsection{CABG New vs. CABG Pilot}

Baseline subject characteristics are presented in the Appendix - Table 25. No differences were noted between the newly recruited and pilot study patients in measures of insulin sensitivity (Appendix - Table 26). LogCRP levels throughout the study period revealed a significant time effect $(\mathrm{p}<0.001)$ as well as an effect of CABG group (new vs. 
pilot) $(\mathrm{p}=0.02)$ but no interaction existed between these two variables (Appendix - Table 27). Baseline FFA levels were similar at baseline and at 72 hours post-op (Appendix - Table 27). Mixed model analysis revealed no effect of time or CABG group.

CABG patients recently recruited were on pump longer than $\mathrm{CABG}$ patients in the pilot study $(\mathrm{p}=0.05)$ (Appendix - Table 28). Intra and postoperative outcomes indicated that pilot study patients required significantly more blood transfusions $(\mathrm{p}=0.005)$, experienced greater total chest tube losses $(p=0.01)$, longer time on mechanical ventilation $(p=0.004)$, longer stay in the CVICU $(p=0.01)$ and longer overall hospital stay $(p=0.05)$ in contrast to recently recruited patients (Appendix - Table 29). No differences in hyperglycemic outcomes were noted (Appendix - Table 30).

Despite these differences, approximately the same number of pilot study patients were randomized to each of the treatment groups $(n=7$, FAST group; $n=6$, CHO group) and thus, these differences would have been consistent in both groups.

\subsubsection{FAST CABG: New vs. Pilot}

Baseline subject characteristics are described in the Appendix - Table 31. Patients who were placed in the FAST group from the pilot study had significantly lower postoperative insulin levels compared with those recently recruited $(\mathrm{p}=0.05)$ (Appendix Table 32). As such, when postoperative HOMA- $\beta$ scores were calculated, patients from the

pilot study were found to have significantly lower $\beta$-cell function $(\mathrm{p}=0.05)$ and a significantly greater decrease from baseline $(\mathrm{p}=0.008)$ in contrast to those in the newly recruited group.

Examining the levels of $\log$ CRP throughout the study course, a significant effect of time was observed $(\mathrm{p}<0.001)$ but no effect of CABG group was noted (Appendix - Table 
33). Baseline FFA levels were similar at baseline and 72 hours post-op (Appendix - Table 33). No time or group effect was observed.

In regards to intra and postoperative outcomes, patients placed in the FAST group from the pilot study received significantly more blood transfusions $(p=0.02)$, more units of packed red blood cells $(p=0.008)$, required more time on mechanical ventilation $(p=0.002)$ and stayed a longer duration in the CVICU $(p=0.002)$ as well as the hospital $(p=0.009)$ in contrast to the newly recruited patients (Appendix - Tables 34 and 35). No differences in hyperglycemia outcomes were noted (Appendix - Table 36).

\subsubsection{CHO CABG: New vs. Pilot}

Baseline subject characteristics are described in the Appendix - Table 37. No differences were noted between CABG groups in measures of insulin sensitivity (Appendix Table 38). Analysis of logCRP levels showed a significant effect of time $(\mathrm{p}<0.001)$ and effect of CABG group (new vs. pilot) $(\mathrm{p}=0.03)$ but no interaction between the two variables (Appendix - Table 39). FFA levels in the recently recruited patients were significantly higher than pilot study patients at baseline $(\mathrm{p}=0.05)$ but no differences were found when change from baseline to 72 hours post-op was calculated (Appendix - Table 39). A significant effect of CABG group on FFA levels was observed $(p=0.009)$ but no effect of time.

No differences were noted between groups in intra and postoperative outcomes (Appendix - Tables 40 and 41) in addition to hyperglycemia outcomes (Appendix - Table 42). 


\subsection{List of Forms and Tables}

Form 1 - Consent form

Form 2 - Spine case report form

Form 3 - CABG case report form

Table 1- PreOp® drink composition

Table 2 - Anesthetics and other drugs

Form 4 - Visual analog scale questionnaire

Table 3 - Medications

Table 4 - Baseline VAS scores

Table 5 - Preoperative VAS scores, unadjusted for baseline scores

Table 6 - Change in scores (Preoperative - Baseline)

Table 7 - Baseline subject characteristics (CABG FAST vs. CABG CHO)

Table 8 - Measures of insulin sensitivity (CABG FAST vs. CABG CHO)

Table 9 - Blood markers throughout study period (CABG FAST vs. CABG CHO)

Table 10 - Intra and postoperative clinical outcomes (CABG FAST vs. CABG CHO)

Table 11 - Other intra and postoperative clinical outcomes (CABG FAST vs. CABG CHO)

Table 12 - Hyperglycemia outcomes (CABG FAST vs. CABG CHO)

Table 13 - Baseline subject characteristics (Spine FAST vs. Spine CHO)

Table 14 - Measures of insulin sensitivity (Spine FAST vs. Spine CHO)

Table 15 - Blood markers throughout study period (Spine FAST vs. Spine CHO)

Table 16 - Intra and postoperative clinical outcomes (Spine FAST vs. Spine CHO)

Table 17 - Other intra and postoperative clinical outcomes (Spine FAST vs. Spine CHO)

Table 18 - Hyperglycemia outcomes (Spine FAST vs. Spine CHO) 
Table 19 - Baseline subject characteristics (Spine vs. CABG)

Table 20 - Measures of insulin sensitivity (Spine vs. CABG)

Table 21 - Blood markers throughout study period (Spine vs. CABG)

Table 22 - Intra and postoperative clinical outcomes (Spine vs. CABG)

Table 23 - Other intra and postoperative clinical outcomes (Spine vs. CABG)

Table 24 - Hyperglycemia outcomes (Spine vs. CABG)

Table 25 - Baseline subject characteristics (CABG New vs. CABG Pilot)

Table 26 - Measures of insulin sensitivity (CABG New vs. CABG Pilot)

Table 27 - Blood markers throughout study period (CABG New vs. CABG Pilot)

Table 28 - Intra and postoperative clinical outcomes (CABG New vs. CABG Pilot)

Table 29 - Other intra and postoperative clinical outcomes (CABG New vs. CABG Pilot)

Table 30 - Hyperglycemia outcomes (CABG New vs. CABG Pilot)

Table 31 - Baseline subject characteristics (FAST CABG: New vs. Pilot)

Table 32 - Measures of insulin sensitivity (FAST CABG: New vs. Pilot)

Table 33 - Blood markers throughout study period (FAST CABG: New vs. Pilot)

Table 34 - Intra and postoperative clinical outcomes (FAST CABG: New vs. Pilot)

Table 35 - Other intra and postoperative clinical outcomes (FAST CABG: New vs. Pilot)

Table 36 - Hyperglycemia outcomes (FAST CABG: New vs. Pilot)

Table 37 - Baseline subject characteristics (CHO CABG: New vs. Pilot)

Table 38 - Measures of insulin sensitivity (CHO CABG: New vs. Pilot)

Table 39 - Blood markers throughout study period (CHO CABG: New vs. Pilot)

Table 40 - Intra and postoperative clinical outcomes (CHO CABG: New vs. Pilot)

Table 41 - Other intra and postoperative clinical outcomes (CHO CABG: New vs. Pilot) 
Table 42 - Hyperglycemia outcomes (CHO CABG: New vs. Pilot) 
Form 1 - Consent form

Consent to Participate in a Research Study

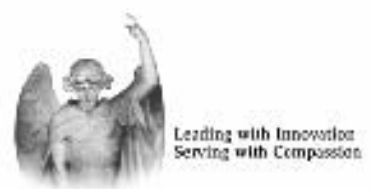

ST. Michael's Hospital

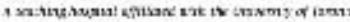

Before agreeing to participate in this research study, it is important that you read and understand this research consent form. This form provides all the information we think you will need to know in order to decide whether you wish to participate in the study. If you have any questions after you read this form, ask your doctor or surgeon. You should not sign this form until you are sure you understand everything on this form. You may also wish to discuss your participation with your family doctor, a family member or a close friend. It is important that you are completely truthful with your study doctor with respect to your health history and any medications you may be taking, in order to prevent any unnecessary harm to you should you decide to participate in this study.

Title of Research Studv

Pre-operative Carbohydrate Feeding Improves Insulin Sensitivity and Inflammatory Markers in Patients Undergoing Bypass and Spinal Surgery

\section{Princinal Investiqator:}

Dr. David Mazer

Department of Anesthesia

Tel: $416-864-5825$

Co-Investigators in the Division of Cardiovascular and Orthopaedic Surgerv

Lee Errett, MD FRCSC, FRCS

Tel. 416-864-5303

Chief, Division of Cardiovascular and Thoracic Surgery

Henry Ahn, MD

Tel: $416-864-6005$

Spine Surgeon, Department of Orthopaedics

Tel. 416-864-5551

Mary Keith $\mathrm{PhD}$, RD

Nutrition

Tel: 416-978-5556

Thomas Wolever, MD

Staff Physician

Studv Coordinators

Susan Tran, MSc Candidate,

Dept. of Nutritional Sciences, University of Toronto

Tel: 416-554-3196

E-mail: TranSu@smh.toronto.on.ca

Douglas Michaud

Research Coordinator III

Dept. of Anesthesia

Tel: $416-864-6060$ Ext. 2920

Studv Sponsors

Divisions of Cardiovascular and Orthopaedic Surgery

Page 1 of 5

Revised February 12, 2008 
Pre-Operative Carbohydrate Feeding Improves Insulin Sensitivity and Inflammatory Markers in Patients Undergoing Coronary Artery Bypass and Spinal Surgery

\section{Purpose of the Research}

The body responds to the stress of surgery as it would with any injury or trauma - by producing a variety of mediators and hormones that help the body to cope with the stress. Insulin is one of the body's hormones that is key in the ability of the cell to take up and use sugar (glucose) from the blood for energy. This hormone seems to be less effective during surgery sometimes resulting in an increased level of glucose in the blood. The purpose of this study is to determine whether consuming a carbohydrate (glucose) rich beverage the evening before and the moming of elective cardiac or spinal surgery, instead of fasting, will help to maintain the effectiveness of insulin resulting in lower levels of blood sugar during and after surgery.

\section{Descrintion of the Resenrch}

This is a study of 60 participants from St. Michael's Hospital. If you choose to participate in this study you will undergo either coronary artery bypass or spinal surgery as has previously been explained by your surgeon. In addition, your operation and your post operative care will be performed in the standard fashion.

If you choose to participate in this study, information will be collected from your chart regarding your medical history by the study coordinator. Subsequently, study participants will be randomized (like "flipping a coin") into one of two study groups - those receiving the preoperative carbohydrate supplement or those who will follow our current practice of preoperative fasting. You will be asked to undergo two tests in order to evaluate how well your body is able to respond to insulin. One of these tests will be done on a morming prior to your surgery and one will be done within 24 hours of your surgery, when you are most likely still asleep. Each test will take approximately one hour and will be supervised by a staff physician who is participating in this study. This insulin sensitivity test will involve having a small cannula placed into a vein on the back of your hand for repeated blood sampling. Your arm will be kept warm in a heating blanket and blood samples will be collected for approximately 15 minutes after you are given an injection of fast acting insulin. Small blood samples will be collected from the cannula so that we can measure the disappearance of glucose from your blood with insulin, thereby indicating how well the insulin is working. Each time we take a blood sample, a drop will be used to determine your blood sugar with a small hand held machine. If your blood sugar drops lower than expected, or if you become uncomfortable, the test will be terminated and you will be given some glucose to raise your blood sugar back into the normal range. Alternatively, 20 minutes after the injection of insulin the test will be finished and you will be provided with some food and juice and your blood sugar level will be measured to ensure that your blood sugar level is within the normal range before you go home. A total of 4 teaspoons of blood $(20 \mathrm{ml})$ will be taken during each test. The post-surgical test will be completed while you are in the intensive care unit and being continuously monitored. You will have many lines that are used for routine blood sampling and the provision of medications. We will use these lines for the insulin tolerance test and will therefore not have to warm your hand or insert any additional cannulas. Your blood sugar levels will be continuously monitored and you will be provided with intravenous glucose (sugar) should your blood sugar drop below the acceptable limit set by our intensive care physician. 
Pre-Operative Carbohydrate Feeding Improves Insulin Sensitivity and Inflammatory Markers in Patients Undergoing Coronary Artery Bypass and Spinal Surgery

At the beginning of your surgery, a small amount of adipose (fat) and muscle tissue will be removed from your chest or spinal incision by your surgeon to measure how well these tissues are able to use glucose. No additional incision is made at the time of surgery in order to collect this tissue.

Participants randomized to receive the carbohydrate drink, will be asked to consume $800 \mathrm{ml}$ (2.5 cups) of beverage on the evening prior to surgery and $400 \mathrm{ml}$ ( 1.5 cups) two hours prior to surgery. Fasting patients will not consume any food after midnight on the day prior to surgery as per the standard protocol. All participants will be asked to complete a short questionnaire on the moming of surgery (3-4 minutes to complete) regarding your feelings of anxiety and hunger. Finally, two tubes of blood $(10 \mathrm{ml}, 2$ teaspoons) will be collected pre and post-operatively as well as 24,48 and 72 hours post surgery in order to measure blood markers of inflammation. These tubes will be collected together with routine blood samples.

\section{Potential Harms (Iniurv, Discomforts or Inconvenience)}

The risks associated with open heart surgery or spinal surgery have been previously discussed with you by your surgeon. Participation in this study involves having a test of how your body responds to insulin done on two occasions. This test has been widely used in the medical literature to measure insulin sensitivity in normal and diabetic subjects. However, since insulin does lower blood sugar levels, there is a small risk that your blood sugar level will drop below the normal range during the test. In order to prevent this, a staff physician will continually monitor your blood sugar throughout the test and the test will be terminated if you wish it to be or if your blood sugar drops to an unacceptable level. In addition, we will provide you with food and juice to ensure that your blood glucose is in the normal range after completion of the test and before you go home. If needed, your blood sugar concentration will be restored to the normal range during your post-operative test by providing a glucose solution through one of the standard lines placed during all surgeries. The insertion of the cannula for blood sampling may result in bruising and/or discomfort. This is temporary and will be gone in a couple of days. Finally, the collection of a small sample of muscle and fat tissue during surgery is not associated with any additional risk.

\section{Women as Research Participants}

If you are female, you may participate in this study if you are certain you are not pregnant. Pregnancy itself is associated with changes in blood sugar levels and therefore would make interpretation of your blood sugar tests impossible.

\section{Potential Benefits}

There are no expected benefits from participating in this study. However, your participation will help us not only to better understand the body's ability to use insulin during surgery but possibly to assist in changing the pre-operative care that we provide to patients undergoing surgery.

Page 3 of 5

Revised February 12, 2008. 
Pre-Operative Carbohydrate Feeding Improves Insulin Sensitivity and Inflammatory Markers in Patients Undergoing Coronary Artery Bypass and Spinal Surgery

\section{Treatment Options}

You do not have to participate in this study. If you decide not to participate in this study, your treatment and that of your family will continue in the usual manner. If you sign this form, you are willing to join the research project described to you on this form. You should ask your physician any questions which you might have about this research study. You may ask him/her questions in the future if you do not understand something that is being done. The surgeons will share with your any new findings which may develop while you are participating in this study.

\section{Confidentiality and Privacy}

The records from this research study, as well as your identity, will be kept confidential and will not be given to anyone who is not helping on this study unless required by law. By signing this consent form, you agree that your records may be provided to regulatory authorities to verify the validity of the clinical information collected. The St. Michael's Hospital Research Ethics Board (REB) may inspect your medical/research records as part of their monitoring of this study.

\section{Reimbursement}

There will be no reimbursement for participating in this study, however, we will provide you with some food and juice following the insulin tolerance test. In addition, we will be able to reimburse your parking/travel expenses related to the pre-operative visit to a maximum of $\$ 15.00$.

\section{Compensation for Injurv:}

If you suffer a physical injury as a direct result of the study, medical care may be obtained by you in the same manner as you would ordinarily obtain any other medical treatment. In no way does signing this form waive your legal rights nor relieve the investigator, sponsors or involved institutions from their legal and professional responsibility.

\section{Publication of Results}

The results of your blood glucose and symptom reports will be reported in medical joumals or at conferences. Your name and identity will be kept secret in these reports by using a code number.

\section{Participation and Withdrawal:}

Your participation in this study is completely voluntary. By signing the consent form, you are agreeing to participate in the study and are expected to return to St. Michael's Hospital for follow-up exams at the intervals described above. If you choose not to participate, you and your family will continue to have access to customary care at St. Michael's Hospital. If you choose to participate, you can withdraw at any time without any effect on the care you and your family will receive at St. Michael's Hospital. 
Pre-Operative Carbohydrate Feeding Improves Insulin Sensitivity and Inflammatory Markers in Patients Undergoing Coronary Artery Bypass and Spinal Surgery

\section{Research Ethics Board}

If you have any questions about the study, you should call the principal investigator, Dr. Mary Keith, at (416) 864-5551; if you have questions about your nights as a research participant, you may call the Chair of the Research Ethics Board (REB) of St. Michael's Hospital, Dr. Julie Spence (416)- 360-4000 Ext. 2557.

\section{Consent to Participate in a Research Trial}

I acknowledge that the research study described above have been explained to me and that any questions that I have asked have been answered to my satisfaction. I have been informed of the altematives to participation in this study, including the right not to participate and the right to withdraw without compromising the quality of medical care at St. Michael's Hospital for me and for other members of my family. As well, the potential risks, harms and discomforts have been explained to me and I also understand the benefits (if any) of participating in the research study.

I understand that I have not waived my legal rights nor released the investigators, sponsors, or involved institutions from their legal and professional duties. I know that I may ask now, or in the future, any questions I have about the study or the research procedures. I have been assured that records relating to me and my care will be kept confidential and that no information will be released or printed that would disclose personal identity without my permission unless required by law. I have been given sufficient time to read and understand the above information.

I hereby consent to participate, and will be given a signed copy of this consent form.

Participant's Signature

Witness to Consent Process To Signature Only

Person Obtaining Consent Signature

Signature of Investigator or Approved Designate
Participants Name (Printed)

Witness Name (Printed)

Person Obtaining Consent Printed

Investigator Name Printed

Date
Date

Date

Date

Page 5 of 5

Revised February 12, 2008. 


\section{Form 2 - Spine case report form}

Patient's Initials

Randomization \#

Date $(\mathrm{d} / \mathrm{m} / \mathrm{y})$ :

Case Report Form Preop

\section{Baseline Visit}

\subsection{Participant Demographics}

Subject Identifier:

Visit Date $(\mathrm{d} / \mathrm{m} / \mathrm{y})$ :

D.O.B. $(d / m / y)$ :

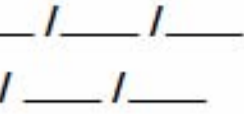

Randomization \#:

Gender $\square$ M $\square$ F

Age Weight (kg):

Insulin Dose (U):

Height (cm):

Work \# ( )

\subsection{Medical History}

\begin{tabular}{|c|c|c|c|}
\hline Condition & NO & YES & IF VES.... \\
\hline 1. Cigarette Smoking & & & current \\
\hline 2. HTN & & & Medication No \\
\hline 3. Family History Heart Disease & & & Primary relative $<65$ years \\
\hline 4. Diabetes & & & Oral agent \\
\hline 5. Hypercholesterolemia/TG & & & Medication No Yes \\
\hline \multicolumn{4}{|l|}{ 6. PVD } \\
\hline \multicolumn{4}{|l|}{ 7. TIA (Transient Ischemic) } \\
\hline \multicolumn{4}{|l|}{ 8. Stroke } \\
\hline 9. Respiratory Disease & & & Emphysema \\
\hline 10. Renal Disease & & & Pre-op serum creatinine= \\
\hline
\end{tabular}


Patient's Initials

Randomization \#

Date $(\mathrm{d} / \mathrm{m} / \mathrm{y})$ :

\section{$\underline{3.0 \text { Spinal Diagnosis }}$}

\begin{tabular}{|c|c|c|c|c|c|}
\hline \multirow[t]{2}{*}{ MRI } & \multirow{2}{*}{\multicolumn{2}{|c|}{ NO YES }} & \multicolumn{3}{|l|}{ IF YES ... } \\
\hline & & & Specify Seve & & \\
\hline 1 Stenosis central & & & Minimum & Moderate & Severe \\
\hline 2 Stenosis foraminal & & & Minimum & Moderate & Severe \\
\hline 3 Disc herniation & & & & & \\
\hline 4 Deformity & & & & & \\
\hline
\end{tabular}

\subsection{Pain Assessment}

\begin{tabular}{|l|l|}
\hline $\begin{array}{l}\text { Preop Oswestry Low Back Pain Scale } \\
\text { Questionnaire }\end{array}$ & \\
\hline Total Score (out of 100) & \\
\hline
\end{tabular}

\subsection{End Point Evaluation}

\subsection{Short Insulin Tolerance Test}

Prior to surgery

5 minutes prior to

insulin injection

3 minutes

5 minutes

7 minutes

9 minutes

11 minutes

13 minutes

15 minutes

20 minutes

Post-operatively 5 minutes prior to insulin injection

3 minutes 5 minutes

7 minutes

\begin{tabular}{|l|}
\hline Insulin: \\
\hline Glucose: \\
\hline
\end{tabular}

9 minutes

11 minutes

13 minutes

15 minutes

20 minutes

\subsection{Patient Discomfort Questionnaire: \\ $\square \quad$ Complete \\ $\square$ Incomplete}

5.3 Blood Work: Inflammatory Mediators

\begin{tabular}{|l|l|l|l|l|l|}
\hline & Baseline & Post-op & 24 hours & 48 hours & 72 hours \\
\hline CRP & & & & & \\
\hline IL-6 & & & & & \\
\hline FFA & & & & & \\
\hline Adiponectin & & & & & \\
\hline
\end{tabular}


Patient's Initials

Randomization \#

Date $(\mathrm{d} / \mathrm{m} / \mathrm{y}):$

\subsection{Intra- Operative Assessment}

6.1 Anesthetic given: Inhaled

Intravenous

6.2 The surgery was done:

ㅁ Electively $=$ not admitted to hospital, date not changed because of symptoms.

․ Urgently = surgery required in $24-72$ hours

\subsection{Surgical Technique}

Surgical Procedure:

$\begin{array}{ll}\square & 3 \text { Level Decompression } \\ \square & 2 \text { Level Decompression } \\ \square & 1 \text { Level Decompression } \\ \square & \text { other specify: }\end{array}$

3 Level Fusion

ㅁ 2 Level Fusion

ㅁ 1 Level Fusion

ㅁ other specify:

\subsection{Intra-Operative Complications}

NO YES

Arrest

Death

Bleeding:

Arrhythmia

Coagulopathy

Hyperglycemia

( $>8 \mathrm{mmolL} / \mathrm{L}$ )

$\square \quad \square$

Significant Hypotension:

민

व $\square$

ㅁำ

$\square \quad \square$

$\square \quad \square \quad$ Maximum glucose level:

*defined as either IABP and/or inotropes used for > $\mathbf{3 0}$ minutes in OR:

Dobutrex

Epinephrine

Dopamine 
Patient's Initials

Randomization \#

Date $(\mathrm{d} / \mathrm{m} / \mathrm{y})$ :

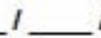

7.0 Post-Operative Assessment

7.1 Post-Operative Adverse Events Local

1. Wound infection

No

Yes

If yes, surgery required? No $\square$ Yes

2. Wound dehiscence

No

Yes

If yes, surgery required? No $\square$ Yes $\square$

3. Hardware failure

No

Yes

If yes, surgery required? No $\square$ Yes $\square$

4. Hardware malposition No $\square \quad$ Yes

\section{Systemic}

1. Myocardial infarction

No $\square \quad$ Yes

2. Stroke

No

Yes

3. Pneumonia

No

Yes

4. Urinary tract infection

No

Yes

5. Ileus

No

Yes

6. Pulmonary embolism/

Deep vein thrombosis

No

Yes

7. Transfusion

No

Yes

8. Sepsis

No

Yes

9. Renal failure

No

Yes

10. Arrhythmia

No

Yes 
Patient's Initials

Randomization \#

Date $(\mathrm{d} / \mathrm{m} / \mathrm{y})$ :

7.2 Follow-Up Results: Post-op Assessment:

Peri-operative morbidity/mortality during hospital admission:

\begin{tabular}{|c|c|}
\hline $\begin{array}{l}\text { Transfusion Required } \square \text { NO } \square \text { YES } \\
\text { Autologous } \_ \text {Homologous }\end{array}$ & $\begin{array}{ll}\text { Platelets } & \text { Units } \\
\text { Whole Blood } & \text { Units } \\
\text { Plasma } & \text { Units } \\
\text { Total PRBC } & \text { Units } \\
\text { Cryoprecipitate } & \text { Units } \\
\text { Recombinant FVIIa } & \text { mg }\end{array}$ \\
\hline Estimated blood loss & Volume: \\
\hline Cell saver volume transfused & Volume: \\
\hline Total OR time & Time: \\
\hline Length of stay in the MSICU/PACU & $\begin{array}{l}\text { Date }(\mathrm{d} / \mathrm{m} / \mathrm{y}) \text { of admission: } \\
\text { Time: } \overline{:} \quad \overline{\text { hrs }} \\
\text { Date }(\mathrm{d} / \mathrm{m} / \mathrm{y}) \text { of discharge: } \\
\text { Time: } \quad: \quad \text { hrs }\end{array}$ \\
\hline $\begin{array}{l}\text { Death occurs during hospital stay } \\
\text { Defined by the death certificate. } \\
\text { NO } \quad \text { YES }\end{array}$ & 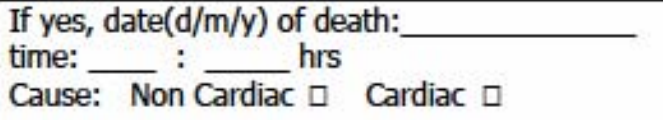 \\
\hline $\begin{array}{l}\text { Infection Post-op } \\
\text { Use of antibiotic(s) for a specific clinically } \\
\text { diagnosed infection that occurs post- } \\
\text { operatively. } \\
\text { NO } \square\end{array}$ & $\begin{array}{l}\text { Pneumonia } \square \text { UTा } \square \text { Wound infection } \square \\
\text { Sepsis } \square \text { Other: } \square \text { specify: }\end{array}$ \\
\hline $\begin{array}{l}\text { Length of time on mechanical ventilation } \\
\text { (from intubation to extubation) }\end{array}$ & \# of hours: \\
\hline Length of stay in hospital & $\begin{array}{l}\text { Date }(\mathrm{d} / \mathrm{m} / \mathrm{y}) \text { of admission to } \\
\text { hospital:__ } \\
\text { Date }(\mathrm{d} / \mathrm{m} / \mathrm{y}) \text { of discharge from } \\
\text { hospital:___ Time: }\end{array}$ \\
\hline Amount of Insulin given (units) & Intra-op \\
\hline $\begin{array}{l}\text { Number of hyperglycemic events } \\
\text { glucose }>8 \mathrm{mmol} / \mathrm{L}\end{array}$ & \\
\hline
\end{tabular}


Patient's Initials

Randomization \#

Date $(\mathrm{d} / \mathrm{m} / \mathrm{y})$ : $-1$

\section{STATUSAT STUDY CLOSE OUI}

口 completed study protocol

a prematurely dropped out of trial Date $(d / m / y)$ of drop out

口 lost to follow-up Date $(\mathrm{d} / \mathrm{m} / \mathrm{y})$ last contacted

$\square$ deceased Date $(\mathrm{d} / \mathrm{m} / \mathrm{y})$ patient died

Person completing this form:

Name of Investigator (print):

Investigator's Signature:

Date $(\mathrm{d} / \mathrm{m} / \mathrm{y})$ form signed: 


\section{Form 3 - CABG case report form}

Patient's Initials

Randomization \#

Date $(\mathrm{d} / \mathrm{m} / \mathrm{y})$

\section{Case Report Form Preop}

\section{Baseline Visit}

\subsection{Participant Demographics}

Subject Identifier:

Visit Date $(d / m / y)$ :

D.O.B. $(d / m / y)$ :

Randomization \#:

Age

Gender $\square$ M $\square$ F

Height (cm):

Weight (kg):

Insulin Dose (U):

Home Tel\#: ( ) Work \# ( )

\subsection{Medical History}

\begin{tabular}{|c|c|c|}
\hline Condition & NO & IF YES.... \\
\hline 1. Cigarette Smoking & & current \\
\hline 2. HTN & & Medication No \\
\hline 3. Family History Heart Disease & & Primary relative $<65$ years \\
\hline 4. Diabetes & & Insulin $\quad$ Oral agent \\
\hline 5. Hypercholesterolemia/TG & & \begin{tabular}{|ll} 
Medication No & Yes \\
\end{tabular} \\
\hline \multicolumn{3}{|l|}{ 6. PVD } \\
\hline \multicolumn{3}{|l|}{ 7. TIA (Transient Ischemic) } \\
\hline \multicolumn{3}{|l|}{ 8. Stroke } \\
\hline 9. Respiratory Disease & & Emphysema \\
\hline 10. Renal Disease & & Pre-op serum creatinine $=$ \\
\hline
\end{tabular}


Patient's Initials

Randomization \#

Date $(\mathrm{d} / \mathrm{m} / \mathrm{y})$ :

\subsection{Coronary Disease}

\begin{tabular}{|c|c|c|c|}
\hline \multirow[t]{2}{*}{ Coronary Angiogram } & \multirow[t]{2}{*}{ NO } & \multirow[t]{2}{*}{ YES } & \multirow{2}{*}{$\begin{array}{c}\text { IF YES ... } \\
\text { Specify Percentage }\end{array}$} \\
\hline & & & \\
\hline 1 Left Main & & & \\
\hline 2 LAD & & & \\
\hline 3 Circumflex & & & \\
\hline 4 RCA & & & \\
\hline 5 Diagonal & & & \\
\hline $\begin{array}{l}6 \text { Obtuse Marginal (Transien } \\
\text { Ischemic) }\end{array}$ & & & \\
\hline 7 Other & & & \\
\hline 8 Other & & & \\
\hline
\end{tabular}

\subsection{Cardiac Functional Class and CCS Class}

\begin{tabular}{|l|l|l|}
\hline CLASS & CCS & NYHA \\
\hline Class I & & \\
\hline Class II & & \\
\hline Class III & & \\
\hline Class IV & & \\
\hline
\end{tabular}

\begin{tabular}{|l|l|}
\hline LV GRADE & \\
\hline Grade I $>50 \%$ & \\
\hline Grade II $(35-50 \%)$ & \\
\hline Grade III $(20-35 \%)$ & \\
\hline Grade IV $(<20 \%)$ & \\
\hline
\end{tabular}

\begin{tabular}{|l|l|}
\hline LV ASSESSMENT & DATE \\
\hline MUGA & \\
\hline ECHO & \\
\hline CATH & \\
\hline
\end{tabular}

\subsection{End Point Evaluation}

\subsection{Short Insulin Tolerance Test}

Prior to surgery

5 minutes prior to

insulin injection

3 minutes

5 minutes

7 minutes

9 minutes

11 minutes

13 minutes

15 minutes

20 minutes

Post-operatively

\begin{tabular}{|l|l|}
5 minutes prior to & Insulin:
\end{tabular}

\begin{tabular}{l|l}
\cline { 2 - 2 } insulin injection & Glucose:
\end{tabular}

3 minutes

5 minutes

7 minutes

9 minutes

11 minutes

13 minutes

15 minutes

20 minutes 
Patient's Initials

Randomization \#

Date $(\mathrm{d} / \mathrm{m} / \mathrm{y})$ :

${ }^{\prime}-$

\subsection{Patient Discomfort Questionnaire: $\square \quad$ Complete $\square$ Incomplete}

5.3 Blood Work: Inflammatory Mediators

\begin{tabular}{|l|l|l|l|l|l|}
\hline & Baseline & Post-op & 24 hours & 48 hours & 72 hours \\
\hline CRP & & & & & \\
\hline IL-6 & & & & & \\
\hline FFA & & & & & \\
\hline Adiponectin & & & & & \\
\hline
\end{tabular}

\subsection{Intra- Operative Assessment}

6.1 Anesthetic given: Inhaled

\section{Intravenous}

6.2 The surgery was done:

ㅁ Electively $=$ not admitted to hospital, date not changed because of symptoms.

ㅁ Urgently = surgery required in $24-72$ hours

\subsection{Surgical Technique}

Aortic Cross Clamp Time:

Surgical Procedure:

Pump Time:
ㅁ 4 Vessel CABG
ㅁ 3 Vessel CABG
ㅁ 2 Vessel CABG
$\square$ other specify:

\subsection{Intra-Operative Complications \\ NO YES}

Arrest

Death

Bleeding:

Arrhythmia:

Hyperglycemia

(>8 mmoll/L)

$\begin{array}{ll}\square & \square \\ \square & \square \\ \square & \square \\ \square & \square \\ \square & \square\end{array}$

Significant Hypotension:

$\square$

$\square \quad$ *Requiring IABP $\square$ *Inotropes $\square$ 
Patient's Initials

Randomization \#

Date $(\mathrm{d} / \mathrm{m} / \mathrm{y})$ :

I

*defined as either IABP and/or inotropes used for > $\mathbf{3 0}$ minutes in OR:

Dobutrex

Epinephrine

Dopamine

Levophed

\subsection{Post-Operative Assessment}

\subsection{Post-Operative Adverse Events (CV-ICU)}

1. New Stroke. Defined as persistent neurological deficit at the time of discharge \pm CT scan consistent with a new stroke

$$
\text { No }
$$

Yes

2. Myocardial Infarction

No

Yes

3. Post-op inotropes required

No

Yes

If YES, defined as inotropes for $>6$ hours at one of the following doses

Dobutrex > $5 \mathrm{ug} / \mathrm{kg} / \mathrm{min}$

Epinephrine $>0.5 \mathrm{ug} / \mathrm{kg} / \mathrm{min}$

Dopamine $>5 \mathrm{ug} / \mathrm{kg} / \mathrm{min}$

Levophed $>0.05 \mathrm{ug} / \mathrm{kg} / \mathrm{min}$ )

4. Post-op IABP Required No $\square \quad$ Yes $\square$ - Total \# hours

1. Other: 
Patient's Initials

Randomization \#

Date (d/m/y): I

7.2 Follow-Up Results: Post-op Assessment:

Peri-operative morbidity/mortality during hospital admission:

\begin{tabular}{|c|c|}
\hline $\begin{array}{l}\text { Transfusion Required } \square \text { NO } \square \text { YES } \\
\text { Autologous _ Homologous }\end{array}$ & \begin{tabular}{|lc} 
Platelets & Units \\
Whole Blood & Units \\
Plasma & Units \\
Total PRBC & Units \\
Cryoprecipitate & Units \\
Recombinant FVIIa & mg \\
\end{tabular} \\
\hline Estimated blood loss & Volume: \\
\hline Total OR time & Time: \\
\hline Chest Tube Losses & Volume $6 \mathrm{hr}: \ldots$ Total volume \\
\hline Length of stay in the CVICU & $\begin{array}{l}\text { Date }(\mathrm{d} / \mathrm{m} / \mathrm{y}) \text { of admission to CVICU:_- } \\
\text { Time: } \overline{\text { hiss }} \\
\text { Date }(\mathrm{d} / \mathrm{m} / \mathrm{y}) \text { of discharge to CVICU: } \\
\text { Time: } \quad: \quad \text { hrs }\end{array}$ \\
\hline $\begin{array}{l}\text { Death occurs during hospital stay } \\
\text { Defined by the death certificate. } \\
\text { NO } \quad \text { YES }\end{array}$ & $\begin{array}{l}\text { If yes, date }(\mathrm{d} / \mathrm{m} / \mathrm{y}) \text { of death: } \\
\text { time: }: \text { hrs } \\
\text { Cause: Non Cardiac } \square \quad \text { Cardiac } \square\end{array}$ \\
\hline $\begin{array}{l}\text { Atrial Fibrillation requiring a change in Rx: } \\
\text { (diagnosed by an ECG or charted as requiring } \\
\text { treatment) } \\
\text { NO } \square\end{array}$ & If yes, Treatment received: \\
\hline $\begin{array}{l}\text { Infection Post-op } \\
\text { Use of antibiotic(s) for a specific clinically } \\
\text { diagnosed infection that occurs post- } \\
\text { operatively. } \\
\text { NO } \square\end{array}$ & $\begin{array}{l}\text { Pneumonia } \square \text { Uा } \square \text { Wound infection } \square \\
\text { Sepsis } \square \text { Other: } \square \text { specify: }\end{array}$ \\
\hline $\begin{array}{l}\text { Length of time on mechanical ventilation } \\
\text { (from intubation to extubation) }\end{array}$ & \# of hours: \\
\hline Length of stay in hospital & $\begin{array}{l}\text { Date }(\mathrm{d} / \mathrm{m} / \mathrm{y}) \text { of admission to } \\
\text { hospital:__ } \\
\text { Date }(\mathrm{d} / \mathrm{m} / \mathrm{y}) \text { of discharge from } \\
\text { hospital:____ hime: }\end{array}$ \\
\hline Amount of Insulin given (units) & Intra-op \\
\hline $\begin{array}{l}\text { Number of hyperglycemic } \epsilon \\
\text { glucose }>8 \mathrm{mmol} / \mathrm{L}\end{array}$ & \\
\hline
\end{tabular}


Patient's Initials

Randomization \#

Date (d/m/y):

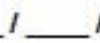

\section{STATUSAI STUDY CLOSE OUI}

口 completed study protocol

口 prematurely dropped out of trial Date $(d / m / y)$ of drop out

口 lost to follow-up

Date $(\mathrm{d} / \mathrm{m} / \mathrm{y})$ last contacted

$\square$ deceased

Date $(\mathrm{d} / \mathrm{m} / \mathrm{y})$ patient died

Person completing this form:

Name of Investigator (print):

Investigator's Signature:

Date $(\mathrm{d} / \mathrm{m} / \mathrm{y})$ form signed: 
Table 1 - PreOp ${ }$ drink composition

\begin{tabular}{lc}
\multicolumn{1}{c}{ Content } & Per $\mathbf{1 0 0 ~} \mathbf{~ L L}$ \\
\hline Energy (kcal) & 50 \\
Protein (g) & 0 \\
Carbohydrate $(\mathrm{g})$ & 12.5 \\
$\quad$ Polysaccharides $(\mathrm{g})$ & 10 \\
$\quad$ Sugars $(\mathrm{g})$ & 2.1 \\
$\quad$ Lactose $(\mathrm{g})$ & 0 \\
Fat $(\mathrm{g})$ & 0 \\
Dietary fibre $(\mathrm{g})$ & 0 \\
Minerals & \\
$\quad$ Sodium $(\mathrm{mg})$ & 50 \\
Potassium $(\mathrm{mg})$ & 122 \\
Chloride $(\mathrm{mg})$ & 6 \\
Calcium $(\mathrm{mg})$ & 6 \\
Phosphorus $(\mathrm{mg})$ & 1 \\
Magnesium $(\mathrm{mg})$ & 1 \\
Water (g) & 92 \\
Osmolarity $(\mathrm{mOsm})$ & 240 \\
Osmolality $\left(\mathrm{mOsm} / \mathrm{H}_{2} \mathrm{O}\right)$ & 260 \\
pH & 4.9 \\
\hline
\end{tabular}


Table 2 - Anesthetics and other drugs

\begin{tabular}{cc}
\hline Intravenous & Inhaled \\
\hline Cefazolin & Desflurane \\
Fentanyl & Soflurane \\
Heparin & Sevoflurane \\
MgSO $_{4}$ & \\
Midazolam & \\
Morphine & \\
Odansetran & \\
Pancuronium & \\
Phenylephrine & \\
Protamine & \\
Remifentanil & \\
Rocuronium & \\
Sufentanil & \\
Thiopental & \\
Tranexamic acid & \\
\hline
\end{tabular}




\section{Form 4 - Visual analog scale questionnaire}

\section{Visual Analog Scale}

Please place an $\mathrm{X}$ along the line where you think you fit.

1. Current level of anxiety

not at all anxious

the most anxious imaginable

2. Current level of depression

not at all depressed

the most depressed imaginable

3. Current level of hunger

not at all hungry

The most hungry imaginable

4. Current level of malaise

no malaise the most imaginable

5. Current inability to concentrate

perfect concentration

no ability to concentrate

6. Current level of nausea

no nausea

the most nausea imaginable

7. Current level of pain

no pain the most pain imaginable

8. Current level of thirst

not thirsty the most thirsty imaginable

9. Current level of tiredness

not tired the most tired imaginable

10. Current level of unfitness

not at all unfit The most unfit imaginable

11. Current level of weakness

not at all weak

The weakest imaginable 
Table 3 - Medications

\begin{tabular}{|c|c|c|c|}
\hline & $\begin{array}{c}\text { Fast } \\
(n=19)\end{array}$ & $\begin{array}{c}\mathrm{CHO} \\
(n=19)\end{array}$ & p-value \\
\hline Statin & $14(74)$ & $13(68)$ & $\mathrm{NS}(0.72)$ \\
\hline ASA & $13(68)$ & $15(79)$ & NS $(0.71)$ \\
\hline B-Blocker & $8(42)$ & $13(68)$ & NS $(0.10)$ \\
\hline ACE Inhibitor & $6(32)$ & $11(58)$ & NS $(0.10)$ \\
\hline Nitrospray & $5(26)$ & $3(16)$ & NS (0.72) \\
\hline Nitropatch & $4(21)$ & $1(5)$ & NS $(0.34)$ \\
\hline NSAID & $4(21)$ & $5(26)$ & NS $(1.00)$ \\
\hline Ca-Channel Blocker & $5(26)$ & $4(21)$ & NS (1.00) \\
\hline Angiontensin II Receptor Blocker & $2(11)$ & $3(16)$ & NS (1.00) \\
\hline Proton Pump Inhibitor & $4(21)$ & $2(11)$ & NS (0.66) \\
\hline Non-Statin & $2(11)$ & 0 & NS (0.49) \\
\hline Acetaminophen & $2(11)$ & $1(5)$ & NS $(1.00)$ \\
\hline Opioid & $3(16)$ & $3(16)$ & NS $(1.00)$ \\
\hline Analgesic & $2(11)$ & 0 & NS (0.49) \\
\hline Anti-depressant & $2(11)$ & $3(16)$ & NS (1.00) \\
\hline Sedative & $2(11)$ & 0 & NS (0.49) \\
\hline Bronchodilator & $2(11)$ & $1(5)$ & NS (1.00) \\
\hline Thyroid Hormone Supplement & $2(11)$ & $1(5)$ & NS (1.00) \\
\hline Bisphosphonate & $1(5)$ & $2(11)$ & NS (1.00) \\
\hline Diuretic & $4(21)$ & $2(11)$ & NS (0.66) \\
\hline Anticoagulant & $3(16)$ & $4(21)$ & NS (1.00) \\
\hline Muscle Relaxant & 0 & $3(16)$ & NS $(0.23)$ \\
\hline Laxative & $1(5)$ & $2(11)$ & NS (1.00) \\
\hline Hormone Replacement Therapy & $1(5)$ & 0 & NS $(1.00)$ \\
\hline Vitamin & $9(47)$ & $7(37)$ & NS $(0.51)$ \\
\hline Alternative medicine & $2(11)$ & $2(11)$ & NS (1.00) \\
\hline
\end{tabular}

$\mathrm{n}(\%) ; \mathrm{x}^{2}$ or Fisher's Exact Test 
Table 4 - Baseline VAS scores

\begin{tabular}{|c|c|c|c|}
\hline & $\begin{array}{c}\text { Fast } \\
(n=12)^{\#}\end{array}$ & $\begin{array}{c}\mathrm{CHO} \\
(\mathrm{n}=13)^{\#}\end{array}$ & p-value \\
\hline Anxiety & $29.0(14.8,50.3)$ & $35.0(11.5,44.0)$ & NS (0.69) \\
\hline Depression & $19.5(13.0,42.8)$ & $13.0(6.5,17.5)$ & NS (0.07) \\
\hline Hunger & $31.5(15.3,41.8)$ & $50.0(32.0,63.5)$ & 0.03 \\
\hline Malaise & $13.0(3.8,27.8)$ & $22.0(7.5,35.0)$ & NS (0.38) \\
\hline $\begin{array}{l}\text { Inability to } \\
\text { concentrate }\end{array}$ & $26.5(17.0,35.3)$ & $30.0(4.0,49.0)$ & NS $(0.85)$ \\
\hline Nausea & $10.0(2.0,36.0)$ & $6.0(2.5,18.5)$ & NS (0.57) \\
\hline Pain & $44.5(10.3,65.5)$ & $20.0(5.0,44.5)$ & NS $(0.32)$ \\
\hline Thirst & $44.5(15.3,54.5)$ & $35.0(9.0,75.0)$ & NS (0.98) \\
\hline Tiredness & $25.0(23.0,60.8)$ & $47.0(8.0,67.0)$ & NS $(0.77)$ \\
\hline Unfitness & $53.5(29.8,70.0)$ & $47.0(17.0,60.5)$ & NS (0.54) \\
\hline Weakness & $44.5(16.3,65.5)$ & $34.0(8.5,52.5)$ & NS $(0.30)$ \\
\hline
\end{tabular}


Table 5 - Preoperative VAS scores, unadjusted for baseline scores

\begin{tabular}{|c|c|c|c|}
\hline & $\begin{array}{c}\text { Fast } \\
(n=12)^{\#}\end{array}$ & $\begin{array}{c}\mathrm{CHO} \\
(\mathrm{n}=13)^{\#}\end{array}$ & p-value \\
\hline Anxiety & $61.5(38.2,71.5)$ & $34.0(17.5,48.0)$ & 0.02 \\
\hline Depression & $26.0(6.8,42.0)$ & $11.0(4.0,43.0)$ & NS $(0.50)$ \\
\hline Hunger & $48.5(28.5,63.5)$ & $25.0(6.5,42.5)$ & NS $(0.11)$ \\
\hline Malaise & $24.5(6.3,49.8)$ & $26.0(8.0,47.5)$ & NS (0.81) \\
\hline $\begin{array}{l}\text { Inability to } \\
\text { concentrate }\end{array}$ & $36.5(6.5,61.0)$ & $25.0(7.5,44.0)$ & NS (0.54) \\
\hline Nausea & $5.5(2.3,12.0)$ & $12.0(4.0,36.5)$ & NS (0.19) \\
\hline Pain & $50.0(7.0,74.0)$ & $17.0(3.0,47.5)$ & NS $(0.30)$ \\
\hline Thirst & $50.0(24.0,69.8)$ & $10.0(7.0,34.0)$ & 0.01 \\
\hline Tiredness & $46.5(4.5,71.5)$ & $38.0(19.5,54.0)$ & NS (0.69) \\
\hline Unfitness & $52.5(22.5,77.3)$ & $57.0(38.0,65.5)$ & NS (0.89) \\
\hline Weakness & $30.5(10.8,54.5)$ & $34.0(9.5,55.0)$ & NS (0.98) \\
\hline
\end{tabular}


Table 6 - Change in scores (Preoperative - Baseline)

\begin{tabular}{|c|c|c|c|}
\hline & $\begin{array}{c}\text { Fast } \\
(n=12)^{\#}\end{array}$ & $\begin{array}{c}\mathrm{CHO} \\
(n=13)^{\#}\end{array}$ & p-value \\
\hline Anxiety & $30.5(18.3,40.8)$ & $0.0(-10.5,21.0)$ & 0.02 \\
\hline Depression & $-3.0(-12.3,17.8)$ & $4.0(-7.5,24.5)$ & NS $(0.50)$ \\
\hline Hunger & $17.0(-7.8,34.0)$ & $-21.0(-43.0,-3.0)$ & 0.002 \\
\hline Malaise & $7.0(-5.3,33.8)$ & $1.0(-11.0,24.0)$ & NS $(0.77)$ \\
\hline $\begin{array}{l}\text { Inability to } \\
\text { concentrate }\end{array}$ & $5.5(-14.0,35.0)$ & $2.0(-14.0,9.5)$ & NS $(0.38)$ \\
\hline Nausea & $-0.5(-10.8,7.5)$ & $7.0(1.0,16.5)$ & NS (0.09) \\
\hline Pain & $2.0(-9.3,19.8)$ & $-7.0(-21.0,13.0)$ & NS $(0.44)$ \\
\hline Thirst & $12.0(-8.8,30.3)$ & $-17.0(-55.0,6.0)$ & 0.03 \\
\hline Tiredness & $4.0(-24.0,40.3)$ & $8.0(-29.0,21.5)$ & NS $(0.41)$ \\
\hline Unfitness & $-3.0(-10.5,3.5)$ & $6.0(-6.5,15.5)$ & NS $(0.27)$ \\
\hline Weakness & $-4.5(-15.0,10.3)$ & $8.0(-8.0,21.0)$ & NS $(0.27)$ \\
\hline
\end{tabular}


Table 7 - Baseline subject characteristics (CABG FAST vs. CABG CHO)

\begin{tabular}{|c|c|c|c|}
\hline & $\begin{array}{c}\text { Fast } \\
(n=13)\end{array}$ & $\begin{array}{c}\mathrm{CHO} \\
(n=13)\end{array}$ & p-value \\
\hline Age (years) ${ }^{*}$ & $59.0(55.0,67.5)$ & $55.0(49.5,62.0)$ & NS (0.11) \\
\hline Body mass index $\left(\mathrm{kg} / \mathrm{m}^{2}\right)^{*}$ & $25.5(23.0,28.0)$ & $27.5(25.1,31.0)$ & NS $(0.17)$ \\
\hline Gender - Male ${ }^{\dagger}$ & $8(62)$ & $13(100)$ & 0.04 \\
\hline Smoker $^{\dagger}$ & $9(69)$ & $6(46)$ & NS $(0.43)$ \\
\hline Hypertension $^{\dagger}$ & $10(77)$ & $9(69)$ & NS (1.00) \\
\hline $\begin{array}{l}\text { Family history of heart } \\
\text { disease }^{\dagger}\end{array}$ & $8(62)$ & $6(50)^{1}$ & NS (0.56) \\
\hline Hypercholesterolemia $^{\dagger}$ & $12(92)$ & $11(85)$ & NS (1.00) \\
\hline $\begin{array}{l}\text { Peripheral vascular } \\
\text { disease }^{\dagger}\end{array}$ & $1(8)$ & $2(15)$ & NS (1.00) \\
\hline Transient ischemic $^{\dagger}$ & 0 & 0 & NS \\
\hline Stroke $^{\dagger}$ & 0 & 0 & NS \\
\hline Respiratory disease $^{\dagger}$ & $2(15)$ & $1(8)$ & NS (1.00) \\
\hline Renal disease $^{\dagger}$ & 0 & 0 & NS \\
\hline \multicolumn{4}{|c|}{$\begin{array}{l}{ }^{*} \text { median }\left(25^{\text {th }}, 75^{\text {th }} \text { percentile); Mann-Whitney U Test }\right. \\
t_{n}(\%) ; x^{2} \text { or Fisher's Exact Test } \\
\text { CCS, Canadian Cardiovascular Society } \\
\text { NS, non-significant } \\
\text { NYHA, New York Heart Association } \\
{ }^{1} n=12 \text {; missing data }\end{array}$} \\
\hline
\end{tabular}


Table 8 - Measures of insulin sensitivity (CABG FAST vs. CABG CHO)

\begin{tabular}{|c|c|c|c|}
\hline & $\begin{array}{c}\text { Fast } \\
(\mathrm{n}=13)\end{array}$ & $\begin{array}{c}\mathrm{CHO} \\
(\mathrm{n}=13)\end{array}$ & $p$-value \\
\hline $\begin{array}{c}\text { KITT (\%/min) } \\
\text { Baseline }\end{array}$ & $1.30(0.83,1.72)^{1}$ & $1.22(0.92,1.56)$ & NS (0.61) \\
\hline Post-op & $0.33(0.16,0.43)^{1 \mathrm{a}}$ & $0.44(0.29,0.60)^{1 \mathrm{~b}}$ & NS $(0.20)$ \\
\hline Change & $-0.89(-2.07,-0.37)^{1}$ & $-0.78(-0.96,-0.45)^{1}$ & NS (0.55) \\
\hline $\begin{array}{l}\text { Relative IS (\%) } \\
\text { (Post/Pre x 100) }\end{array}$ & $28.3(9.3,53.6)^{1}$ & $41.2(16.9,48.7)^{1}$ & NS (0.41) \\
\hline $\begin{array}{l}\text { HOMA-IR (units) } \\
\text { Baseline }\end{array}$ & $1.8(1.3,2.0)$ & $2.2(1.4,2.9)$ & NS (0.29) \\
\hline Post-op & $1.8(1.1,3.8)$ & $3.2(0.9,6.3)^{2}$ & NS $(0.44)$ \\
\hline Change & $-0.1(-0.6,1.8)$ & $0.3(-0.5,3.7)^{2}$ & NS (0.35) \\
\hline $\begin{array}{c}\text { HOMA- } \beta(\%) \\
\text { Baseline }\end{array}$ & $95.3(60.0,121.6)$ & $98.9(71.8,127.5)$ & NS (0.72) \\
\hline Post-op & $37.3(18.8,83.8)^{c}$ & $72.7(32.8,107.0)^{2}$ & NS (0.12) \\
\hline Change & $-38.6(-82.1,-15.7)$ & $-29.9(-62.1,9.6)^{2}$ & NS $(0.44)$ \\
\hline $\begin{array}{l}\text { Glucose (mmol/L) } \\
\text { Baseline }\end{array}$ & $5.1(4.8,5.7)$ & $5.3(5.1,5.5)$ & NS $(0.34)$ \\
\hline Post-op & $6.6(5.9,8.1)^{d}$ & $6.7(5.4,7.1)^{\mathrm{e}}$ & NS (0.31) \\
\hline Change & $1.2(0.6,2.4)$ & $0.9(-0.1,2.2)$ & NS (0.35) \\
\hline $\begin{array}{l}\text { Insulin (pmol/L) } \\
\text { Baseline }\end{array}$ & $48.0(41.0,60.5)$ & $66.0(41.5,87.5)$ & NS (0.39) \\
\hline Post-op & $44.0(26.5,74.5)$ & $75.5(26.0,137.0)^{2}$ & NS (0.32) \\
\hline Change & $-16.0(-36.0,27.0)$ & $7.5(-18.0,61.0)^{2}$ & NS (0.35) \\
\hline 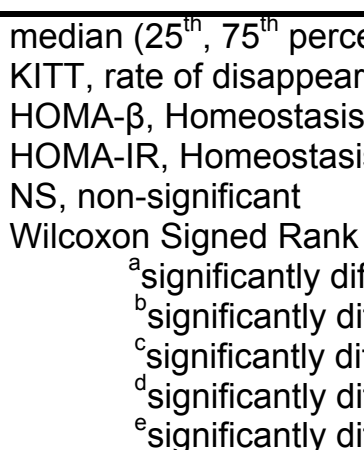 & $\begin{array}{l}\text { Mann-Whitney U Test } \\
\text { blood glucose } \\
\text { assessment for } \beta \text {-cell fu } \\
\text { I assessment for insulin } \\
\\
\text { rom baseline, } p=0.002 \\
\text { rom baseline, } p=0.003 \\
\text { rom baseline, } p=0.05 \\
\text { rom baseline, } p=0.001 \\
\text { rom baseline, } p=0.02\end{array}$ & $\begin{array}{l}\begin{array}{l}n=12 ; S I \\
2 n=12 ; \text { ins } \\
\text { ction } \\
\text { sistance }\end{array} \\
\end{array}$ & from analysis \\
\hline
\end{tabular}


Table 9 - Blood markers throughout study period (CABG FAST vs. CABG CHO)

\begin{tabular}{|c|c|c|c|c|c|}
\hline & Baseline & Postoperative & 24 hours post-op & 48 hours post-op & 72 hours post-op \\
\hline $\mathrm{CHO}$ & $-0.09(-0.38,0.21)^{2}$ & $-0.25(-0.47,0.21)^{3}$ & $2.01(1.96,2.16)^{1}$ & $2.29(2.18,2.34)^{1}$ & $2.19(2.06,2.25)^{1}$ \\
\hline $\begin{array}{l}\log \operatorname{lo}^{\prime}-6(\mathrm{pg} / \mathrm{mL})^{\#} \\
\text { FAST }\end{array}$ & $0.02(-0.17,0.34)$ & $1.79(1.73,1.91)$ & $2.12(1.87,2.32)$ & $2.13(1.88,2.24)$ & $1.62(1.42,1.85)$ \\
\hline $\begin{array}{l}\text { FFA (mEq/L) } \\
\text { FAST }\end{array}$ & $0.45(0.32,0.71)$ & $0.40(0.35,0.59)$ & $0.42(0.34,0.55)$ & $0.37(0.33,0.54)$ & $0.40(0.15,0.51)$ \\
\hline $\mathrm{CHO}$ & $0.28(0.18,0.44)$ & $0.38(0.29,0.45)$ & $0.31(0.24,0.46)$ & $0.34(0.22,0.45)$ & $0.28(0.19,0.41)^{2}$ \\
\hline $\begin{array}{l}\text { Adiponectin (ug/mL) } \\
\text { FAST }\end{array}$ & $8.43(4.28,11.83)$ & $N / A$ & $\mathrm{~N} / \mathrm{A}$ & $N / A$ & $\mathrm{~N} / \mathrm{A}$ \\
\hline
\end{tabular}


Table 10 - Intra and postoperative clinical outcomes (CABG FAST vs. CABG CHO)

\begin{tabular}{|c|c|c|c|}
\hline & $\begin{array}{c}\text { Fast } \\
(n=13)\end{array}$ & $\begin{array}{c}\mathrm{CHO} \\
(n=13)\end{array}$ & $p$-value \\
\hline Vessels bypassed* & $3.0(2.5,4.0)$ & $3.0(2.0,3.5)$ & NS (0.55) \\
\hline Cross clamp time $(\mathrm{min})^{*}$ & $44.0(30.8,48.5)^{1}$ & $39.0(31.0,47.5)$ & NS (0.89) \\
\hline Pump time (min)* & $61.0(51.8,72.5)^{1}$ & $59.0(50.5,81.5)$ & NS (0.85) \\
\hline OR time $(\min )^{*}$ & $220.0(195.0,240.0)$ & $220.0(197.5,242.5)$ & NS (0.88) \\
\hline Intra-op bleeding $^{\dagger}$ & $2(15)$ & 0 & NS (0.48) \\
\hline Intra-op hypotension ${ }^{\dagger}$ & $6(46)$ & $3(23)$ & NS $(0.41)$ \\
\hline Wound infection $^{\dagger}$ & 0 & $1(8)$ & NS (1.00) \\
\hline Other infection ${ }^{\dagger}$ & $1(8)$ & 0 & NS (1.00) \\
\hline Pneumonia $^{\dagger}$ & 0 & 0 & NS \\
\hline Urinary tract infection $^{\dagger}$ & 0 & 0 & NS \\
\hline Myocardial infarction $^{\dagger}$ & $1(8)$ & 0 & NS (1.00) \\
\hline Post-op inotropes $^{\dagger}$ & $3(25)^{1}$ & $3(23)$ & NS (1.00) \\
\hline Post-op IABP ${ }^{\dagger}$ & $1(8)^{1}$ & 0 & NS (0.48) \\
\hline Atrial fibrillation $^{\dagger}$ & $4(31)$ & $3(23)$ & NS (1.00) \\
\hline Pleural effusion ${ }^{\dagger}$ & $4(31)$ & $2(15)$ & NS (0.65) \\
\hline 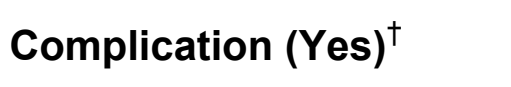 & $13(100)$ & $13(100)$ & NS \\
\hline Total complications $^{\dagger \dagger}$ & 51 & 34 & 0.04 \\
\hline
\end{tabular}

\footnotetext{
${ }^{*}$ median $\left(25^{\text {th }}, 75^{\text {th }}\right.$ percentile); Mann-Whitney U Test

${ }^{\dagger} n(\%) ; x^{2}$ or Fisher's Exact Test

${ }^{\mathrm{t}} \mathrm{n}$; Independent Samples T-Test

NS, non-significant

${ }^{1} \mathrm{n}=12$; missing data
} 
Table 11 - Other intra and postoperative clinical outcomes (CABG FAST vs. CABG CHO)

\begin{tabular}{|c|c|c|c|}
\hline & $\begin{array}{c}\text { Fast } \\
(n=13)\end{array}$ & $\begin{array}{c}\mathrm{CHO} \\
(\mathrm{n}=13)\end{array}$ & $p$-value \\
\hline Transfusion required $^{\dagger}$ & $9(69)$ & $3(23)$ & 0.05 \\
\hline Platelets (Units)* & $0(0,0)$ & 0 & NS $(0.51)$ \\
\hline Whole blood (Units)* & $0(0,0)$ & $0(0,0.5)$ & NS (0.76) \\
\hline Plasma (Units)* & $0(0,2.0)$ & 0 & NS (0.19) \\
\hline Red Blood Cells (Units)* & $1(0,4.5)$ & 0 & 0.002 \\
\hline $\begin{array}{l}\text { Chest tube losses - } 6 \\
\text { hour }(\mathrm{mL})^{*}\end{array}$ & $345.0(220.0,652.5)^{1}$ & $340.0(150.0,437.5)$ & NS (0.35) \\
\hline $\begin{array}{l}\text { Chest tube losses - total } \\
(\mathrm{mL})^{*}\end{array}$ & $890.0(640.0,1090.0)^{2}$ & $830.0(405.0,1085.0)$ & NS (0.39) \\
\hline $\begin{array}{l}\text { Time on ventilation } \\
\text { (hours)* }^{*}\end{array}$ & $6.7(4.6,12.5)^{1}$ & $6.0(4.1,11.2)$ & NS (0.69) \\
\hline LOS CVICU (hours)* & $23.1(21.8,25.6)^{1}$ & $21.3(20.4,22.9)$ & NS $(0.06)$ \\
\hline $\begin{array}{l}\text { Length of hospital stay } \\
\text { (days)* }\end{array}$ & $5.0(5.0,6.0)^{1}$ & $4.0(4.0,5.0)$ & 0.03 \\
\hline $\begin{array}{l}{ }^{*} \text { median }\left(25^{\text {th }}, 75^{\text {th }} \text { percentile); }\right. \\
{ }^{n} n(\%) ; \text { Fisher's Exact Test } \\
\text { LOS, length of stay } \\
\text { NS, non-significant } \\
{ }^{1} n=12 ; \text { missing data } \\
{ }^{2} n=11 \text {; missing data }\end{array}$ & n-Whitney U Test & & \\
\hline
\end{tabular}


Table 12 - Hyperglycemia outcomes (CABG FAST vs. CABG CHO)

\begin{tabular}{|c|c|c|c|}
\hline & $\begin{array}{c}\text { Fast } \\
(n=13)\end{array}$ & $\begin{array}{c}\mathrm{CHO} \\
(n=13)\end{array}$ & $p$-value \\
\hline Intra-op hyperglycemia $^{\dagger}$ & $8(62)$ & $9(69)$ & $\mathrm{NS}(1.00)$ \\
\hline $\begin{array}{l}\text { Insulin within } 24 \text { hours } \\
\text { (Units)* }^{*}\end{array}$ & $0.0(0.0,3.8)^{1}$ & $0.0(0.0,0.0)$ & NS $(0.73)$ \\
\hline Insulin received (yes) ${ }^{\dagger}$ & $5(38)$ & $2(15)$ & NS $(0.38)$ \\
\hline $\begin{array}{l}\text { Average insulin } \\
\text { administered (Units)* }\end{array}$ & $5.0(3.3,16.5)^{2}$ & $14.5(10.0,--)^{3}$ & NS (0.38) \\
\hline $\begin{array}{l}\text { Intra-op hyperglycemic } \\
\text { events* }\end{array}$ & $2.0(0.0,5.0)$ & $1.0(0.0,2.5)$ & NS $(0.45)$ \\
\hline $\begin{array}{l}\text { Postoperative } \\
\text { hyperglycemic events* }\end{array}$ & $4.0(1.5,5.0)$ & $2.0(0.5,3.5)$ & NS $(0.10)$ \\
\hline $\begin{array}{l}\text { OR and postoperative } \\
\text { hyperglycemic events* }\end{array}$ & $5.0(3.5,8.0)$ & $3.0(1.0,5.0)$ & 0.04 \\
\hline $\begin{array}{l}\text { Peak glucose level on } \\
\text { day of surgery } \\
\text { (mmol/L) }\end{array}$ & $10.3(8.8,11.1)$ & $9.4(8.4,10.2)$ & NS $(0.17)$ \\
\hline \multicolumn{4}{|c|}{$\begin{array}{l}\text { NOTES: } \\
\text { 'Hyperglycemia' defined as }>8.0 \mathrm{mmol} / \mathrm{L} \\
\text { 'Insulin received' refers to \# of patients who received insulin during hospital stay } \\
\text { 'Average insulin administered' refers to the average amount of insulin administered to patients who } \\
\quad \text { received insulin }\end{array}$} \\
\hline \multicolumn{4}{|c|}{$\begin{array}{l}{ }^{*} \text { median }\left(25^{\text {th }}, 75^{\text {th }} \text { percentile); Mann-Whitney U Test }\right. \\
{ }^{t} n \text { (\%); Fisher's Exact Test } \\
\text { NS, non-significant } \\
{ }^{n} n=12 \text {; missing data }\end{array}$} \\
\hline
\end{tabular}


Table 13 - Baseline subject characteristics (Spine FAST vs. Spine CHO)

\begin{tabular}{|c|c|c|c|}
\hline & $\begin{array}{l}\text { Fast } \\
(n=6)\end{array}$ & $\begin{array}{l}\mathrm{CHO} \\
(\mathrm{n}=6)\end{array}$ & p-value \\
\hline Age (years)* & $53.0(38.0,60.3)$ & $67(52.0,78.0)$ & $\mathrm{NS}(0.13)$ \\
\hline Body mass index $\left(\mathrm{kg} / \mathrm{m}^{2}\right)^{*}$ & $29.2(24.7,34.9)$ & $25.4(24.0,30.0)$ & NS $(0.31)$ \\
\hline Gender - Male $^{\dagger}$ & $1(17)$ & $2(33)$ & NS (1.00) \\
\hline Smoker ${ }^{\dagger}$ & $1(17)$ & $1(17)$ & NS (1.00) \\
\hline Hypertension $^{\dagger}$ & $1(17)$ & $5(83)$ & NS $(0.08)$ \\
\hline $\begin{array}{l}\text { Family history of heart } \\
\text { disease }^{\dagger}\end{array}$ & $3(50)$ & $1(17)$ & NS $(0.55)$ \\
\hline Hypercholesterolemia $^{\dagger}$ & $3(50)$ & $3(50)$ & NS (1.00) \\
\hline $\begin{array}{l}\text { Peripheral vascular } \\
\text { disease }^{\dagger}\end{array}$ & 0 & $1(17)$ & NS (1.00) \\
\hline Transient ischemic $^{\dagger}$ & 0 & 0 & NS \\
\hline Stroke $^{\dagger}$ & 0 & $1(17)$ & NS (1.00) \\
\hline Respiratory disease $^{\dagger}$ & $1(17)$ & $1(17)$ & NS (1.00) \\
\hline Renal disease $^{\dagger}$ & 0 & 0 & NS \\
\hline Central stenosis $^{\dagger}$ & $5(83)$ & $6(100)$ & NS (1.00) \\
\hline Foraminal stenosis $^{\dagger}$ & $4(67)$ & $5(83)$ & NS (1.00) \\
\hline Deformity $^{\dagger}$ & $1(17)$ & $1(17)$ & NS (1.00) \\
\hline Disc herniation $^{\dagger}$ & 0 & $1(17)$ & NS (1.00) \\
\hline
\end{tabular}

${ }^{\text {*}}$ median $\left(25^{\text {th }}, 75^{\text {th }}\right.$ percentile $)$; Mann-Whitney U Test

${ }^{\dagger} \mathrm{n}(\%)$; Fisher's Exact Test

NS, non-significant 
Table 14 - Measures of insulin sensitivity (Spine FAST vs. Spine CHO)

\begin{tabular}{|c|c|c|c|}
\hline & $\begin{array}{l}\text { Fast } \\
(\mathrm{n}=6)\end{array}$ & $\begin{array}{l}\mathrm{CHO} \\
(\mathrm{n}=6)\end{array}$ & $p$-value \\
\hline $\begin{array}{c}\text { KITT (\%/min) } \\
\text { Baseline }\end{array}$ & $1.64(1.41,2.17)$ & $0.98(0.79,1.19)$ & 0.002 \\
\hline Post-op & $0.41(0.28,0.48)^{a}$ & $0.25(0.20,0.36)^{1 \mathrm{~b}}$ & NS $(0.18)$ \\
\hline Change & $-1.21(-1.82,-1.00)$ & $-0.71(-0.98,-0.45)^{1}$ & 0.02 \\
\hline $\begin{array}{l}\text { Relative IS (\%) } \\
\text { (Post/Pre x 100) }\end{array}$ & $22.1(14.4,33.3)$ & $24.7(18.7,43.8)^{1}$ & NS $(0.66)$ \\
\hline $\begin{array}{l}\text { HOMA-IR (units) } \\
\text { Baseline }\end{array}$ & $1.4(1.1,2.3)$ & $2.5(1.6,3.0)$ & NS (0.24) \\
\hline Post-op & $1.9(1.2,3.0)$ & $2.0(1.3,5.1)$ & NS $(0.70)$ \\
\hline Change & $0.6(-0.6,1.4)$ & $0.2(-1.7,2.5)$ & NS $(0.94)$ \\
\hline $\begin{array}{c}\text { HOMA- } \beta(\%) \\
\text { Baseline }\end{array}$ & $111.6(86.6,736.1)$ & $137.4(81.8,188.3)$ & NS (0.82) \\
\hline Post-op & $31.6(26.5,53.1)^{\mathrm{a}}$ & $73.9(43.7,163.5)$ & NS $(0.18)$ \\
\hline Change & $-77.2(-692.9,-59.0)$ & $-23.2(-135.4,33.5)$ & NS $(0.18)$ \\
\hline $\begin{array}{l}\text { Glucose (mmol/L) } \\
\text { Baseline }\end{array}$ & $4.7(4.4,4.8)$ & $4.9(4.6,5.7)$ & NS (0.31) \\
\hline Post-op & $6.7(6.0,8.1)^{\mathrm{a}}$ & $5.8(5.4,6.4)^{\mathrm{c}}$ & NS (0.09) \\
\hline Change & $2.3(1.3,3.4)$ & $0.8(0.3,1.4)$ & 0.02 \\
\hline $\begin{array}{c}\text { Insulin (pmol/L) } \\
\text { Baseline }\end{array}$ & $46.5(35.5,87.5)$ & $77.0(52.5,84.3)$ & NS (0.59) \\
\hline Post-op & $39.0(28.8,61.3)$ & $53.0(36.0,133.0)$ & NS (0.49) \\
\hline Change & $-8.0(-27.3,7.5)$ & $-4.0(-44.5,57.8)$ & NS $(0.70)$ \\
\hline \multicolumn{4}{|c|}{$\begin{array}{l}\text { median }\left(25^{\text {hn }}, 75^{\text {th }} \text { percentile); Mann-Whitney U Test }\right. \\
\text { KITT, rate of disappearance of blood glucose } \\
\text { HOMA- } \beta \text {, Homeostasis model assessment for } \beta \text {-cell fu } \\
\text { HOMA-IR, Homeostasis model assessment for insulin } \\
\text { NS, non-significant } \\
\text { Wilcoxon Signed Rank Test } \\
\text { a significantly different from baseline, } p=0.03 \\
\text { b significantly different from baseline, } p=0.04 \\
\text { c significantly different from baseline, } p=0.05 \\
{ }^{1} n=5 \text {; SITT not completed }\end{array}$} \\
\hline
\end{tabular}


Table 15 - Blood markers throughout study period (Spine FAST vs. Spine CHO)

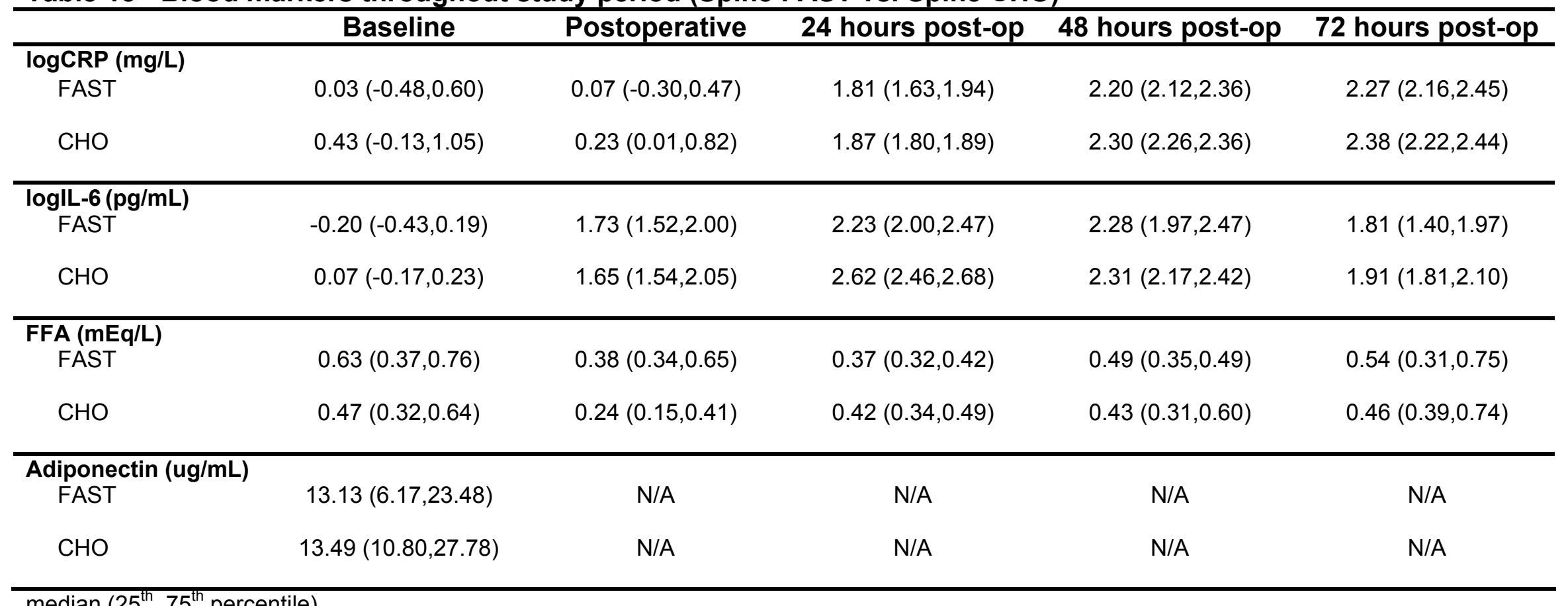

median $\left(25^{\text {th }}, 75^{\text {th }}\right.$ percentile $)$

CRP, C-reactive protein; IL-6, interleukin-6; FFA, free fatty acid

$\mathrm{N} / \mathrm{A}$, not applicable 
Table 16 - Intra and postoperative clinical outcomes (Spine FAST vs. Spine $\mathrm{CHO}$

\begin{tabular}{|c|c|c|c|}
\hline & $\begin{array}{c}\text { Fast } \\
(n=6)\end{array}$ & $\begin{array}{l}\mathrm{CHO} \\
(\mathrm{n}=6)\end{array}$ & $p$-value \\
\hline Levels decompression* & $2.0(1.5,3.0)$ & $2.0(2.0,3.0)$ & NS (0.82) \\
\hline Levels fusion* & $2.0(2.0,3.0)$ & $2.0(2.0,3.0)$ & NS (0.94) \\
\hline OR time $(\min )^{*}$ & $375.0(262.5,442.5)$ & $352.5(298.8,438.8)$ & NS (1.00) \\
\hline Intra-op bleeding $^{\dagger}$ & $1(17)$ & 0 & NS (1.00) \\
\hline Intra-op hypotension ${ }^{\dagger}$ & $2(33)$ & $1(17)$ & NS $(1.00)$ \\
\hline Wound infection $^{\dagger}$ & 0 & 0 & NS \\
\hline Other infection ${ }^{\dagger}$ & 0 & 0 & NS \\
\hline Pneumonia $^{\dagger}$ & 0 & $1(17)$ & NS (1.00) \\
\hline Urinary tract infection ${ }^{\dagger}$ & $1(17)$ & 0 & NS (1.00) \\
\hline Myocardial infarction $^{\dagger}$ & 0 & 0 & NS \\
\hline Post-op inotropes ${ }^{\dagger}$ & 0 & 0 & NS \\
\hline Post-op IABP ${ }^{\dagger}$ & 0 & 0 & NS \\
\hline PE/DVT ${ }^{\dagger}$ & $1(17)$ & 0 & NS (1.00) \\
\hline Complication (Yes) ${ }^{\dagger}$ & $5(83)$ & $5(83)$ & NS (1.00) \\
\hline Total complications $^{\dagger \dagger}$ & 10 & 10 & NS (1.00) \\
\hline
\end{tabular}

${ }^{*}$ median $\left(25^{\text {th }}, 75^{\text {th }}\right.$ percentile); Mann-Whitney U Test

${ }^{\dagger} \mathrm{n}(\%)$; Fisher's Exact Test

${ }^{+\dagger} \mathrm{n}$; Independent Samples T-Test

NS, non-significant 
Table 17 - Other intra and postoperative clinical outcomes (Spine FAST vs. Spine $\mathrm{CHO}$ )

\begin{tabular}{|c|c|c|c|}
\hline & $\begin{array}{l}\text { Fast } \\
(n=6)\end{array}$ & $\begin{array}{l}\mathrm{CHO} \\
(\mathrm{n}=6)\end{array}$ & p-value \\
\hline Transfusion required $^{\dagger}$ & $3(50)$ & $5(83)$ & NS (0.55) \\
\hline Platelets (Units)* & $0(0,1)$ & $0(0,0.5)$ & NS (0.94) \\
\hline Whole blood (Units)* & $0(0,2.0)$ & $0(0,0.3)$ & NS (0.59) \\
\hline Plasma (Units)* & $0(0,2.3)$ & $0(0,2.0)$ & NS (0.94) \\
\hline Red Blood Cells (Units)* & $0(0,4.3)$ & $1(0,4.8)$ & NS (0.49) \\
\hline LOS PACU (hours)* & $3.9(1.7,7.4)$ & $3.4(2.3,4.0)$ & NS (0.59) \\
\hline LOS MSICU (hours)* & $0.0(0.0,24.4)$ & $0.0(0.0,4.5)$ & NS $(0.70)$ \\
\hline $\begin{array}{l}\text { LOS before ward } \\
\text { (hours) }^{*}\end{array}$ & $13.8(3.3,49.3)$ & $3.7(3.2,7.9)$ & NS (0.31) \\
\hline $\begin{array}{l}\text { Length of hospital stay } \\
\text { (days)* }\end{array}$ & $6.5(5.0,13.0)$ & $4.5(4.0,7.3)$ & NS (0.13) \\
\hline \multicolumn{4}{|c|}{$\begin{array}{l}\text { NOTE: 'Time on ventilation' variable not included: only } 1 \text { patient in each group was mechanically } \\
\text { ventilated postoperatively }\end{array}$} \\
\hline \multicolumn{4}{|c|}{$\begin{array}{l}{ }^{*} \text { median }\left(25^{\text {th }}, 75^{\text {th }} \text { percentile); Mann-Whitney U Test }\right. \\
t_{n}(\%) ; \text { Fisher's Exact Test } \\
\text { LOS, length of stay } \\
\text { NS, non-significant }\end{array}$} \\
\hline
\end{tabular}


Table 18 - Hyperglycemia outcomes (Spine FAST vs. Spine CHO)

\begin{tabular}{|c|c|c|c|}
\hline & $\begin{array}{l}\text { Fast } \\
(\mathrm{n}=6)\end{array}$ & $\begin{array}{l}\mathrm{CHO} \\
(\mathrm{n}=6)\end{array}$ & p-value \\
\hline Intra-op hyperglycemia $^{\dagger}$ & $1(17)$ & $1(17)$ & $\mathrm{NS}(1.00)$ \\
\hline $\begin{array}{l}\text { Insulin within } 24 \text { hours } \\
\text { (Units) }^{*}\end{array}$ & 0 & 0 & NS \\
\hline Insulin received (yes) ${ }^{\dagger}$ & 0 & 0 & NS \\
\hline $\begin{array}{l}\text { Average insulin } \\
\text { administered (Units)* }\end{array}$ & 0 & 0 & NS \\
\hline $\begin{array}{l}\text { Intra-op hyperglycemic } \\
\text { events* }\end{array}$ & $0.0(0.0,0.0)$ & $0.0(0.0,0.0)$ & NS (1.00) \\
\hline $\begin{array}{l}\text { Postoperative } \\
\text { hyperglycemic events* }\end{array}$ & $0.0(0.0,0.0)$ & $0.0(0.0,0.0)$ & NS $(0.94)$ \\
\hline $\begin{array}{l}\text { OR and postoperative } \\
\text { hyperglycemic events* }\end{array}$ & $0.0(0.0,0.0)$ & $0.0(0.0,0.0)$ & NS (1.00) \\
\hline $\begin{array}{l}\text { Peak glucose level on } \\
\text { day of surgery } \\
\text { (mmol/L) }\end{array}$ & $7.0(5.0,7.8)$ & $6.6(5.5,8.3)$ & NS (1.00) \\
\hline
\end{tabular}

NOTES:

'Hyperglycemia' defined as $>8.0 \mathrm{mmol} / \mathrm{L}$

'Insulin received' refers to \# of patients who received insulin during hospital stay

'Average insulin administered' refers to the average amount of insulin administered to patients who received insulin

${ }^{*}$ median $\left(25^{\text {th }}, 75^{\text {th }}\right.$ percentile); Mann-Whitney U Test

${ }^{\dagger} \mathrm{n}(\%)$; Fisher's Exact Test

NS, non-significant 
Table 19 - Baseline subject characteristics (Spine vs. CABG)

\begin{tabular}{|c|c|c|c|}
\hline & $\begin{array}{l}\text { Spine } \\
(n=12)\end{array}$ & $\begin{array}{l}\text { CABG } \\
(n=26)\end{array}$ & $p$-value \\
\hline Age (years)* & $60.5(43.0,70.0)$ & $59.0(52.8,64.3)$ & NS (0.96) \\
\hline Body mass index $\left(\mathrm{kg} / \mathrm{m}^{2}\right)^{*}$ & $25.9(24.5,31.8)$ & $26.8(23.8,29.3)$ & NS $(0.68)$ \\
\hline Gender - Male $^{\dagger}$ & $3(25)$ & $21(81)$ & 0.003 \\
\hline Smoker $^{\dagger}$ & $2(17)$ & $15(58)$ & 0.03 \\
\hline Hypertension $^{\dagger}$ & $6(50)$ & $19(73)$ & NS $(0.16)$ \\
\hline $\begin{array}{l}\text { Family history of heart } \\
\text { disease }^{\dagger}\end{array}$ & $4(33)$ & $14(56)^{1}$ & NS $(0.30)$ \\
\hline Hypercholesterolemia $^{\dagger}$ & $6(50)$ & $23(88)$ & 0.02 \\
\hline $\begin{array}{l}\text { Peripheral vascular } \\
\text { disease }^{\dagger}\end{array}$ & $1(8)$ & $3(12)$ & NS (1.00) \\
\hline Transient ischemic $^{\dagger}$ & 0 & 0 & NS \\
\hline Stroke $^{\dagger}$ & $1(8)$ & 0 & NS (0.32) \\
\hline Respiratory disease $^{\dagger}$ & $2(17)$ & $3(12)$ & NS $(0.64)$ \\
\hline Renal disease $^{\dagger}$ & 0 & 0 & NS \\
\hline
\end{tabular}

${ }^{*}$ median $\left(25^{\text {th }}, 75^{\text {th }}\right.$ percentile); Mann-Whitney U Test

${ }^{\dagger} n(\%) ; x^{2}$ or Fisher's Exact Test

NS, non-significant

${ }^{1} \mathrm{n}=25$; missing data 
Table 20 - Measures of insulin sensitivity (Spine vs. CABG)

\begin{tabular}{|c|c|c|c|}
\hline & $\begin{array}{l}\text { Spine } \\
(\mathrm{n}=12) \\
\end{array}$ & $\begin{array}{l}\text { CABG } \\
(n=26)\end{array}$ & p-value \\
\hline $\begin{array}{c}\text { KITT (\%/min) } \\
\text { Baseline }\end{array}$ & $1.29(0.97,1.64)$ & $1.22(0.92,1.65)^{1}$ & NS (0.62) \\
\hline Post-op & $0.30(0.21,0.43)^{2 a}$ & $0.37(0.22,0.51)^{3 b}$ & NS (0.61) \\
\hline Change & $-1.03(-1.21,-0.71)^{2}$ & $-0.83(-1.23,-0.43)^{3}$ & NS (0.35) \\
\hline $\begin{array}{c}\text { Relative IS (\%) } \\
\text { (Post/Pre x 100) }\end{array}$ & $24.7(15.6,31.8)^{2}$ & $31.9(12.8,48.7)$ & NS (0.39) \\
\hline $\begin{array}{l}\text { HOMA-IR (units) } \\
\text { Baseline }\end{array}$ & $1.9(1.3,2.8)$ & $1.9(1.3,2.7)$ & NS (0.96) \\
\hline Post-op & $2.0(1.3,3.1)$ & $2.7(1.0,4.4)^{4}$ & NS (0.89) \\
\hline Change & $0.2(-1.3,1.6)$ & $0.2(-0.6,2.8)^{4}$ & NS $(0.88)$ \\
\hline $\begin{array}{c}\text { HOMA- } \beta(\%) \\
\text { Baseline }\end{array}$ & $117.8(85.2,174.7)$ & $96.3(62.9,126.9)$ & NS $(0.10)$ \\
\hline Post-op & $46.0(27.4,90.1)^{\mathrm{C}}$ & $40.7(29.0,103.9)^{4 d}$ & NS (0.94) \\
\hline Change & $-70.5(-128.4,-19.5)$ & $-37.9(-64.4,-1.1)^{4}$ & NS $(0.23)$ \\
\hline $\begin{array}{l}\text { Glucose (mmol/L) } \\
\text { Baseline }\end{array}$ & $4.7(4.6,5.1)$ & $5.1(5.0,5.5)$ & NS (0.08) \\
\hline Post-op & $6.1(5.7,7.0)^{\mathrm{a}}$ & $6.7(5.5,7.4)^{b}$ & NS $(0.77)$ \\
\hline Change & $1.2(0.8,2.4)$ & $1.2(0.3,2.3)$ & NS (0.51) \\
\hline $\begin{array}{l}\text { Insulin (pmol/L) } \\
\text { Baseline }\end{array}$ & $65.5(40.8,85.3)$ & $51.5(42.0,80.5)$ & NS (0.68) \\
\hline Post-op & $45.5(29.8,75.3)$ & $54.0(26.5,109.0)^{4}$ & NS (0.96) \\
\hline Change & $-8.0(-32.3,23.5)$ & $-7.0(-20.0,46.5)^{4}$ & NS $(0.71)$ \\
\hline
\end{tabular}

median $\left(25^{\text {th }}, 75^{\text {th }}\right.$ percentile); Mann-Whitney $\cup$ Test

KITT, rate of disappearance of blood glucose

HOMA- $\beta$, Homeostasis model assessment for $\beta$-cell function

HOMA-IR, Homeostasis model assessment for insulin resistance

NS, non-significant

Wilcoxon Signed Rank Test

${ }^{a}$ significantly different from baseline, $p=0.003$

${ }^{b}$ significantly different from baseline, $p<0.001$

csignificantly different from baseline, $p=0.02$

${ }^{d}$ significantly different from baseline, $p=0.009$

${ }^{1} \mathrm{n}=25$; SITT not completed

${ }^{2} \mathrm{n}=11$; SITT not completed

${ }^{3} n=24$; SITT not completed

${ }^{4} n=25$; insulin outlier excluded from analysis 
Table 21 - Blood markers throughout study period (Spine vs. CABG)

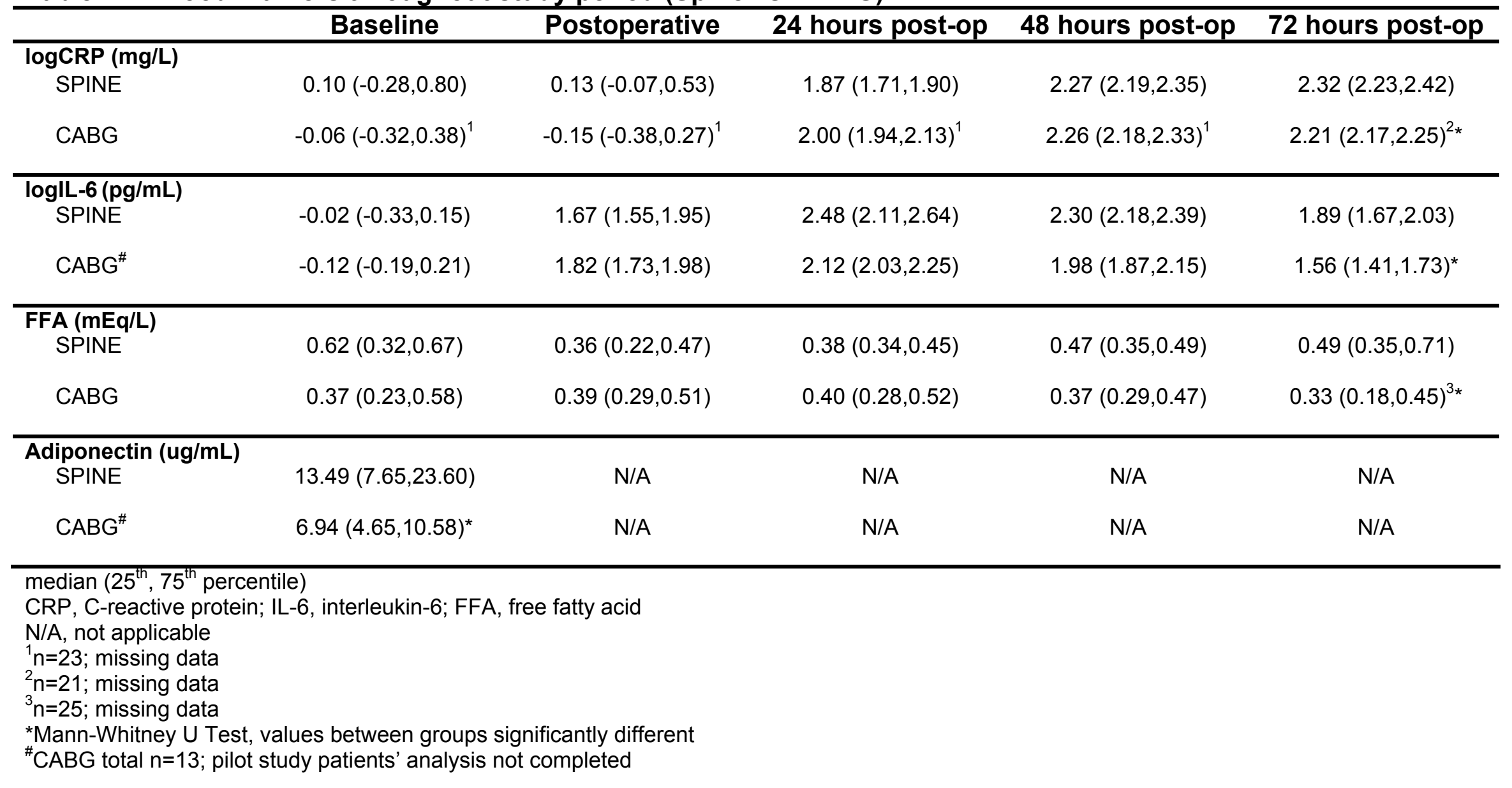


Table 22 - Intra and postoperative clinical outcomes (Spine vs. CABG)

\begin{tabular}{lccc}
\hline & $\begin{array}{c}\text { Spine } \\
(\mathbf{n = 1 2})\end{array}$ & $\begin{array}{c}\text { CABG } \\
(\mathbf{n = 2 6 )}\end{array}$ & p-value \\
\hline OR time (min) $^{*}$ & $357.5(286.3,435.0)$ & $220.0(198.8,240.0)$ & $<0.001$ \\
Intra-op bleeding $^{\dagger}$ & $1(8)$ & $2(8)$ & NS $(1.00)$ \\
Intra-op hypotension $^{\dagger}$ & $3(25)$ & $9(35)$ & NS $(0.71)$ \\
Wound infection $^{\dagger}$ & 0 & $1(4)$ & NS (1.00) \\
Other infection $^{\dagger}$ & 0 & $1(4)$ & NS (1.00) \\
Pneumonia $^{\dagger}$ & $1(8)$ & 0 & NS $(0.32)$ \\
Urinary tract infection $^{\dagger}$ & $1(8)$ & 0 & NS $(0.32)$ \\
Myocardial infarction $^{\dagger}$ & 0 & $1(4)$ & NS (1.00) \\
Post-op inotropes $^{\dagger}$ & 0 & $6(23)^{1}$ & NS $(0.15)$ \\
Post-op IABP $^{\dagger}$ & 0 & $1(4)^{1}$ & NS $(1.00)$ \\
Complication (Yes) $^{\dagger}$ & $10(83)$ & $26(100)$ & NS $(0.09)$ \\
Total complications $^{\dagger \dagger}$ & 20 & 85 & 0.006 \\
\hline
\end{tabular}

\footnotetext{
${ }^{*}$ median $\left(25^{\text {th }}, 75^{\text {th }}\right.$ percentile); Mann-Whitney U Test

${ }^{\dagger} n$ (\%); Fisher's Exact Test

${ }^{\mathrm{t}} \mathrm{n}$; Independent Samples T-Test

NS, non-significant

${ }^{1} \mathrm{n}=25$; missing data
} 
Table 23 - Other intra and postoperative clinical outcomes (Spine vs. CABG)

\begin{tabular}{|c|c|c|c|}
\hline & $\begin{array}{l}\text { Spine } \\
(n=12)\end{array}$ & $\begin{array}{l}\text { CABG } \\
(n=26)\end{array}$ & $p$-value \\
\hline Transfusion required $^{\dagger}$ & $8(67)$ & $12(46)$ & NS (0.31) \\
\hline Platelets (Units)* & $0(0,0)$ & $0(0,0)$ & NS (0.72) \\
\hline Whole blood (Units)* & $0(0,0.8)$ & $0(0,0)$ & NS (0.68) \\
\hline Plasma (Units)* & $0(0,0)$ & $0(0,0)$ & NS (0.91) \\
\hline Red Blood Cells (Units)* & $0.5(0,3.3)$ & $0(0,1.3)$ & NS (0.45) \\
\hline $\begin{array}{l}\text { Time on ventilation } \\
\text { (hours) }{ }^{\star \S}\end{array}$ & $17.8(15.5,--)$ & $6.0(4.7,11.6)$ & 0.05 \\
\hline $\begin{array}{l}\text { LOS before ward } \\
\text { (hours)* }\end{array}$ & $4.0(3.3,22.4)$ & $22.3(21.1,23.5)^{1}$ & 0.009 \\
\hline $\begin{array}{l}\text { Length of hospital stay } \\
\text { (days)* }\end{array}$ & $5.0(2.3,8.0)$ & $5.0(4.0,6.0)^{1}$ & NS (0.19) \\
\hline \multicolumn{4}{|c|}{ 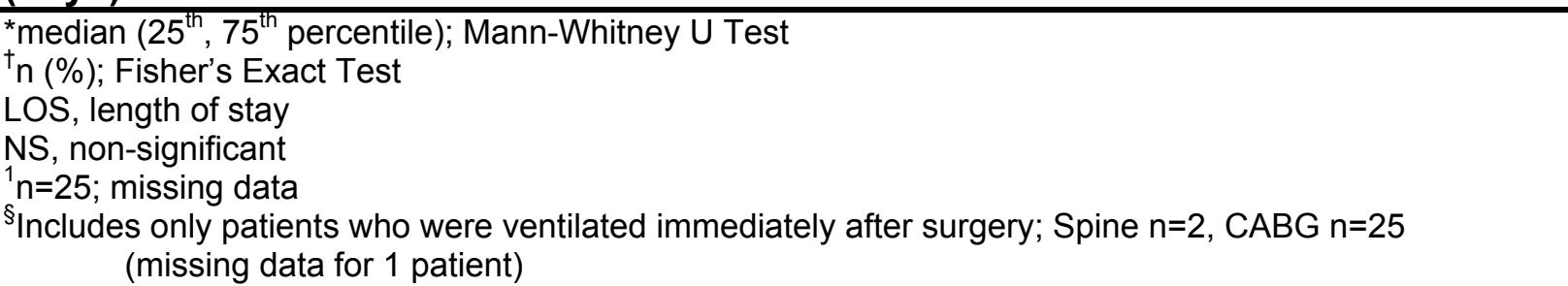 } \\
\hline
\end{tabular}


Table 24 - Hyperglycemia outcomes (Spine vs. CABG)

\begin{tabular}{|c|c|c|c|}
\hline & $\begin{array}{l}\text { Spine } \\
(n=12)\end{array}$ & $\begin{array}{l}\text { CABG } \\
(n=26)\end{array}$ & $p$-value \\
\hline Intra-op hyperglycemia $^{\dagger}$ & $2(17)$ & $17(65)$ & 0.01 \\
\hline $\begin{array}{l}\text { Insulin within } 24 \text { hours } \\
\text { (Units) }^{*}\end{array}$ & 0 & $0(0,0)^{1}$ & NS (0.34) \\
\hline Insulin received (yes) ${ }^{\dagger}$ & 0 & $7(27)$ & NS $(0.07)$ \\
\hline $\begin{array}{l}\text { Average insulin } \\
\text { administered (Units)* }\end{array}$ & $0^{2}$ & $9.0(5.0,19.0)^{3}$ & -- \\
\hline $\begin{array}{l}\text { Intra-op hyperglycemic } \\
\text { events* }\end{array}$ & $0.0(0.0,0.0)$ & $1.0(0.0,3.0)$ & 0.005 \\
\hline $\begin{array}{l}\text { Postoperative } \\
\text { hyperglycemic events* }\end{array}$ & $0.0(0.0,1.0)$ & $2.0(1.0,5.0)$ & 0.001 \\
\hline $\begin{array}{l}\text { OR and postoperative } \\
\text { hyperglycemic events* }\end{array}$ & $0.0(0.0,1.8)$ & $4.5(2.8,7.0)$ & $<0.001$ \\
\hline $\begin{array}{l}\text { Peak glucose level on } \\
\text { day of surgery } \\
\text { (mmol/L) }\end{array}$ & $6.6(5.2,8.0)$ & $9.7(8.5,11.0)$ & $<0.001$ \\
\hline \multicolumn{4}{|c|}{$\begin{array}{l}\text { NOTES: } \\
\text { 'Hyperglycemia' defined as }>8.0 \mathrm{mmol} / \mathrm{L} \\
\text { 'Insulin received' refers to \# of patients who received insulin during hospital stay } \\
\text { 'Average insulin administered' refers to the average amount of insulin administered to patients who } \\
\text { received insulin }\end{array}$} \\
\hline \multicolumn{4}{|c|}{$\begin{array}{l}{ }^{*} \text { median }\left(25^{\text {th }}, 75^{\text {th }} \text { percentile); Mann-Whitney U Test }\right. \\
{ }^{n} n(\%) ; \text { Fisher's Exact Test } \\
\text { NS, non-significant } \\
1 n=25 ; \text { missing data }\end{array}$} \\
\hline
\end{tabular}


Table 25 - Baseline subject characteristics (CABG New vs. CABG Pilot)

\begin{tabular}{|c|c|c|c|}
\hline & $\begin{array}{c}\text { New } \\
(n=13)\end{array}$ & $\begin{array}{c}\text { Pilot } \\
(n=13)\end{array}$ & $p$-value \\
\hline Age (years) & $59.0(52.0,68.5)$ & $58.0(53.0,62.0)$ & NS (0.55) \\
\hline Body mass index $\left(\mathrm{kg} / \mathrm{m}^{2}\right)^{*}$ & $26.9(25.1,29.6)$ & $26.7(22.5,29.4)$ & NS $(0.45)$ \\
\hline Gender - Male ${ }^{\dagger}$ & $12(92)$ & $9(69)$ & NS $(0.32)$ \\
\hline Smoker ${ }^{\dagger}$ & $6(46)$ & $9(69)$ & NS $(0.43)$ \\
\hline Hypertension $^{\dagger}$ & $9(69)$ & $10(77)$ & NS (1.00) \\
\hline $\begin{array}{l}\text { Family history of heart } \\
\text { disease }^{\dagger}\end{array}$ & $11(85)$ & $3(25)^{1}$ & 0.005 \\
\hline Hypercholesterolemia $^{\dagger}$ & $12(92)$ & $11(85)$ & NS (1.00) \\
\hline $\begin{array}{l}\text { Peripheral vascular } \\
\text { disease }^{\dagger}\end{array}$ & $1(8)$ & $2(15)$ & NS (1.00) \\
\hline Transient ischemic $^{\dagger}$ & 0 & 0 & NS \\
\hline Stroke $^{\dagger}$ & 0 & 0 & NS \\
\hline Respiratory disease $^{\dagger}$ & $1(8)$ & $2(15)$ & NS (1.00) \\
\hline Renal disease $^{\dagger}$ & 0 & 0 & NS \\
\hline $\begin{array}{l}\text { CCS Angina Class }^{\dagger} \\
\text { Class I-II } \\
\text { Class III-IV }\end{array}$ & $\begin{array}{l}10(77) \\
3(23)\end{array}$ & $\begin{array}{l}6(46) \\
7(54)\end{array}$ & NS $(0.23)$ \\
\hline $\begin{array}{l}\text { NYHA Class }^{\dagger} \\
\text { Class I-II } \\
\text { Class III-IV }\end{array}$ & $\begin{array}{l}8(89) \\
1(8)^{2}\end{array}$ & $\begin{array}{l}9(75) \\
3(23)^{1}\end{array}$ & NS $(0.60)$ \\
\hline $\begin{array}{l}\text { Left ventricular grade } \\
\text { Grade I-II } \\
\text { Grade III-IV }\end{array}$ & $\begin{array}{c}12(92) \\
1(8)\end{array}$ & $\begin{array}{l}10(77) \\
3(23)\end{array}$ & NS (0.59) \\
\hline $\begin{array}{l}\text { Previous myocardial } \\
\text { infarction }\end{array}$ & $2(15)$ & $4(31)$ & NS (0.65) \\
\hline \multicolumn{2}{|c|}{$\begin{array}{l}{ }^{*} \text { median }\left(25^{\text {th }}, 75^{\text {th }} \text { percentile); Mann-Whitney U Test }\right. \\
{ }^{t} \text { ( }(\%) ; \text { Fisher's Exact Test } \\
\text { CCS, Canadian Cardiovascular Society } \\
\text { NS, non-significant }\end{array}$} & $\begin{array}{l}\text { NYHA, New York Hea } \\
{ }^{1} n=12 \text {; missing data } \\
{ }^{2} n=9 ; \text { missing data }\end{array}$ & ssociation \\
\hline
\end{tabular}


Table 26 - Measures of insulin sensitivity (CABG New vs. CABG Pilot)

\begin{tabular}{|c|c|c|c|}
\hline & $\begin{array}{c}\text { New } \\
(n=13)\end{array}$ & $\begin{array}{c}\text { Pilot } \\
(n=13)\end{array}$ & $p$-value \\
\hline $\begin{array}{c}\text { KITT (\%/min) } \\
\text { Baseline }\end{array}$ & $1.39(1.01,1.65)$ & $0.95(0.82,1.70)^{1}$ & NS (0.54) \\
\hline Post-op & $0.43(0.20,0.58)^{1 \mathrm{a}}$ & $0.34(0.22,0.47)^{1 \mathrm{~b}}$ & NS (0.38) \\
\hline Change & $-0.83(-1.23,-0.60)^{1}$ & $-0.80(-1.45,-0.36)^{1}$ & NS (0.89) \\
\hline $\begin{array}{l}\text { Relative IS (\%) } \\
\text { (Post/Pre x 100) }\end{array}$ & $31.9(15.4,46.4)^{1}$ & $32.5(12.8,53.4)^{1}$ & NS (0.98) \\
\hline $\begin{array}{l}\text { HOMA-IR (units) } \\
\text { Baseline }\end{array}$ & $1.8(1.4,2.6)$ & $2.0(1.2,2.8)$ & NS $(0.84)$ \\
\hline Post-op & $2.8(1.1,4.6)^{2}$ & $1.8(0.8,4.8)$ & NS (0.77) \\
\hline Change & $0.6(-0.6,2.9)^{2}$ & $0.1(-1.0,2.0)$ & NS (0.61) \\
\hline $\begin{array}{c}\text { HOMA- } \beta(\%) \\
\text { Baseline }\end{array}$ & $88.3(61.1,106.3)$ & $108.0(70.7,132.0)$ & NS $(0.29)$ \\
\hline Post-op & $60.1(37.9,99.0)^{2}$ & $35.2(18.8,105.0)^{c}$ & NS (0.25) \\
\hline Change & $-29.9(-59.4,7.8)^{2}$ & $-44.7(-82.1,-12.0)$ & NS (0.32) \\
\hline $\begin{array}{l}\text { Glucose (mmol/L) } \\
\text { Baseline }\end{array}$ & $5.3(5.0,5.7)$ & $5.1(4.9,5.5)$ & NS (0.42) \\
\hline Post-op & $6.2(5.6,6.8)^{d}$ & $6.8(5.4,8.1)^{d}$ & NS (0.29) \\
\hline Change & $0.9(0.3,1.7)$ & $1.9(0.5,2.5)$ & NS (0.15) \\
\hline $\begin{array}{l}\text { Insulin (pmol/L) } \\
\text { Baseline }\end{array}$ & $48.0(43.5,75.0)$ & $61.0(36.5,88.5)$ & NS (0.76) \\
\hline Post-op & $60.0(31.0,108.5)^{2}$ & $44.0(21.0,117.0)$ & NS (0.57) \\
\hline Change & $7.5(-19.0,47.8)^{2}$ & $-7.0(-49.0,38.0)$ & NS (0.54) \\
\hline
\end{tabular}

median $\left(25^{\text {th }}, 75^{\text {th }}\right.$ percentile); Mann-Whitney $U$ Test

KITT, rate of disappearance of blood glucose

HOMA- $\beta$, Homeostasis model assessment for $\beta$-cell function

HOMA-IR, Homeostasis model assessment for insulin resistance

NS, non-significant

Wilcoxon Signed Rank Test

${ }^{a}$ significantly different from baseline, $p=0.004$

${ }^{b}$ significantly different from baseline, $p=0.002$

'significantly different from baseline, $p=0.03$

'significantly different from baseline, $p=0.003$

${ }^{1} \mathrm{n}=12$; SITT not completed

${ }^{2} n=12$; insulin outlier excluded from analysis 
Table 27 - Blood markers throughout study period (CABG New vs. CABG Pilot)

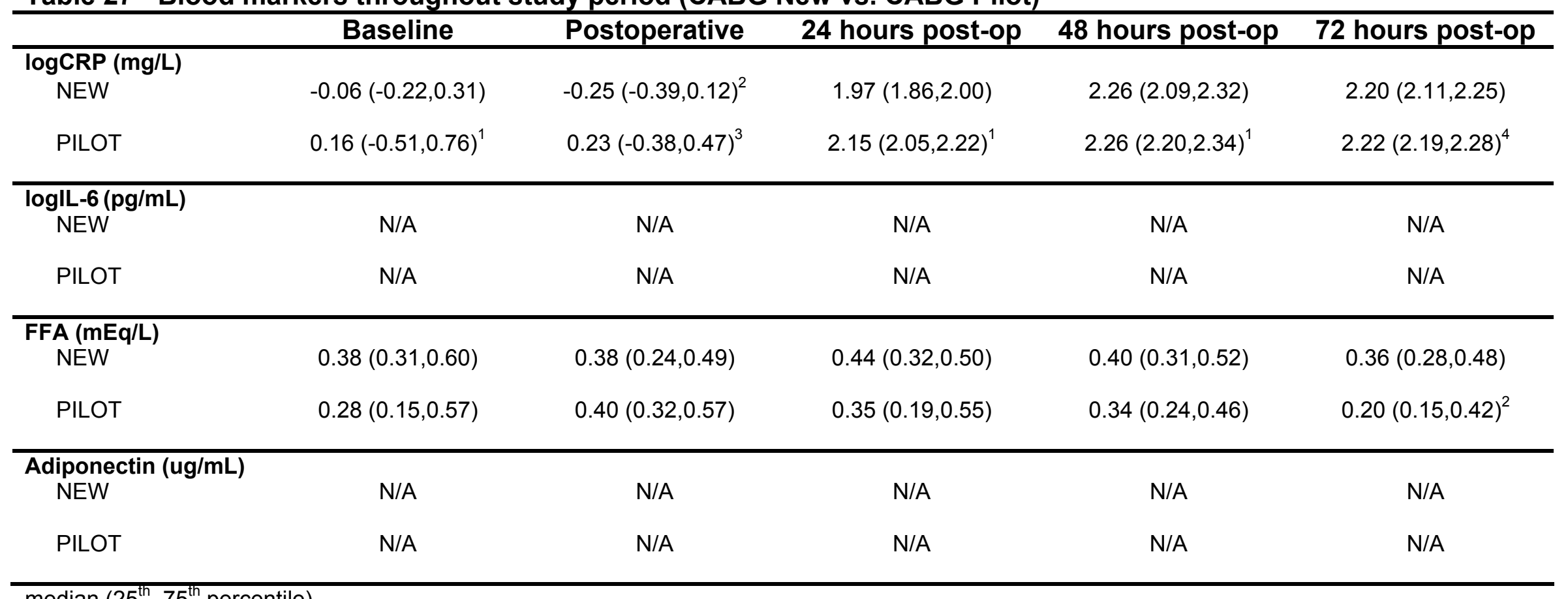

median $\left(25^{\text {th }}, 75^{\text {th }}\right.$ percentile $)$

CRP, C-reactive protein; IL-6, interleukin-6; FFA, free fatty acid

$\mathrm{N} / \mathrm{A}$, not applicable

${ }^{1} \mathrm{n}=10$; missing data

${ }^{2} \mathrm{n}=12$; missing data

${ }^{3} n=11$; missing data

${ }^{4} n=8$; missing data 
Table 28 - Intra and postoperative clinical outcomes (CABG New vs. CABG Pilot)

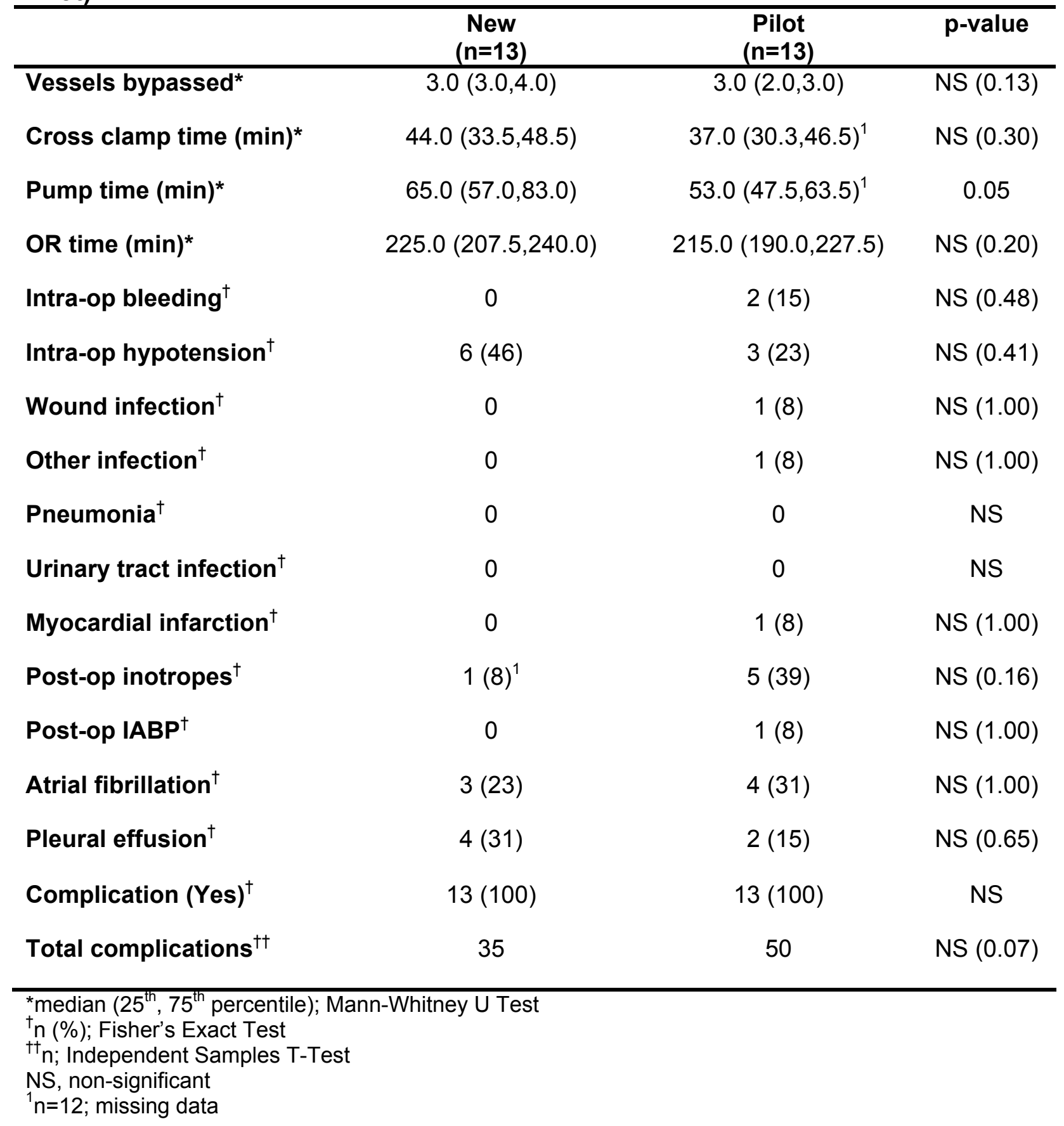


Table 29 - Other intra and postoperative clinical outcomes (CABG New vs. CABG Pilot)

\begin{tabular}{|c|c|c|c|}
\hline & $\begin{array}{c}\text { New } \\
(n=13)\end{array}$ & $\begin{array}{c}\text { Pilot } \\
(n=13)\end{array}$ & p-value \\
\hline Transfusion required $^{\dagger}$ & $2(15)$ & $10(77)$ & 0.005 \\
\hline Platelets (Units)* & 0 & $0(0,0)$ & NS (0.51) \\
\hline Whole blood (Units)* & 0 & $0(0,1)$ & NS $(0.10)$ \\
\hline Plasma (Units)* & 0 & $0(0,2)$ & NS (0.19) \\
\hline Red Blood Cells (Units) & $0(0,0)$ & $1(0,4.5)$ & NS (0.07) \\
\hline $\begin{array}{l}\text { Chest tube losses - } 6 \\
\text { hour }(m L)^{*}\end{array}$ & $300.0(152.5,387.5)^{1}$ & $450.0(259.0,625.0)$ & NS (0.19) \\
\hline $\begin{array}{l}\text { Chest tube losses - } \\
\text { total }(\mathrm{mL})^{*}\end{array}$ & $665.0(392.5,865.0)^{1}$ & $1080.0(680.0,1165.0)^{1}$ & 0.01 \\
\hline $\begin{array}{l}\text { Time on ventilation } \\
\text { (hours)* }\end{array}$ & $4.8(3.3,7.8)$ & $10.9(6.3,14.1)^{1}$ & 0.004 \\
\hline LOS CVICU (hours)* & $21.3(20.4,22.5)$ & $23.5(22.0,25.9)^{1}$ & 0.01 \\
\hline $\begin{array}{l}\text { Length of hospital stay } \\
\text { (days)* }\end{array}$ & $4.0(4.0,5.0)$ & $5.5(4.3,6.0)^{1}$ & 0.05 \\
\hline $\begin{array}{l}{ }^{*} \text { median }\left(25^{\text {th }}, 75^{\text {th }} \text { percentile); }\right. \\
\left.{ }^{n} \text { ( } \%\right) \text {; Fisher's Exact Test } \\
\text { LOS, length of stay } \\
\text { NS, non-significant } \\
\text { 'n=12; missing data }\end{array}$ & Vhitney U Test & & \\
\hline
\end{tabular}


Table 30 - Hyperglycemia outcomes (CABG New vs. CABG Pilot)

\begin{tabular}{|c|c|c|c|}
\hline & $\begin{array}{c}\text { New } \\
(n=13)\end{array}$ & $\begin{array}{c}\text { Pilot } \\
(n=13)\end{array}$ & p-value \\
\hline Intra-op hyperglycemia ${ }^{\dagger}$ & $8(62)$ & $9(69)$ & $\mathrm{NS}(1.00)$ \\
\hline $\begin{array}{l}\text { Insulin within } 24 \text { hours } \\
\text { (Units)* }^{*}\end{array}$ & $0.0(0.0,8.0)^{1}$ & $0.0(0.0,0.0)$ & NS (0.35) \\
\hline Insulin received (yes) ${ }^{\dagger}$ & $6(46)$ & $1(8)$ & NS (0.07) \\
\hline $\begin{array}{l}\text { Average insulin } \\
\text { administered (Units)* }\end{array}$ & $7.0(4.1,12.3)^{2}$ & $0^{3}$ & NS (0.29) \\
\hline $\begin{array}{l}\text { Intra-op hyperglycemic } \\
\text { events* }\end{array}$ & $1.0(0.0,4.0)$ & $2.0(0.0,3.0)$ & NS (1.00) \\
\hline $\begin{array}{l}\text { Postoperative } \\
\text { hyperglycemic events* }\end{array}$ & $3.0(1.0,5.0)$ & $2.0(1.0,4.5)$ & NS $(0.72)$ \\
\hline $\begin{array}{l}\text { OR and postoperative } \\
\text { hyperglycemic events* }\end{array}$ & $5.0(1.5,7.0)$ & $4.0(3.0,5.0)$ & NS $(0.58)$ \\
\hline $\begin{array}{l}\text { Peak glucose level on } \\
\text { day of surgery } \\
\text { (mmol/L) }\end{array}$ & $8.7(8.3,10.7)$ & $9.9(9.1,11.2)$ & NS $(0.20)$ \\
\hline \multicolumn{4}{|c|}{$\begin{array}{l}\text { NOTES: } \\
\text { 'Hyperglycemia' defined as }>8.0 \mathrm{mmol} / \mathrm{L} \\
\text { 'Insulin received' refers to \# of patients who received insulin during hospital stay } \\
\text { 'Average insulin administered' refers to the average amount of insulin administered to patients who } \\
\quad \text { received insulin }\end{array}$} \\
\hline \multicolumn{4}{|c|}{$\begin{array}{l}{ }^{*} \text { median }\left(25^{\text {th }}, 75^{\text {th }} \text { percentile); Mann-Whitney U Test }\right. \\
t_{n}(\%) ; \text { Fisher's Exact Test } \\
\text { NS, non-significant } \\
{ }^{n} n=12 ; \text { missing data }\end{array}$} \\
\hline
\end{tabular}


Table 31 - Baseline subject characteristics (FAST CABG: New vs. Pilot)

\begin{tabular}{|c|c|c|c|}
\hline & $\begin{array}{c}\text { New } \\
(n=6)\end{array}$ & $\begin{array}{l}\text { Pilot } \\
(\mathrm{n}=7)\end{array}$ & p-value \\
\hline Age (years)* & $62.0(57.0,72.0)$ & $59.0(54.0,64.0)$ & NS (0.53) \\
\hline Body mass index $\left(\mathrm{kg} / \mathrm{m}^{2}\right)^{*}$ & $25.6(24.1,27.5)$ & $25.1(22.5,29.3)$ & NS (1.00) \\
\hline Gender - Male ${ }^{\dagger}$ & $5(83)$ & $3(43)$ & NS (0.27) \\
\hline Smoker $^{\dagger}$ & $4(67)$ & $5(71)$ & NS (1.00) \\
\hline Hypertension $^{\dagger}$ & $4(67)$ & $6(86)$ & NS (0.56) \\
\hline $\begin{array}{l}\text { Family history of heart } \\
\text { disease }^{\dagger}\end{array}$ & $6(100)$ & $2(29)$ & 0.02 \\
\hline Hypercholesterolemia $^{\dagger}$ & $6(100)$ & $6(86)$ & NS (1.00) \\
\hline $\begin{array}{l}\text { Peripheral vascular } \\
\text { disease }^{\dagger}\end{array}$ & 0 & $1(14)$ & NS (1.00) \\
\hline Transient ischemic $^{\dagger}$ & 0 & 0 & NS \\
\hline Stroke $^{\dagger}$ & 0 & 0 & NS \\
\hline Respiratory disease $^{\dagger}$ & 0 & $2(29)$ & NS $(0.46)$ \\
\hline Renal disease $^{\dagger}$ & 0 & 0 & NS \\
\hline $\begin{array}{c}\text { CCS Angina Class }^{\dagger} \\
\text { Class I-II } \\
\text { Class III-IV }\end{array}$ & $\begin{array}{l}4(67) \\
2(33)\end{array}$ & $\begin{array}{l}3(43) \\
4(57)\end{array}$ & NS (0.59) \\
\hline $\begin{array}{l}\text { NYHA Class }^{\dagger} \\
\text { Class I-II } \\
\text { Class III-IV }\end{array}$ & $\begin{array}{l}3(75) \\
1(25)^{1}\end{array}$ & $\begin{array}{l}5(83) \\
1(17)^{2}\end{array}$ & NS (1.00) \\
\hline $\begin{array}{c}\text { Left ventricular grade } \\
\text { Grade I-II } \\
\text { Grade III-IV }\end{array}$ & $\begin{array}{l}5(83) \\
1(17)\end{array}$ & $\begin{array}{l}5(71) \\
2(29)\end{array}$ & NS (1.00) \\
\hline $\begin{array}{l}\text { Previous myocardial } \\
\text { infarction }\end{array}$ & $2(33)$ & $4(67)$ & NS (0.59) \\
\hline \multicolumn{2}{|c|}{$\begin{array}{l}{ }^{*} \text { median }\left(25^{\text {th }}, 75^{\text {th }} \text { percentile); Mann-Whitney U Test }\right. \\
{ }^{t} n \text { (\%); Fisher's Exact Test } \\
\text { CCS, Canadian Cardiovascular Society } \\
\text { NS, non-significant } \\
\text { NYHA, New York Heart Association }\end{array}$} & $\begin{array}{l}{ }^{1} \mathrm{n}=4 ; \text { missing } \\
{ }^{2} \mathrm{n}=6 ; \text { missing }\end{array}$ & \\
\hline
\end{tabular}


Table 32 - Measures of insulin sensitivity (FAST CABG: New vs. Pilot)

\begin{tabular}{|c|c|c|c|}
\hline & $\begin{array}{l}\text { New } \\
(n=6)\end{array}$ & $\begin{array}{l}\text { Pilot } \\
(n=7)\end{array}$ & p-value \\
\hline $\begin{array}{c}\text { KITT (\%/min) } \\
\text { Baseline }\end{array}$ & $1.52(1.08,1.82)$ & $0.95(0.68,2.05)^{1}$ & NS (0.59) \\
\hline Post-op & $0.42(-0.13,0.45)^{a}$ & $0.26(0.20,0.44)^{1 \mathrm{a}}$ & NS $(0.82)$ \\
\hline Change & $-1.10(-2.25,-0.65)$ & $-0.60(-1.85,-0.29)^{1}$ & NS (0.49) \\
\hline $\begin{array}{l}\text { Relative IS (\%) } \\
\text { (Post/Pre x 100) }\end{array}$ & $28.3(-8.8,43.3)$ & $30.5(11.5,60.8)^{1}$ & NS $(0.70)$ \\
\hline $\begin{array}{l}\text { HOMA-IR (units) } \\
\text { Baseline }\end{array}$ & $1.8(1.3,1.8)$ & $1.9(1.1,2.6)$ & NS (0.63) \\
\hline Post-op & $3.3(1.4,5.1)$ & $1.5(0.4,2.7)$ & NS $(0.14)$ \\
\hline Change & $1.8(-0.5,3.4)$ & $-0.4(-1.7,0.1)$ & NS $(0.10)$ \\
\hline $\begin{array}{c}\text { HOMA- } \beta(\%) \\
\text { Baseline }\end{array}$ & $73.9(56.6,95.8)$ & $108.0(61.2,229.4)$ & NS $(0.14)$ \\
\hline Post-op & $55.1(36.0,121.9)$ & $21.1(9.2,37.9)^{b}$ & 0.05 \\
\hline Change & $-15.7(-39.7,60.7)$ & $-65.3(-194.2,-38.6)$ & 0.008 \\
\hline $\begin{array}{l}\text { Glucose (mmol/L) } \\
\text { Baseline }\end{array}$ & $5.3(5.0,6.0)$ & $5.1(4.7,5.1)$ & NS $(0.37)$ \\
\hline Post-op & $6.4(6.2,7.1)^{\mathrm{a}}$ & $7.0(5.4,8.9)^{b}$ & NS $(0.84)$ \\
\hline Change & $1.2(0.5,2.0)$ & $1.9(0.6,3.3)$ & NS $(0.45)$ \\
\hline $\begin{array}{l}\text { Insulin (pmol/L) } \\
\text { Baseline }\end{array}$ & $46.5(42.0,50.3)$ & $60.0(34.0,100.0)$ & NS (0.53) \\
\hline Post-op & $70.5(33.8,122.5)$ & $28.0(10.0,54.0)^{b}$ & 0.05 \\
\hline Change & $27.0(-19.0,78.0)$ & $-18.0(-56.0,-7.0)$ & NS $(0.07)$ \\
\hline \multicolumn{4}{|c|}{$\begin{array}{l}\text { median }\left(25^{\text {th }}, 75^{\text {th }} \text { percentile); Mann-Whitney U Test }\right. \\
\text { KITT, rate of disappearance of blood glucose } \\
\text { HOMA- } \beta \text {, Homeostasis model assessment for } \beta \text {-cell function } \\
\text { HOMA-IR, Homeostasis model assessment for insulin resistance } \\
\text { NS, non-significant } \\
\text { Wilcoxon Signed Rank Test } \\
\text { a significantly different from baseline, } p=0.03 \\
\text { bsignificantly different from baseline, } p=0.02 \\
\text { 1n=6; SITT not completed }\end{array}$} \\
\hline
\end{tabular}


Table 33 - Blood markers throughout study period (FAST CABG: New vs. Pilot)

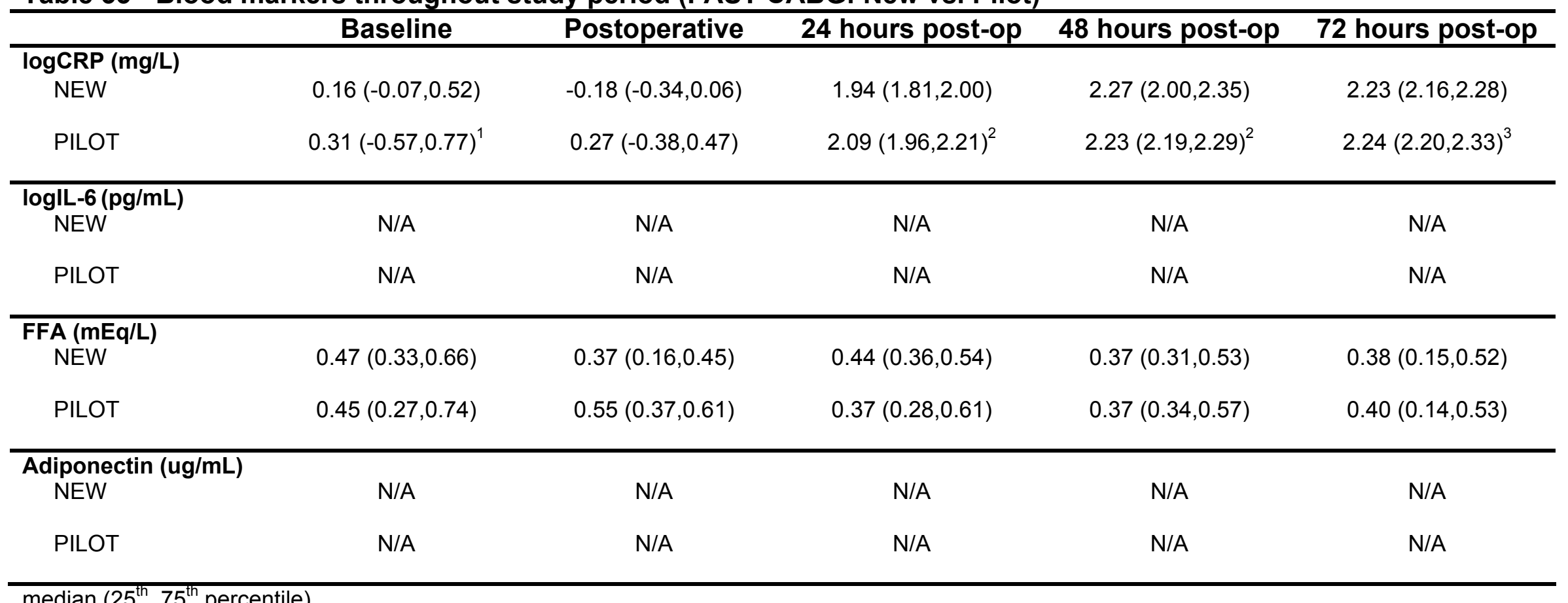

median $\left(25^{\text {th }}, 75^{\text {th }}\right.$ percentile $)$

CRP, C-reactive protein; IL-6, interleukin-6; FFA, free fatty acid

$\mathrm{N} / \mathrm{A}$, not applicable

${ }^{1} \mathrm{n}=5$; missing data

${ }^{2} \mathrm{n}=6$; missing data

${ }^{3} \mathrm{n}=4$; missing data 
Table 34 - Intra and postoperative clinical outcomes (FAST CABG: New vs. Pilot)

\begin{tabular}{|c|c|c|c|}
\hline & $\begin{array}{c}\text { New } \\
(n=6)\end{array}$ & $\begin{array}{l}\text { Pilot } \\
(n=7)\end{array}$ & $p$-value \\
\hline Vessels bypassed ${ }^{*}$ & $3.5(3.0,4.0)$ & $3.0(2.0,3.0)$ & NS (0.10) \\
\hline Cross clamp time $(\mathrm{min})^{*}$ & $44.0(34.5,55.0)$ & $39.0(29.3,51.3)^{1}$ & NS (0.59) \\
\hline Pump time (min)* & $65.0(56.3,77.8)$ & $57.0(48.3,68.8)^{1}$ & NS $(0.31)$ \\
\hline OR time $(\min )^{*}$ & $230.0(203.8,240.0)$ & $215.0(190.0,225.0)$ & NS $(0.53)$ \\
\hline Intra-op bleeding ${ }^{\dagger}$ & 0 & $2(29)$ & NS $(0.46)$ \\
\hline Intra-op hypotension $^{\dagger}$ & $4(67)$ & $2(29)$ & NS (0.29) \\
\hline Wound infection $^{\dagger}$ & 0 & 0 & NS \\
\hline Other infection ${ }^{\dagger}$ & 0 & $1(14)$ & NS (1.00) \\
\hline Pneumonia $^{\dagger}$ & 0 & 0 & NS \\
\hline Urinary tract infection $^{\dagger}$ & 0 & 0 & NS \\
\hline Myocardial infarction $^{\dagger}$ & 0 & $1(14)$ & NS (1.00) \\
\hline Post-op inotropes $^{\dagger}$ & $1(20)^{2}$ & $2(29)$ & NS (1.00) \\
\hline Post-op IABP ${ }^{\dagger}$ & $0^{2}$ & $1(14)$ & NS (1.00) \\
\hline Atrial fibrillation $^{\dagger}$ & $1(17)$ & $3(43)$ & NS (0.56) \\
\hline Pleural effusion $^{\dagger}$ & $2(33)$ & $2(29)$ & NS (1.00) \\
\hline Complication (Yes) ${ }^{\dagger}$ & $6(100)$ & $7(100)$ & NS \\
\hline Total complications $^{\dagger \dagger}$ & 19 & 32 & NS (0.17) \\
\hline
\end{tabular}

\footnotetext{
${ }^{*}$ median $\left(25^{\text {th }}, 75^{\text {th }}\right.$ percentile); Mann-Whitney U Test

${ }^{\dagger} \mathrm{n}$ (\%); Fisher's Exact Test

${ }^{\mathrm{t}} \mathrm{n}$; Independent Samples T-Test

NS, non-significant

${ }^{1} n=6$; missing data

${ }^{2} \mathrm{n}=5$; missing data
} 
Table 35 - Other intra and postoperative clinical outcomes (FAST CABG: New vs. Pilot)

\begin{tabular}{|c|c|c|c|}
\hline & $\begin{array}{l}\text { New } \\
(n=6)\end{array}$ & $\begin{array}{l}\text { Pilot } \\
(n=7)\end{array}$ & $p$-value \\
\hline Transfusion required $^{\dagger}$ & $2(33)$ & $7(100)$ & 0.02 \\
\hline Platelets (Units)* & 0 & $0(0,5)$ & NS $(0.45)$ \\
\hline Whole blood (Units)* & 0 & $0(0,1)$ & NS (0.45) \\
\hline Plasma (Units)* & 0 & $2(0,4)$ & NS $(0.10)$ \\
\hline Red Blood Cells (Units)* & $0(0,1.5)$ & $4(0,5)$ & 0.008 \\
\hline $\begin{array}{l}\text { Chest tube losses - } 6 \\
\text { hour }(m L)^{*}\end{array}$ & $290.0(175.0,530.0)^{1}$ & $580.0(280.0,1170.0)$ & NS $(0.43)$ \\
\hline $\begin{array}{l}\text { Chest tube losses - } \\
\text { total }(\mathrm{mL})^{*}\end{array}$ & $690.0(500.0,950.0)^{1}$ & $1055.0(807.5,1512.0)^{2}$ & NS $(0.13)$ \\
\hline $\begin{array}{l}\text { Time on ventilation } \\
\text { (hours) }\end{array}$ & $4.7(3.8,5.4)$ & $12.0(10.0,18.9)^{2}$ & 0.002 \\
\hline LOS CVICU (hours)* & $21.8(20.1,22.6)$ & $24.9(23.5,42.9)^{2}$ & 0.002 \\
\hline $\begin{array}{l}\text { Length of hospital stay } \\
\text { (days)* }\end{array}$ & $5.0(4.0,5.0)$ & $6.0(5.8,8.3)^{2}$ & 0.009 \\
\hline $\begin{array}{l}{ }^{*} \text { median }\left(25^{\text {th }}, 75^{\text {th }} \text { percentile); }\right. \\
{ }_{n}^{n}(\%) ; \text { Fisher's Exact Test } \\
\text { LOS, length of stay } \\
\text { NS, non-significant } \\
{ }^{n} n=5 ; \text { missing data } \\
{ }^{n} n=6 ; \text {; missing data }\end{array}$ & -Whitney U Test & & \\
\hline
\end{tabular}


Table 36 - Hyperglycemia outcomes (FAST CABG: New vs. Pilot)

\begin{tabular}{|c|c|c|c|}
\hline & $\begin{array}{c}\text { New } \\
(n=6)\end{array}$ & $\begin{array}{l}\text { Pilot } \\
(n=7)\end{array}$ & p-value \\
\hline Intra-op hyperglycemia $^{\dagger}$ & $4(67)$ & $4(57)$ & NS (1.00) \\
\hline $\begin{array}{l}\text { Insulin within } 24 \text { hours } \\
\text { (Units)* }^{*}\end{array}$ & $0.0(0.0,7.0)^{1}$ & $0.0(0.0,0.0)$ & NS (0.64) \\
\hline Insulin received (yes) ${ }^{\dagger}$ & $4(67)$ & $1(14)$ & NS $(0.10)$ \\
\hline $\begin{array}{l}\text { Average insulin } \\
\text { administered (Units)* }\end{array}$ & $5.0(2.4,8.0)^{2}$ & $0^{3}$ & NS $(0.40)$ \\
\hline $\begin{array}{l}\text { Intra-op hyperglycemic } \\
\text { events* }\end{array}$ & $4.0(0.0,5.5)$ & $1.0(0.0,3.0)$ & NS $(0.30)$ \\
\hline $\begin{array}{l}\text { Postoperative } \\
\text { hyperglycemic events* }\end{array}$ & $3.0(0.8,5.0)$ & $4.0(2.0,8.0)$ & NS (0.37) \\
\hline $\begin{array}{l}\text { OR and postoperative } \\
\text { hyperglycemic events* }\end{array}$ & $6.0(4.0,8.3)$ & $5.0(3.0,9.0)$ & NS $(0.73)$ \\
\hline $\begin{array}{l}\text { Peak glucose level on } \\
\text { day of surgery } \\
\text { (mmol/L)* }\end{array}$ & $9.6(8.3,11.0)$ & $10.3(9.5,11.2)$ & NS (0.23) \\
\hline
\end{tabular}

NOTES:

'Hyperglycemia' defined as $>8.0 \mathrm{mmol} / \mathrm{L}$

'Insulin received' refers to \# of patients who received insulin during hospital stay

'Average insulin administered' refers to the average amount of insulin administered to patients who received insulin

${ }^{*}$ median $\left(25^{\text {th }}, 75^{\text {th }}\right.$ percentile $)$; Mann-Whitney U Test

${ }^{\dagger} \mathrm{n}(\%)$; Fisher's Exact Test

NS, non-significant

${ }^{1} n=5$; missing data

${ }^{2} n=4$; number of patients administered insulin in New group

${ }^{3} n=1$; number of patients administered insulin in Pilot group 
Table 37 - Baseline subject characteristics (CHO CABG: New vs. Pilot)

\begin{tabular}{|c|c|c|c|}
\hline & $\begin{array}{l}\text { New } \\
(n=7)\end{array}$ & $\begin{array}{l}\text { Pilot } \\
(n=6)\end{array}$ & $p$-value \\
\hline Age (years)* & $53.0(49.0,67.0)$ & $56.5(48.3,60.3)$ & NS (0.84) \\
\hline Body mass index $\left(\mathrm{kg} / \mathrm{m}^{2}\right)^{*}$ & $27.5(26.3,37.2)$ & $27.9(22.0,30.0)$ & NS $(0.45)$ \\
\hline Gender - Male ${ }^{\dagger}$ & $7(100)$ & $6(100)$ & NS \\
\hline Smoker ${ }^{\dagger}$ & $2(29)$ & $4(67)$ & NS (0.29) \\
\hline Hypertension $^{\dagger}$ & $5(71)$ & $4(67)$ & NS (1.00) \\
\hline $\begin{array}{l}\text { Family history of heart } \\
\text { disease }^{\dagger}\end{array}$ & $5(71)$ & $1(20)^{1}$ & NS $(0.24)$ \\
\hline Hypercholesterolemia $^{\dagger}$ & $6(86)$ & $5(83)$ & NS (1.00) \\
\hline $\begin{array}{l}\text { Peripheral vascular } \\
\text { disease }^{\dagger}\end{array}$ & $1(14)$ & $1(17)$ & NS (1.00) \\
\hline Transient ischemic $^{\dagger}$ & 0 & 0 & NS \\
\hline Stroke $^{\dagger}$ & 0 & 0 & NS \\
\hline Respiratory disease $^{\dagger}$ & $1(14)$ & 0 & NS (1.00) \\
\hline Renal disease $^{\dagger}$ & 0 & 0 & NS \\
\hline $\begin{array}{l}\text { Ccs Angina Class }^{\dagger} \\
\text { Class I-II } \\
\text { Class III-IV }\end{array}$ & $\begin{array}{l}6(86) \\
1(14)\end{array}$ & $\begin{array}{l}3(50) \\
3(50)\end{array}$ & NS $(0.27)$ \\
\hline $\begin{array}{l}\text { NYHA } \text { Class }^{\dagger} \\
\text { Class I-II }^{\text {Class III-IV }}\end{array}$ & $\begin{array}{c}5(100) \\
0^{1}\end{array}$ & $\begin{array}{l}4(67) \\
2(33)\end{array}$ & NS (0.46) \\
\hline $\begin{array}{l}\text { Left ventricular } \text { grade }^{\dagger} \\
\text { Grade I-II } \\
\text { Grade III-IV }\end{array}$ & $\begin{array}{c}7(100) \\
0\end{array}$ & $\begin{array}{l}5(83) \\
1(17)\end{array}$ & NS (0.46) \\
\hline $\begin{array}{l}\text { Previous myocardial } \\
\text { infarction }\end{array}$ & 0 & 0 & NS \\
\hline \multicolumn{2}{|c|}{$\begin{array}{l}{ }^{*} \text { median }\left(25^{\text {th }}, 75^{\text {th }} \text { percentile); Mann-Whitney U Test }\right. \\
{ }^{n} n \text { (\%); Fisher's Exact Test } \\
\text { CCS, Canadian Cardiovascular Society } \\
\text { NS, non-significant } \\
\text { NYHA, New York Heart Association }\end{array}$} & $n=5 ;$ missing & \\
\hline
\end{tabular}


Table 38 - Measures of insulin sensitivity (CHO CABG: New vs. Pilot)

\begin{tabular}{|c|c|c|c|}
\hline & $\begin{array}{l}\text { New } \\
(n=7)\end{array}$ & $\begin{array}{l}\text { Pilot } \\
(n=6)\end{array}$ & $p$-value \\
\hline $\begin{array}{c}\text { KITT (\%/min) } \\
\text { Baseline }\end{array}$ & $1.31(0.93,1.53)$ & $1.08(0.85,1.89)$ & NS (0.95) \\
\hline Post-op & $0.56(0.25,0.70)^{1 a}$ & $0.36(0.26,0.53)^{b}$ & NS $(0.31)$ \\
\hline Change & $-0.69(-0.94,-0.36)^{1}$ & $-0.89(-1.34,-0.39)$ & NS (0.49) \\
\hline $\begin{array}{l}\text { Relative IS (\%) } \\
\text { (Post/Pre x 100) }\end{array}$ & $45.1(25.1,76.1)^{1}$ & $32.9(11.2,50.7)$ & NS (0.59) \\
\hline $\begin{array}{l}\text { HOMA-IR (units) } \\
\text { Baseline }\end{array}$ & $2.4(1.5,2.9)$ & $2.2(1.0,3.0)$ & NS $(0.84)$ \\
\hline Post-op & $1.9(0.8,4.5)^{2}$ & $4.7(1.2,7.5)$ & NS (0.39) \\
\hline Change & $0.2(-1.0,1.6)^{2}$ & $1.9(-0.3,5.4)$ & NS $(0.31)$ \\
\hline $\begin{array}{c}\text { HOMA- } \beta \text { (\%) } \\
\text { Baseline }\end{array}$ & $98.9(63.4,167.4)$ & $100.6(62.4,126.9)$ & NS $(0.84)$ \\
\hline Post-op & $60.6(38.1,86.4)^{2 a}$ & $105.0(27.4,124.8)$ & NS (0.49) \\
\hline Change & $-45.6(-85.4,-11.1)^{2}$ & $-12.0(-55.1,47.1)$ & NS $(0.24)$ \\
\hline $\begin{array}{l}\text { Glucose (mmol/L) } \\
\text { Baseline }\end{array}$ & $5.3(5.0,5.5)$ & $5.3(5.1,5.5)$ & NS (0.95) \\
\hline Post-op & $5.7(5.2,6.7)$ & $6.8(5.4,7.7)$ & NS $(0.23)$ \\
\hline Change & $0.5(-0.1,1.4)$ & $1.8(-0.1,2.4)$ & NS $(0.37)$ \\
\hline $\begin{array}{l}\text { Insulin (pmol/L) } \\
\text { Baseline }\end{array}$ & $71.0(44.0,90.0)$ & $64.0(30.5,86.8)$ & NS (0.73) \\
\hline Post-op & $48.0(23.8,101.5)^{2}$ & $117.0(28.3,153.0)$ & NS (0.39) \\
\hline Change & $-2.0(-30.5,19.8)^{2}$ & $38.0(-16.5,88.0)$ & NS $(0.18)$ \\
\hline \multicolumn{4}{|c|}{$\begin{array}{l}\text { median }\left(25^{\text {th }}, 75^{\text {th }} \text { percentile); Mann-Whitney U Test }\right. \\
\text { KITT, rate of disappearance of blood glucose } \\
\text { HOMA- } \beta \text {, Homeostasis model assessment for } \beta \text {-cell function } \\
\text { HOMA-IR, Homeostasis model assessment for insulin resistance } \\
\text { NS, non-significant } \\
\text { Wilcoxon Signed Rank Test } \\
\quad \text { asignificantly different from baseline, } p=0.05 \\
{ }^{b} \text { significantly different from baseline, } p=0.03 \\
{ }^{1} n=6 ; \text { SITT not completed } \\
{ }^{2} n=6 ; \text { insulin outlier excluded from analysis }\end{array}$} \\
\hline
\end{tabular}


Table 39 - Blood markers throughout study period (CHO CABG: New vs. Pilot)

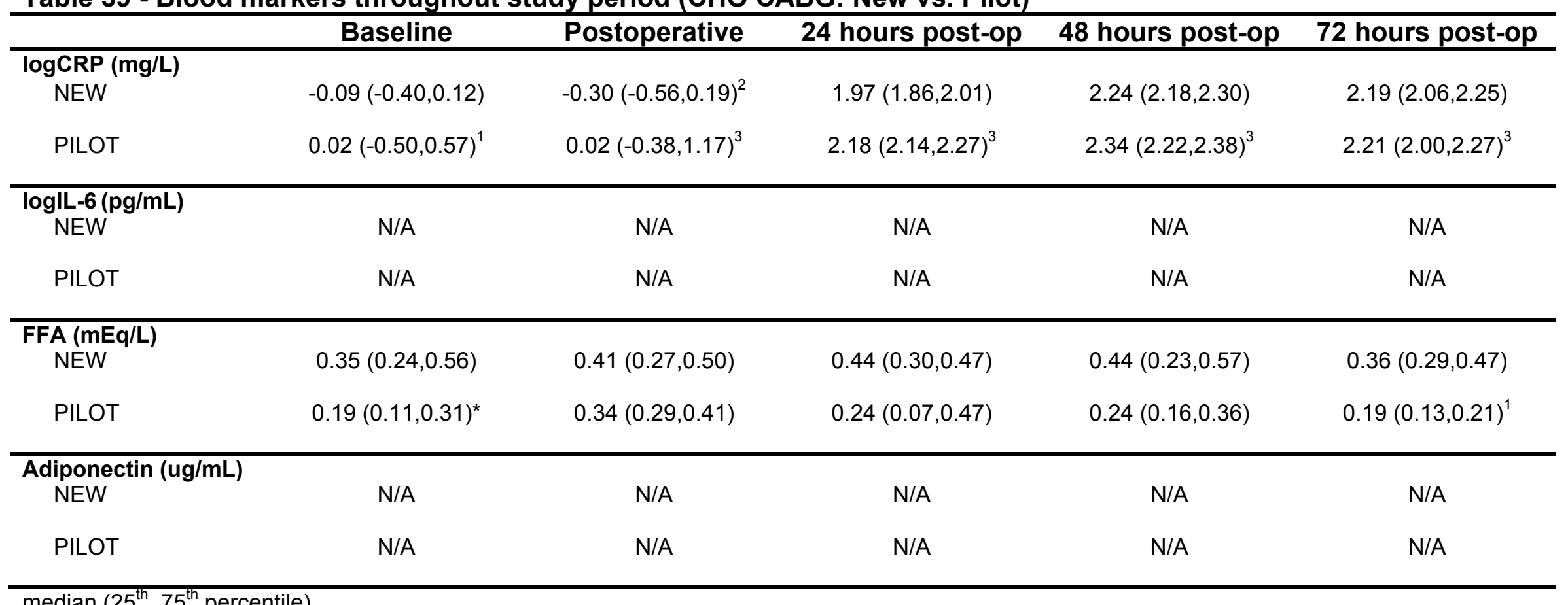

median $\left(25^{\text {th }}, 75^{\text {th }}\right.$ percentile $)$

CRP, C-reactive protein; IL-6, interleukin-6; FFA, free fatty acid

$\mathrm{N} / \mathrm{A}$, not applicable

${ }^{1} n=5$; missing data

${ }^{2} \mathrm{n}=6$; missing data

${ }^{3} \mathrm{n}=4$; missing data

*Mann Whitney U Test, values between groups significantly different 
Table 40 - Intra and postoperative clinical outcomes (CHO CABG: New vs. Pilot)

\begin{tabular}{|c|c|c|c|}
\hline & $\begin{array}{l}\text { New } \\
(n=7)\end{array}$ & $\begin{array}{l}\text { Pilot } \\
(n=6)\end{array}$ & $p$-value \\
\hline Vessels bypassed $^{*}$ & $3.0(2.0,4.0)$ & $2.5(2.0,3.5)$ & $\mathrm{NS}(0.63)$ \\
\hline Cross clamp time $(\mathrm{min})^{*}$ & $44.0(31.0,48.0)$ & $37.0(29.5,49.0)$ & NS (0.37) \\
\hline Pump time (min)* & $65.0(56.0,86.0)$ & $50.5(45.5,68.8)$ & NS (0.07) \\
\hline OR time $(\min )^{*}$ & $225.0(205.0,255.0)$ & $210.0(176.3,238.8)$ & NS $(0.37)$ \\
\hline Intra-op bleeding ${ }^{\dagger}$ & 0 & 0 & NS \\
\hline Intra-op hypotension $^{\dagger}$ & $2(29)$ & $1(17)$ & NS (1.00) \\
\hline Wound infection $^{\dagger}$ & 0 & $1(17)$ & NS (0.46) \\
\hline Other infection ${ }^{\dagger}$ & 0 & 0 & NS \\
\hline Pneumonia $^{\dagger}$ & 0 & 0 & NS \\
\hline Urinary tract infection $^{\dagger}$ & 0 & 0 & NS \\
\hline Myocardial infarction $^{\dagger}$ & 0 & 0 & NS \\
\hline Post-op inotropes ${ }^{\dagger}$ & 0 & $3(50)$ & NS (0.07) \\
\hline Post-op IABP ${ }^{\dagger}$ & 0 & 0 & NS \\
\hline Atrial fibrillation $^{\dagger}$ & $2(29)$ & $1(17)$ & NS (1.00) \\
\hline Pleural effusion $^{\dagger}$ & $2(29)$ & 0 & NS (0.46) \\
\hline Complication (Yes) ${ }^{\dagger}$ & $7(100)$ & $6(100)$ & NS \\
\hline Total complications $^{\dagger \dagger}$ & 16 & 18 & NS (0.30) \\
\hline
\end{tabular}

\footnotetext{
${ }^{*}$ median $\left(25^{\text {th }}, 75^{\text {th }}\right.$ percentile); Mann-Whitney U Test

${ }^{\dagger} \mathrm{n}(\%)$; Fisher's Exact Test

${ }^{\dagger+} \mathrm{n}$; Independent Samples T-Test

NS, non-significant
} 
Table 41 - Other intra and postoperative clinical outcomes (CHO CABG: New vs. Pilot)

\begin{tabular}{|c|c|c|c|}
\hline & $\begin{array}{l}\text { New } \\
(n=7)\end{array}$ & $\begin{array}{l}\text { Pilot } \\
(n=6)\end{array}$ & p-value \\
\hline Transfusion required $^{\dagger}$ & 0 & $3(50)$ & $\overline{N S}(0.07)$ \\
\hline Platelets (Units)* & 0 & 0 & NS \\
\hline Whole blood (Units)* & 0 & $0.5(0,1)$ & NS $(0.14)$ \\
\hline Plasma (Units)* & 0 & 0 & NS \\
\hline Red Blood Cells (Units)* & 0 & 0 & NS \\
\hline $\begin{array}{l}\text { Chest tube losses - } 6 \\
\text { hour }(m L)^{*}\end{array}$ & $310.0(140.0,380.0)$ & $395.0(170.0,500.0)$ & NS $(0.37)$ \\
\hline $\begin{array}{l}\text { Chest tube losses - } \\
\text { total }(\mathrm{mL})^{*}\end{array}$ & $570.0(380.0,870.0)$ & $1085.0(480.0,1155.0)$ & NS $(0.14)$ \\
\hline $\begin{array}{l}\text { Time on ventilation } \\
\text { (hours) }\end{array}$ & $5.5(3.1,10.2)$ & $6.6(5.1,12.8)$ & NS (0.53) \\
\hline LOS CVICU (hours)* & $21.1(20.2,22.5)$ & $22.1(20.6,23.7)$ & NS (0.45) \\
\hline $\begin{array}{l}\text { Length of hospital stay } \\
\text { (days)* }\end{array}$ & $4.0(4.0,5.0)$ & $4.5(4.0,5.3)$ & NS (0.63) \\
\hline
\end{tabular}


Table 42 - Hyperglycemia outcomes (CHO CABG: New vs. Pilot)

\begin{tabular}{|c|c|c|c|}
\hline & $\begin{array}{l}\text { New } \\
(n=7)\end{array}$ & $\begin{array}{l}\text { Pilot } \\
(\mathrm{n}=6)\end{array}$ & p-value \\
\hline Intra-op hyperglycemia $^{\dagger}$ & $4(57)$ & $5(83)$ & NS (0.56) \\
\hline $\begin{array}{l}\text { Insulin within } 24 \text { hours } \\
\text { (Units)* }\end{array}$ & $0.0(0.0,10.0)$ & 0 & NS $(0.45)$ \\
\hline Insulin received (yes) ${ }^{\dagger}$ & $2(29)$ & 0 & NS $(0.46)$ \\
\hline $\begin{array}{l}\text { Average insulin } \\
\text { administered (Units)* }\end{array}$ & $14.5(10,--)^{1}$ & $0^{2}$ & -- \\
\hline $\begin{array}{l}\text { Intra-op hyperglycemic } \\
\text { events* }\end{array}$ & $1.0(0.0,1.0)$ & $2.0(0.8,3.0)$ & NS $(0.18)$ \\
\hline $\begin{array}{l}\text { Postoperative } \\
\text { hyperglycemic events* }\end{array}$ & $3.0(1.0,5.0)$ & $1.0(0.0,2.0)$ & NS $(0.10)$ \\
\hline $\begin{array}{l}\text { OR and postoperative } \\
\text { hyperglycemic events* }\end{array}$ & $4.0(1.0,7.0)$ & $3.0(1.0,4.3)$ & NS (0.63) \\
\hline $\begin{array}{l}\text { Peak glucose level on } \\
\text { day of surgery } \\
\text { (mmol/L) }\end{array}$ & $8.7(9.1,10.2)$ & $9.7(8.4,10.4)$ & NS (0.63) \\
\hline \multicolumn{4}{|c|}{$\begin{array}{l}\text { NOTES: } \\
\text { 'Hyperglycemia' defined as }>8.0 \mathrm{mmol} / \mathrm{L} \\
\text { 'Insulin received' refers to \# of patients who received insulin during hospital stay } \\
\text { 'Average insulin administered' refers to the average amount of insulin administered to patients who } \\
\quad \text { received insulin }\end{array}$} \\
\hline \multicolumn{4}{|c|}{$\begin{array}{l}{ }^{*} \text { median }\left(25^{\text {th }}, 75^{\text {th }} \text { percentile); Mann-Whitney U Test }\right. \\
{ }_{n} n(\%) ; \text { Fisher's Exact Test } \\
\text { NS, non-significant } \\
{ }^{n} n=2 ; \text { number of patients administered insulin in New group } \\
{ }^{n} n=0 ; \text { number of patients administered insulin in Pilot group }\end{array}$} \\
\hline
\end{tabular}

